\title{
Advanced High Temperature Reactor Thermal Hydraulics Analysis and Salt Clean-up System Description
}

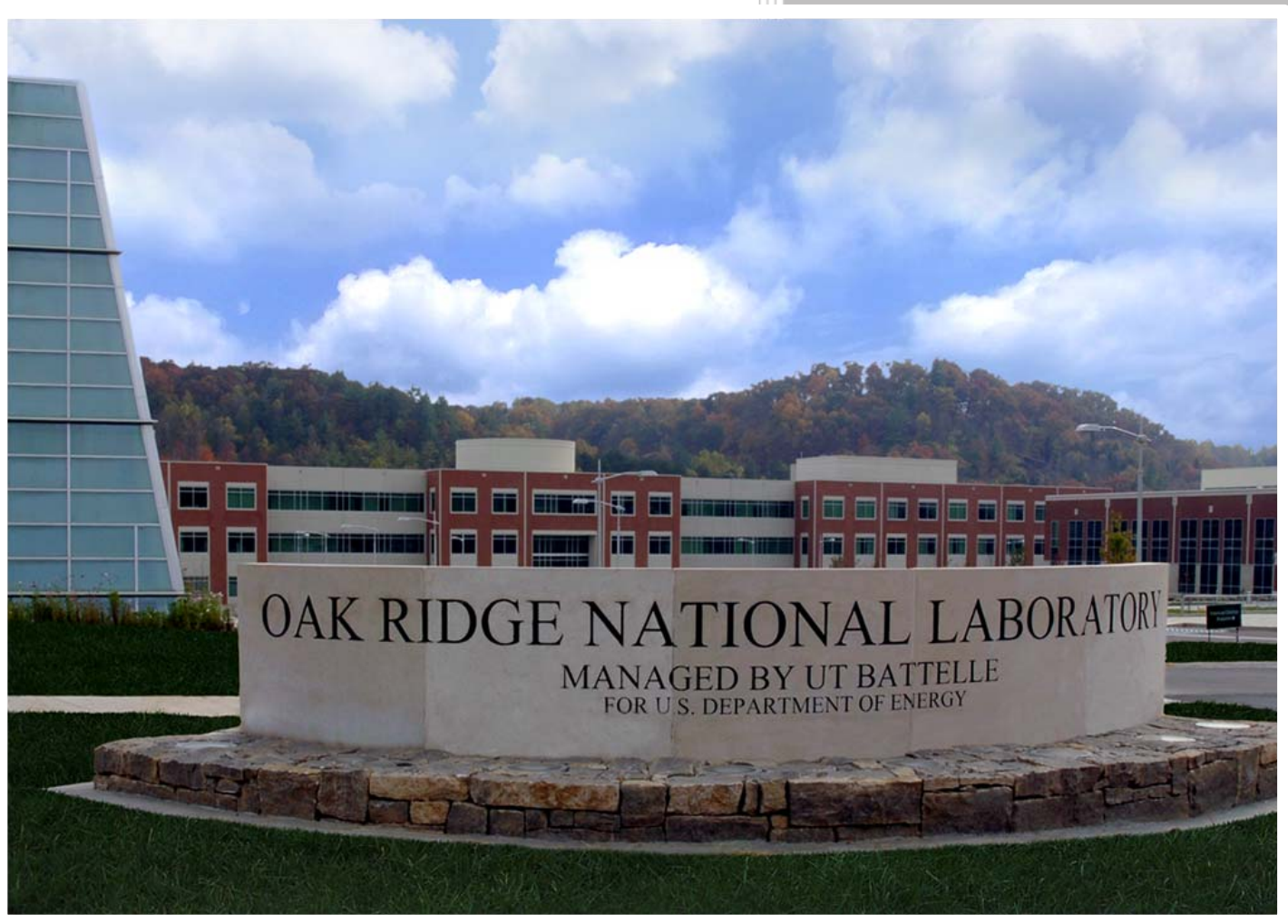

Approved for public release: distribution is unlimited.
Compiled by

G. L. Yoder

Contributors
A. T. Bopp
D. E. Holcomb
W. D. Pointer
D. Wang

September 2014 


\section{DOCUMENT AVAILABILITY}

Reports produced after January 1, 1996, are generally available free via US Department of Energy (DOE) SciTech Connect.

Website http://www.osti.gov/scitech/

Reports produced before January 1, 1996, may be purchased by members of the public from the following source:

National Technical Information Service

5285 Port Royal Road

Springfield, VA 22161

Telephone 703-605-6000 (1-800-553-6847)

TDD 703-487-4639

Fax 703-605-6900

E-mail info@ntis.gov

Website http://www.ntis.gov/help/ordermethods.aspx

Reports are available to DOE employees, DOE contractors, Energy Technology Data Exchange representatives, and International Nuclear Information System representatives from the following source:

Office of Scientific and Technical Information

PO Box 62

Oak Ridge, TN 37831

Telephone 865-576-8401

Fax 865-576-5728

E-mail reports@osti.gov

Website http://www.osti.gov/contact.html

This report was prepared as an account of work sponsored by an agency of the United States Government. Neither the United States Government nor any agency thereof, nor any of their employees, makes any warranty, express or implied, or assumes any legal liability or responsibility for the accuracy, completeness, or usefulness of any information, apparatus, product, or process disclosed, or represents that its use would not infringe privately owned rights. Reference herein to any specific commercial product, process, or service by trade name, trademark, manufacturer, or otherwise, does not necessarily constitute or imply its endorsement, recommendation, or favoring by the United States Government or any agency thereof. The views and opinions of authors expressed herein do not necessarily state or reflect those of the United States Government or any agency thereof. 
ORNL/TM-2014/499

Reactor and Nuclear Systems Division

\title{
Advanced High Temperature Reactor Thermal Hydraulics Analysis and Salt Clean-up System Description
}

\author{
Complied by \\ G. L. Yoder \\ Contributors \\ A. T. Bopp \\ D. E. Holcomb \\ W. D. Pointer \\ D. Wang
}

Date Published: September 2014:

Prepared by

OAK RIDGE NATIONAL LABORATORY

Oak Ridge, Tennessee 37831-6283

managed by

UT-BATTELLE, LLC

for the

US DEPARTMENT OF ENERGY

under contract DE-AC05-00OR22725 



\section{CONTENTS}

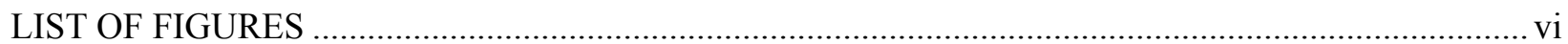

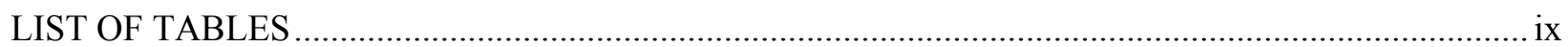

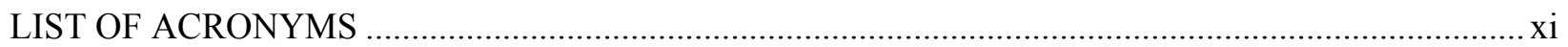

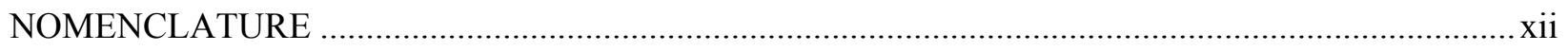

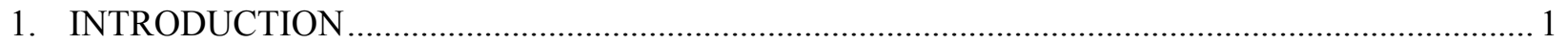

2. FUEL ASSEMBLY COMPUTATIONAL FLUID DYNAMICS ANALYSIS ................................. 4

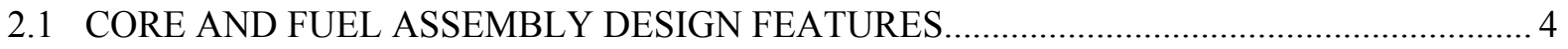

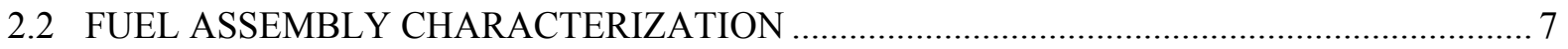

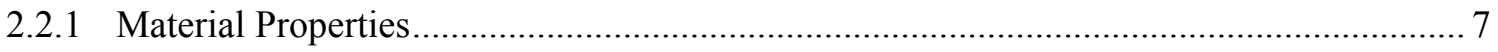

2.2.2 Coolant Channel Thermal Hydraulic Characteristics ................................................. 9

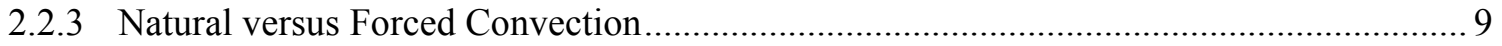

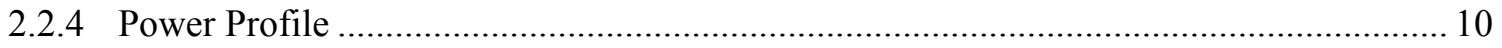

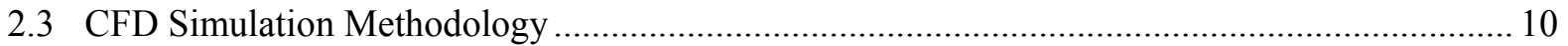

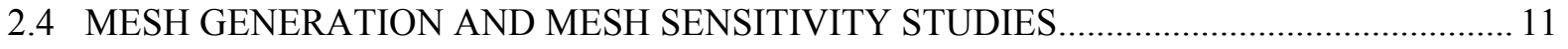

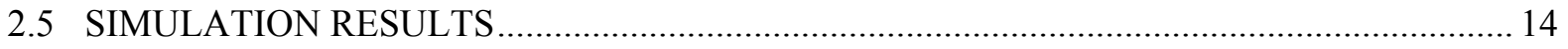

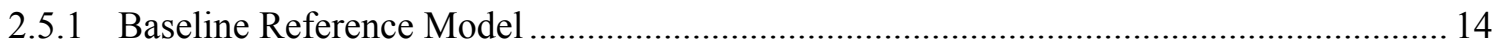

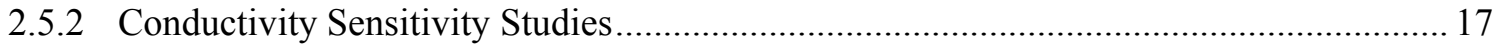

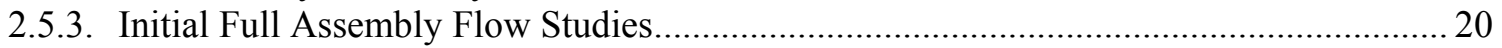

2.6 FUEL ASSEMBLY DESIGN RECOMMENDATIONS AND FUTURE WORK .................... 22

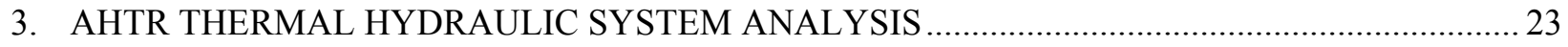

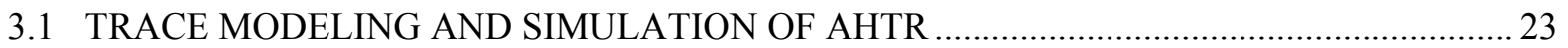

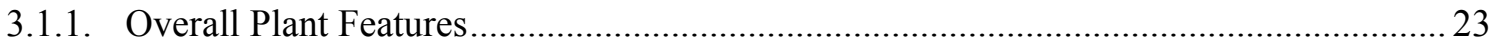

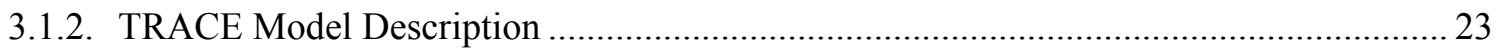

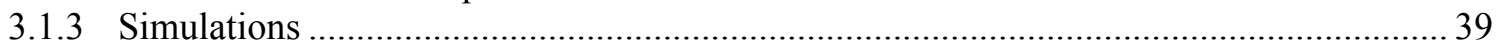

3.1.4 Summary of TRACE Model Development................................................................. 44

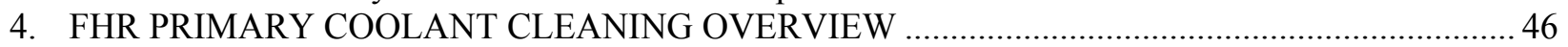

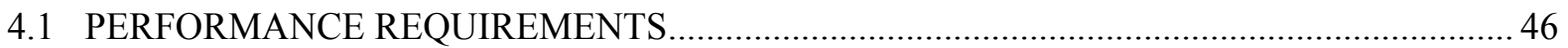

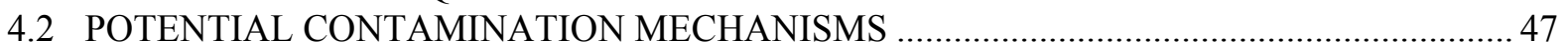

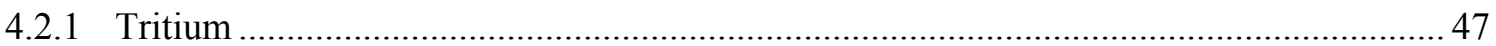

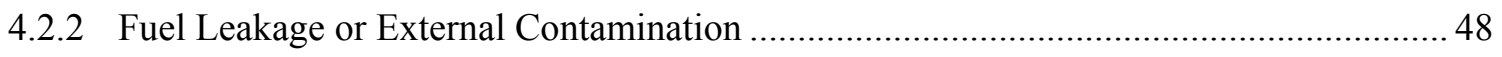

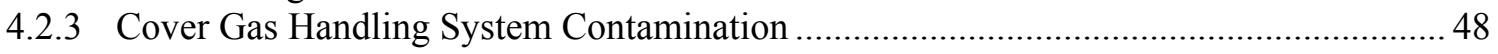

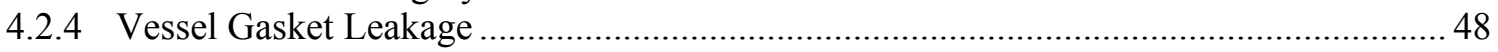

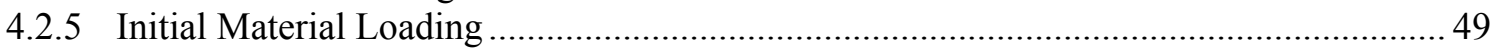

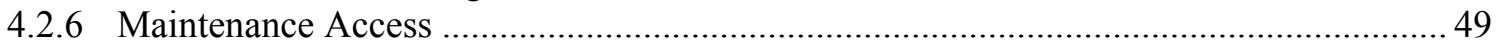

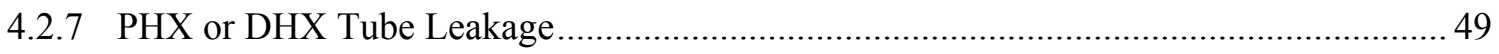

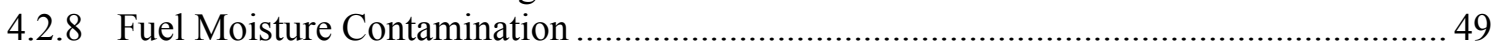

4.2.9 Primary Coolant Pump Shaft Seal Leakage ............................................................. 49

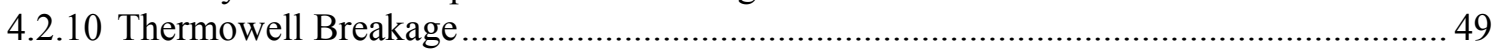

4.2.11 Material (Bismuth) Carryover from the Primary Salt Cleanup System ........................... 50

4.2.12 Dissolved or Entrained Corrosion Product Activation ............................................... 50

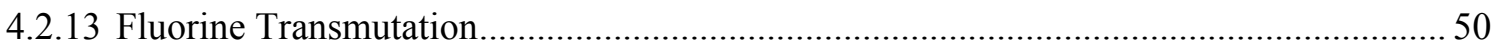

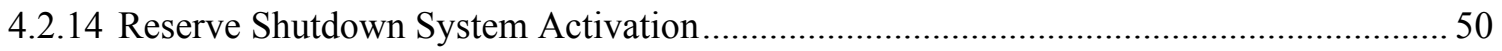

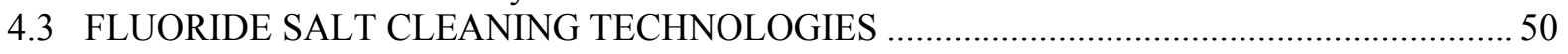

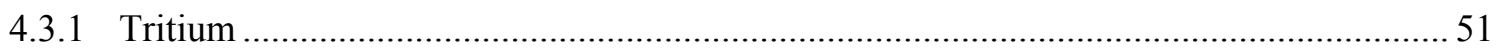

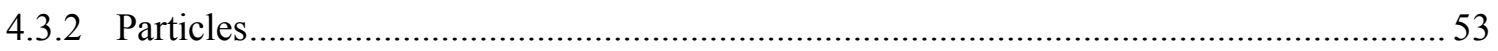




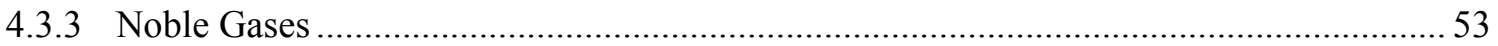

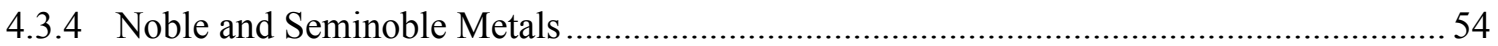

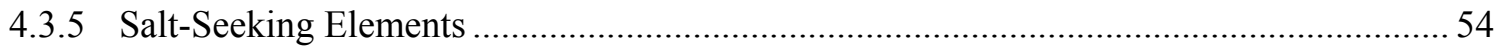

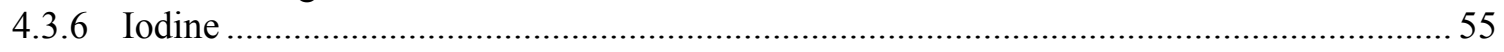

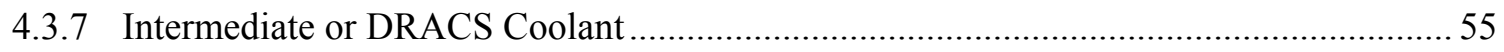

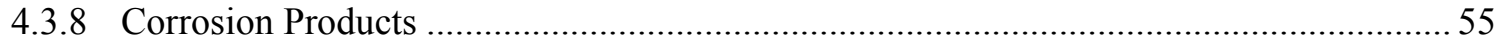

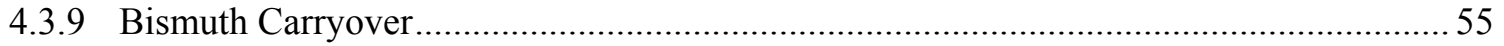

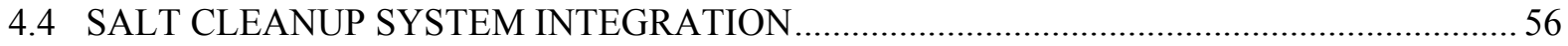

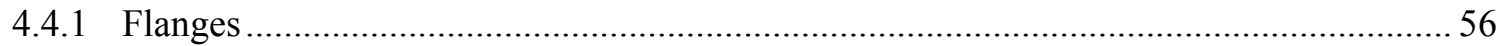

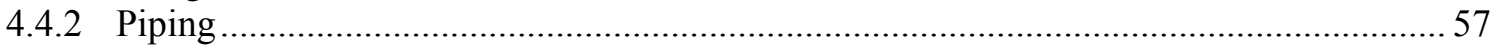

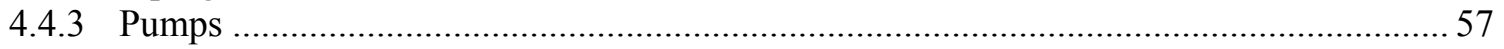

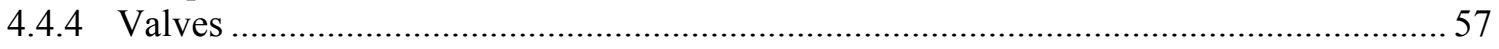

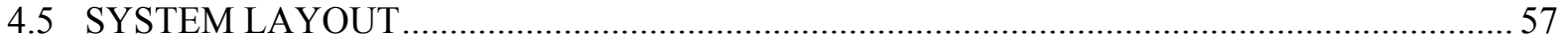

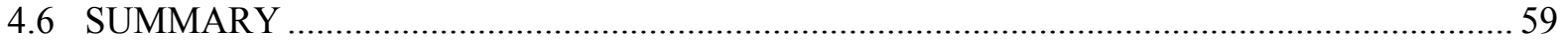

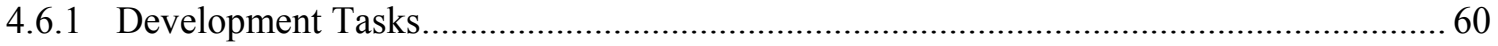

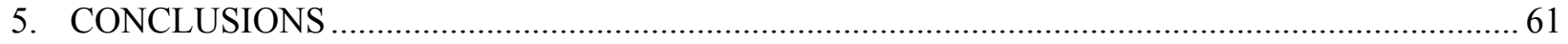

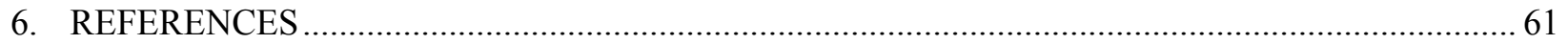




\section{LIST OF FIGURES}

\section{Figure}

Page

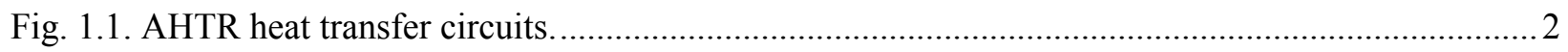

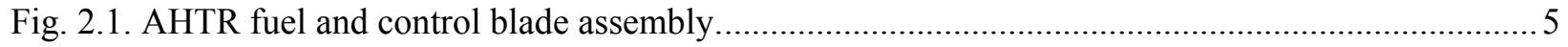

Fig. 2.2. Cross section of a fuel plate; dimensions in centimeters. ..................................................... 5

Fig. 2.3. Transverse cross section of the fuel assembly; dimensions in centimeters. ................................ 6

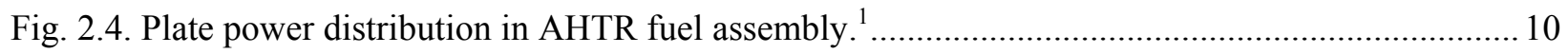

Fig. 2.5. Computational mesh distribution at mid-height cross section of the single channel model......... 12

Fig. 2.6. The CFD model used in these studies considers $1 / 3$ of an AHTR fuel assembly, as shown in (a). Periodic rotational coupled boundaries are used on the upper and right side faces of the model to replicate the interactions with the other $2 / 3$ of the assembly, as illustrated in (b).

Fig. 2.7. Computational mesh distribution used in the CFD simulations of heat transfer. Solids are shown as gray, and coolant is shown as blue.

Fig. 2.8. Predicted velocity profile in coolant channels at top of fueled region for baseline case. Results are duplicated across rotationally periodic boundaries to form the complete assembly....

Fig. 2.9. Predicted turbulent kinetic energy profile in coolant channels for baseline case. Results are duplicated across rotationally periodic boundaries to form the complete assembly.....

Fig.2.10. Predicted temperature profile for baseline case. Results are duplicated across rotationally periodic boundaries to form the complete assembly.

Fig. 2.11. Predicted surface temperatures of the AHTR fuel plates. In the upper right third of the assembly, only the fuel stripes are shown.

Fig. 2.12. Location of data sampling line in $1 / 3$ AHTR assembly model.

Fig. 2.13. Comparison of sample data extracted along the line shown in Fig. 2.12 using 100 vs. 500 uniformly spaced sampling points.

Fig. 2.14. Comparison of nominal and minimum conductivity cases

Fig. 2.15. Impact of uncertainty in the fuel box thermal conductivity on predicted temperature distributions

Fig. 2.16. Impact of uncertainty in the fuel plate thermal conductivity on predicted temperature distributions

.Fig. 2.17. Impact of uncertainty in the fuel strip thermal conductivity on predicted temperature distributions

Fig. 2.18. Initial velocity predictions in the upper regions of the AHTR fuel assembly 


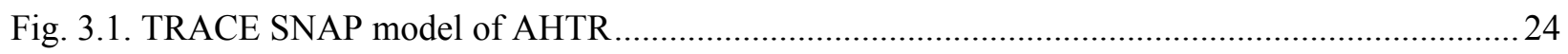

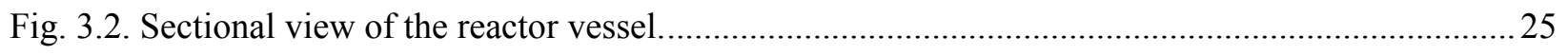

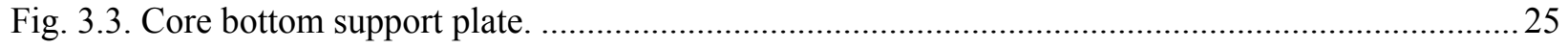

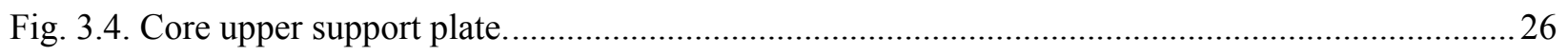

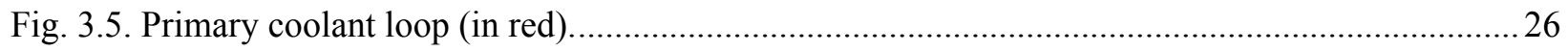

Fig. 3.6 Schematic drawing of tube-and-shell exchanger ................................................................... 27

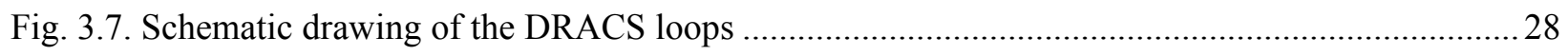

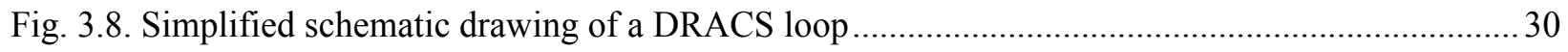

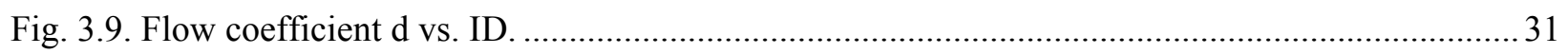

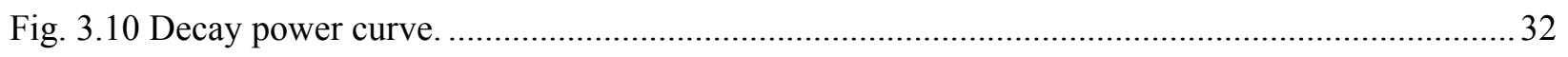

Fig. 3.11. Control systems for calculating HTC and K-loss of DHX.............................................. 37

Fig. 3.12. Control systems for calculating HTC and K-loss for DAC ................................................ 38

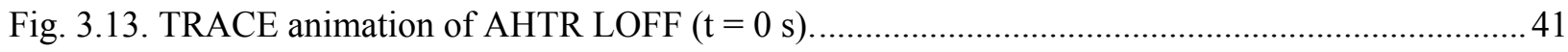

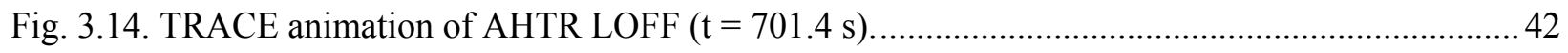

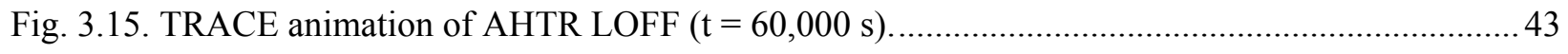

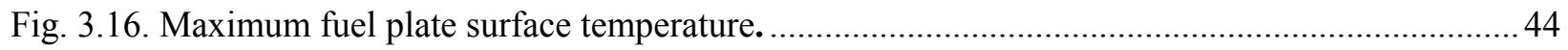

Fig. 4.1. Layer structure of tritium stripping system......................................................................... 52

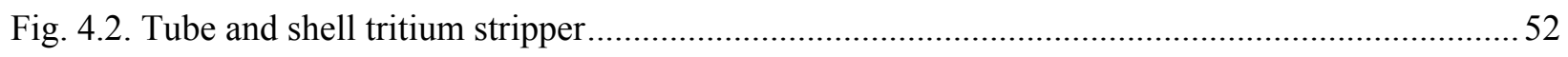

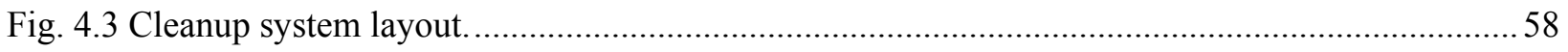




\section{LIST OF TABLES}

Table

Page

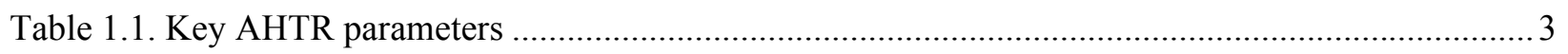

Table 2.1. Key characteristics of the fuel assembly (18 fuel plates $)$....................................................... 7

Table 2.2. Thermophysical properties of fluoride salts used in CFD simulations ...................................... 8

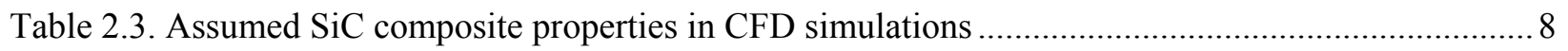

Table 2.4. Meshing parameters used in CFD model development ......................................................... 12

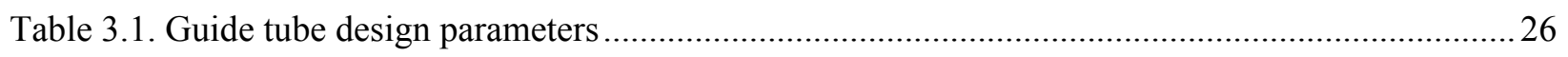

Table 3.2. PHX design parameters and coolant thermal properties ........................................................2 27

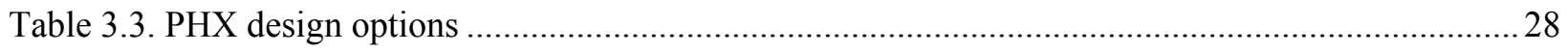

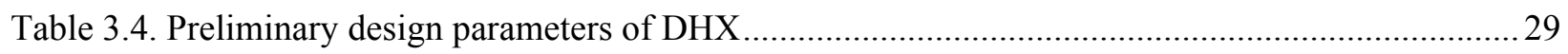

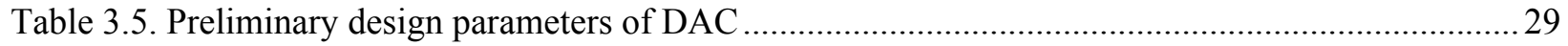

Table 3.6. TRACE input values of pipe and downcomer region of the DHX ......................................... 31

Table 3.7. TRACE input values of pipe component and vessel DAC region .......................................... 32

Table 3.8. TRACE input of thermal properties of Hastelloy $\mathrm{N}$............................................................... 33

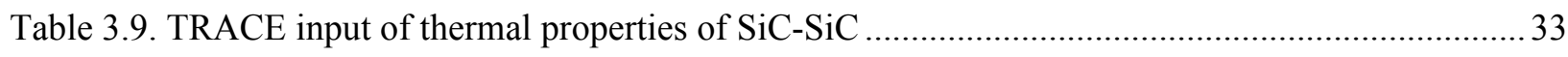

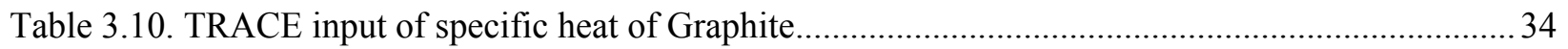

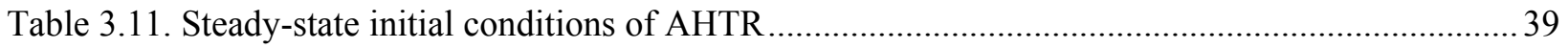

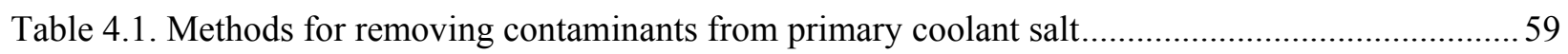





\section{LIST OF ACRONYMS}

$\begin{array}{ll}\text { AHTR } & \text { advanced high temperature reactor } \\ \text { Be } & \text { beryllium } \\ \text { BeF } 2 & \text { beryllium fluoride } \\ \text { CAD } & \text { computer-assisted design } \\ \text { CDF } & \text { core damage frequency } \\ \text { CFD } & \text { computational fluid dynamics } \\ \text { CRBRP } & \text { Clinch River Breeder Reactor Plant } \\ \text { CVCS } & \text { chemistry and volume control system } \\ \text { DAC } & \text { DRACS air cooler } \\ \text { DBA } & \text { design basis accident } \\ \text { DBE } & \text { design basis event } \\ \text { DHX } & \text { DRACS heat exchanger } \\ \text { DNS } & \text { direct numerical simulation } \\ \text { DRACS } & \text { direct reactor auxiliary cooling system } \\ \text { F } & \text { Fluorine } \\ \text { FA } & \text { Flow area } \\ \text { FHR } & \text { fluoride salt-cooled high-temperature reactor } \\ \text { FLiBe } & \text { 2LiF-BeF } \text { salt } \\ \text { HD } & \text { Hydraulic diameter } \\ \text { HF } & \text { hydrogen fluoride } \\ \text { HTC } & \text { heat transfer coefficient } \\ \text { HTGR } & \text { high-temperature gas-cooled reactor } \\ \text { HX } & \text { heat exchanger } \\ \text { ID } & \text { internal diameter } \\ \text { LES } & \text { large eddy simulation } \\ \text { LOFF } & \text { loss of forced flow } \\ \text { MHC } & \text { molybdenum-hafnium-carbon composite } \\ \text { MSBR } & \text { Molten Salt Breeder Reactor } \\ \text { MSR } & \text { molten salt reactor } \\ \text { MSRE } & \text { Molten Salt Reactor Experiment } \\ \text { MW } & \text { megawatt } \\ \text { MWth } & \text { megawatt thermal } \\ \text { NGNP } & \text { Next Generation Nuclear Plant } \\ \text { NIST } & \text { National Institute of Standards and Technology } \\ \text { NRC } & \text { Nuclear Regulatory Commission } \\ \text { OD } & \text { outer diameter } \\ \text { ORNL } & \text { Oak Ridge National Laboratory } \\ \text { PHX } & \text { primary heat exchanger } \\ \text { PSS } & \text { porous stainless steel } \\ \text { PWR } & \text { pressurized water reactor } \\ \text { RANS } & \text { Reynolds-Averaged Navier-Stokes } \\ \text { RD\&D } & \text { research, development, and demonstration } \\ \text { SiC } & \text { silicon carbide } \\ \text { SIMPLE } & \text { semi-implicit method for pressure linked Equations } \\ \text { TRACE } & \text { TRAC/RELAP Advanced Computational Engine } \\ \text { TRISO } & \text { tristructural isotropic } \\ & \end{array}$


UCO uranium oxycarbide

YSZ yttria-stabilized zirconia

NOMENCLATURE

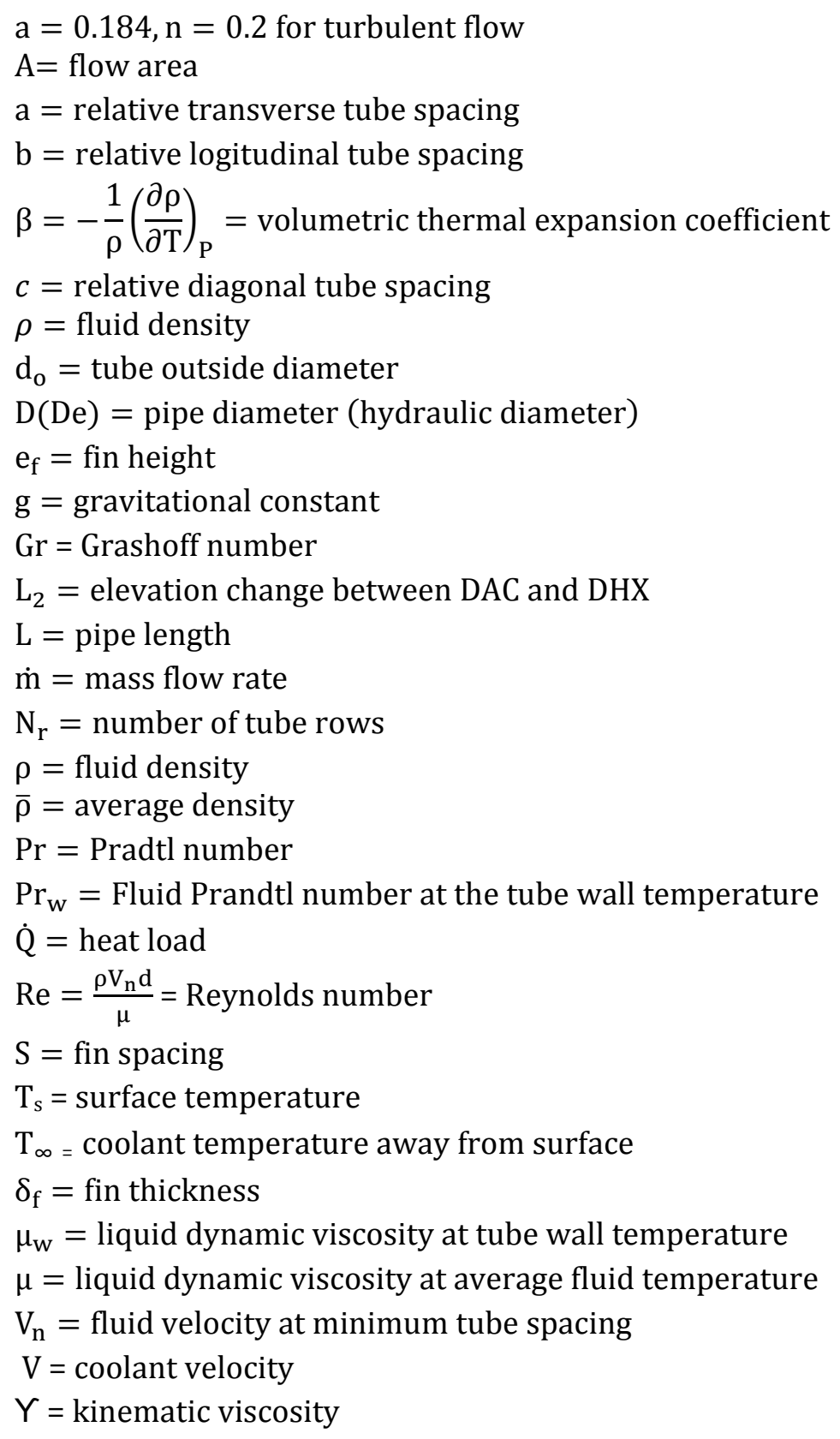




\section{INTRODUCTION}

The Advanced High Temperature Reactor (AHTR) is a liquid salt-cooled reactor design concept intended to safely, efficiently, and economically produce large amounts of electricity with minimal impact on the environment. The AHTR is a member of the fluoride salt-cooled high-temperature reactor (FHR) class. The AHTR features low-pressure molten fluoride salt coolant, a carbon composite fuel form with embedded coated particle fuel, passively triggered negative reactivity insertion mechanisms, and fully passive decay heat rejection. An initial baseline mechanical design has been established based on preliminary core design studies ${ }^{1}$ and system dynamics studies. ${ }^{2}$

Overall AHTR design objectives include:

- plant operational life of at least 60 years,

- net thermal efficiency of $45 \%$,

- plant availability of $92 \%$,

- operator action not required at any time due to essential safety features,

- construction time less than 36 months,

- all components transportable by rail or air, and

- levelized unit cost of electricity lower than competing technologies.

In order to achieve these goals, a molten salt coolant and coated particle fuel form have been selected which allow the reactor to operate at higher temperatures than conventional light water reactor (LWR) designs and enable fully passive decay heat rejection and reactor shutdown. The baseline AHTR design is a 3400 megawatt thermal $\left(\mathrm{MW}_{\text {th }}\right.$ ) concept with a net electrical power rating of $1530 \mathrm{MW}_{\mathrm{e}}$ assuming that $45 \%$ efficiency is achieved. The reactor uses carbon composite fuel assembly structures with embedded tristructural isotropic (TRISO) particle fuel that includes a uranium oxycarbide (UCO) kernel enclosed in a layer of pyrolytic graphite, a silicon carbide cladding layer, and another layer of pyrolytic graphite. The primary heat transfer fluid is $2 \mathrm{LiF}-\mathrm{BeF}_{2}$, commonly known as FLiBe. Alternate salts may be used for the intermediate heat transfer system and the direct reactor auxiliary cooling system (DRACS) which transfers decay heat directly to the atmosphere. AHTR heat transfer loops are illustrated in Figure 1.1, and key parameters are described in Table 1.1.

This report discusses two key technology areas required to further define and develop the AHTR:

1. the thermal hydraulic performance of the core and primary system, and

2. the fluoride salt clean-up system that will be needed to allow reliable and safe reactor operation.

The first two chapters of this report document initial analysis results that describe the thermal hydraulic behavior of the AHTR design. Up to this point, only scoping analysis has been performed to assist in the other supporting AHTR design activities. Although these calculations represent only the initial phases of thermal hydraulic analysis for this reactor, they will be used to provide feedback to other design features needed as this design advances.

This analysis uses the information provided in references 1 and 2 as a basis for developing thermal hydraulic models of the AHTR reactor. For this preliminary thermal hydraulic assessment, two models were developed and two types of thermal hydraulic calculations were performed.

Chapter 2 describes a computational fluid dynamics (CFD) model of the FHR reactor core used to study the detailed thermal and fluid features of the parallel plate core coolant channel design and the plate fuel thermal behavior. The model was developed and CFD calculations were performed using the commercial CFD code, STAR CCM+. ${ }^{3}$ Analysis was accomplished by modeling one third of a fuel assembly under periodic boundary conditions (a full core has 252 assemblies). This also allowed 
examination of the flow behavior just above the fuel assembly. Initial recommendations for modification of the existing fuel assembly were also developed. This model will form the foundation for more advanced and expanded thermal hydraulic analysis of the core, upper plenum, lower plenum, and downcomer regions.

Chapter 3 describes an AHTR system model developed using the Nuclear Regulatory Commission (NRC) thermal hydraulic transient code TRAC/RELAP Advanced Computational Engine (TRACE). ${ }^{4}$ The TRACE model includes all of the primary components: the core, downcomer, hot legs, cold legs, pumps, the DRACS, the primary heat exchangers (PHXs), etc. The TRACE model was used to help define and size systems such as the direct reactor auxiliary cooling system (DRACS) and the PHX. A loss of flow transient was also simulated to evaluate the performance of the reactor during an anticipated transient event. Some initial recommendations for modifying system component designs are also discussed. The TRACE model will be used as the basis for developing more detailed designs and ultimately will be used to perform transient safety analysis for the reactor.

A complete compendium of the needs and requirements for AHTR thermal hydraulic analysis was presented in the AHTR roadmap report. ${ }^{5}$ The analysis presented here is the first step in progressing along that path.

Chapter 4 of the report identifies the systems and processes needed to maintain the purity of the AHTR primary system coolant salt. This discussion covers tritium, fission product, oxides and moisture, and solids removal, among other impurities. Origins of these impurities are identified and technologies are presented for addressing each of these clean-up issues.

The work described in this report provides initial investigation into AHTR thermal hydraulics and the identification of and overall coolant clean-up system needed for the AHTR. It serves as a starting point for additional studies needed to advance the AHTR thermal hydraulic design, and it identifies the system components needed to maintain coolant salt purity.

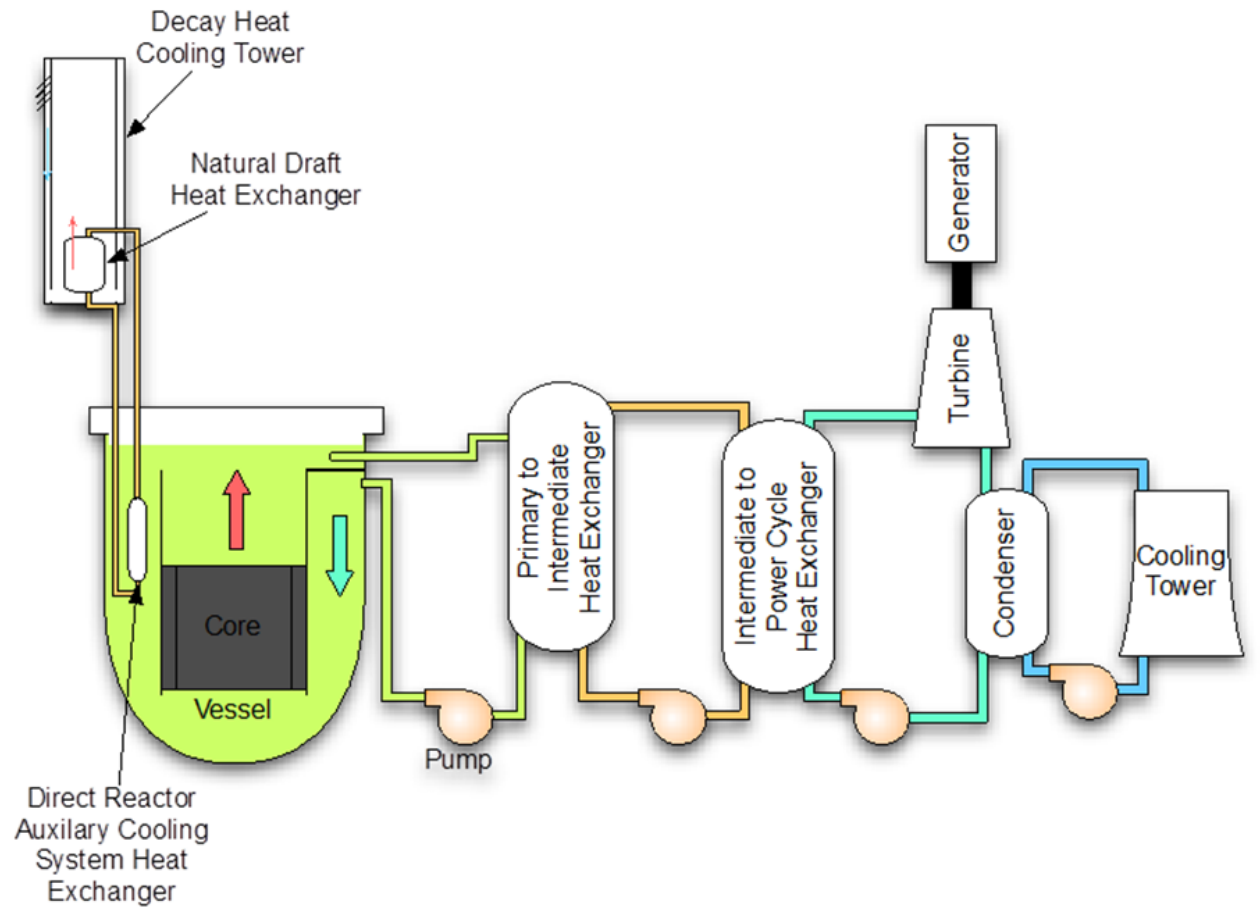

Fig. 1.1. AHTR heat transfer circuits. 
Table 1.1. Key AHTR parameters

\begin{tabular}{lll}
\hline Parameter & Value & Units \\
\hline & & \\
Core thermal power & 3,400 & Megawatt (MW) \\
Net electrical power & 1,530 & MW \\
Overall thermal efficiency & $45 \%$ & \\
Number of coolant primary loops & 3 & \\
Number of DRACS loops & 3 & \\
Reactor vessel outer diameter (OD) & 10.5 & $\mathrm{~m}$ \\
Number of fuel assemblies & 252 & \\
Assembly lattice type & Hexagonal & \\
Fuel plates per assembly & 18 & \\
Core height (fueled region) & 5.5 & $\mathrm{~m}$ \\
Core height (including axial reflector) & 6.0 & $\mathrm{~m}$ \\
Core diameter (including radial reflector) & 9.56 & $\mathrm{~m}$ \\
Coolant channel gap & $7 \mathrm{e}-3$ & $\mathrm{~m}$ \\
& & \\
Primary coolant salt & $2 \mathrm{LiF}-\mathrm{BeF}_{2}$ & $\mathrm{~K}$ \\
Average reactor outlet temperature & 973 & $\mathrm{~K}$ \\
Primary coolant return temperature & 923 & $\mathrm{~kg} / \mathrm{s}$ \\
Primary coolant flow rate & 28,500 & \\
Primary coolant pressure & Atmospheric & $\mathrm{kPa}$ \\
Coolant pressure drop across core & 70 & $\mathrm{~m} / \mathrm{s}$ \\
Average coolant flow velocity & 1.94 & \\
& & $\mathrm{~K}$ \\
Intermediate coolant salt & $\mathrm{KF}-\mathrm{ZrF}{ }_{4}$ & $\mathrm{~K}$ \\
Intermediate salt outlet temperature & 948 & $\mathrm{~kg} / \mathrm{s}$ \\
Intermediate salt inlet temperature & 873 & \\
Intermediate salt flow rate & 43,200 & \\
\hline
\end{tabular}




\title{
2. FUEL ASSEMBLY COMPUTATIONAL FLUID DYNAMICS ANALYSIS
}

\author{
David Pointer, \\ Andrew Bopp ${ }^{1}$
}

This chapter documents the development of computational fluid dynamics (CFD) models of the reference AHTR fuel assembly for detailed assessment of core flow and heat transport characteristics. Simulations for steady-state core conditions have been completed, and the results are discussed. Based on these preliminary analyses, some recommendations for fuel assembly design improvements are provided, and recommendations on the path toward a more optimized design are summarized at the end of this chapter.

\subsection{CORE AND FUEL ASSEMBLY DESIGN FEATURES}

The current early phase mechanical design of the AHTR is described in the 2012 preconceptual design report [Ref. 1]. The AHTR reactor core contains a hexagonal array of 252 fuel assemblies each holding 18 fuel plates and a molybdenum-hafnium-carbon (MHC) composite control blade as shown in Fig. 2.1. Each fuel plate, as shown in Fig. 2.2, consists of a central carbon matrix layer sandwiched between two fuel stripes consisting of TRISO particle compacts. Spacers to maintain the coolant gap between adjacent plates and the channel box are formed as part of the thin external carbon matrix sleeve that covers the fuel plate. Each assembly is topped with a silicon carbide composite grappling head that interfaces with the fuel handling machine.

Fuel plates are arranged between the fuel channel box wall and the central support $Y$ as shown in Fig. 2.3 , with $0.7 \mathrm{~cm}$ of FLiBe coolant thickness between two fuel plates. There are 15 such channels per assembly. The coolant channel thickness is reduced to $0.35 \mathrm{~cm}$ for the channels bounded by only one fuel plate (i.e., the outermost channels, 6 per assembly). Adjacent fuel assemblies are not in full direct contact and are separated by $1.75 \mathrm{~cm}$ of coolant to accommodate mechanical distortion. Key fuel assembly parameters are summarized in Table 2.1

\footnotetext{
${ }^{1}$ Nuclear Energy Science Laboratory Synthesis (NESLS) program participant, currently at Georgia Institute of Technology
} 


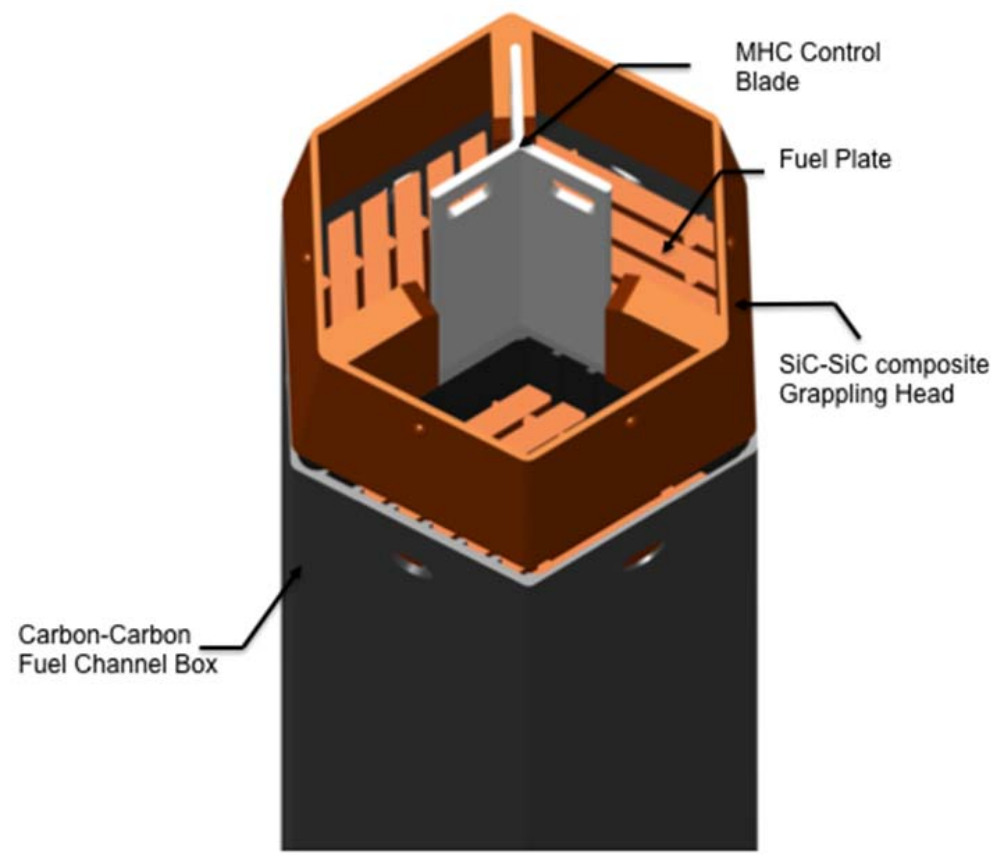

Fig. 2.1. AHTR fuel and control blade assembly.

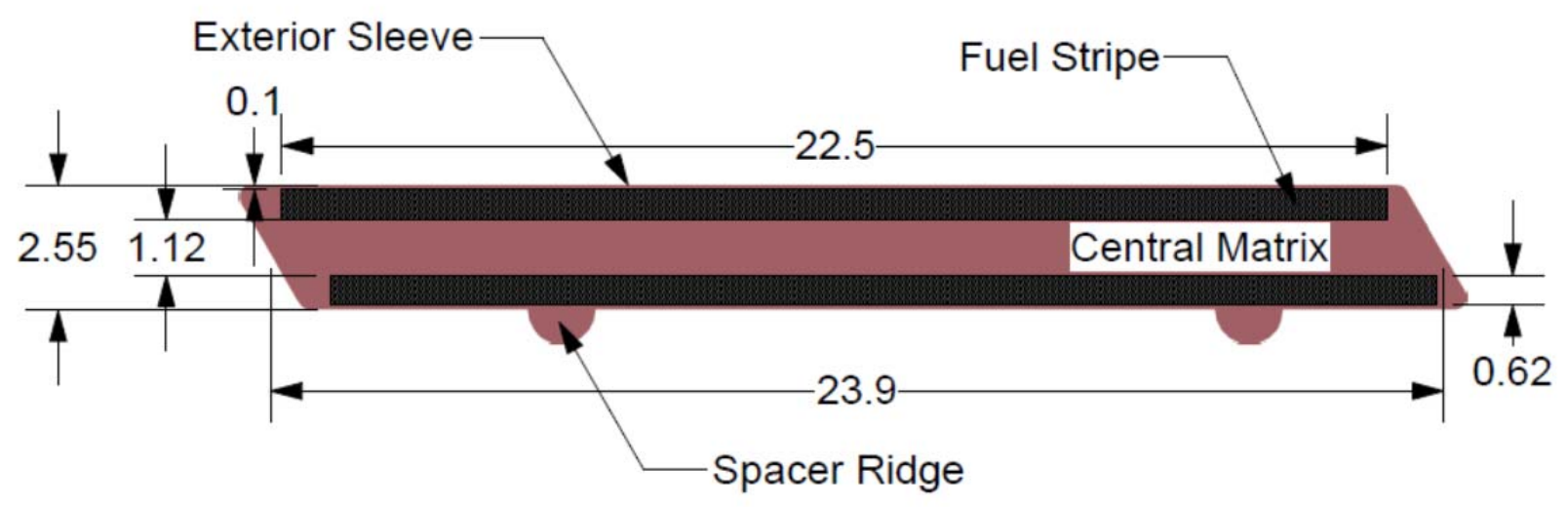

Fig. 2.2. Cross section of a fuel plate; dimensions in centimeters. 


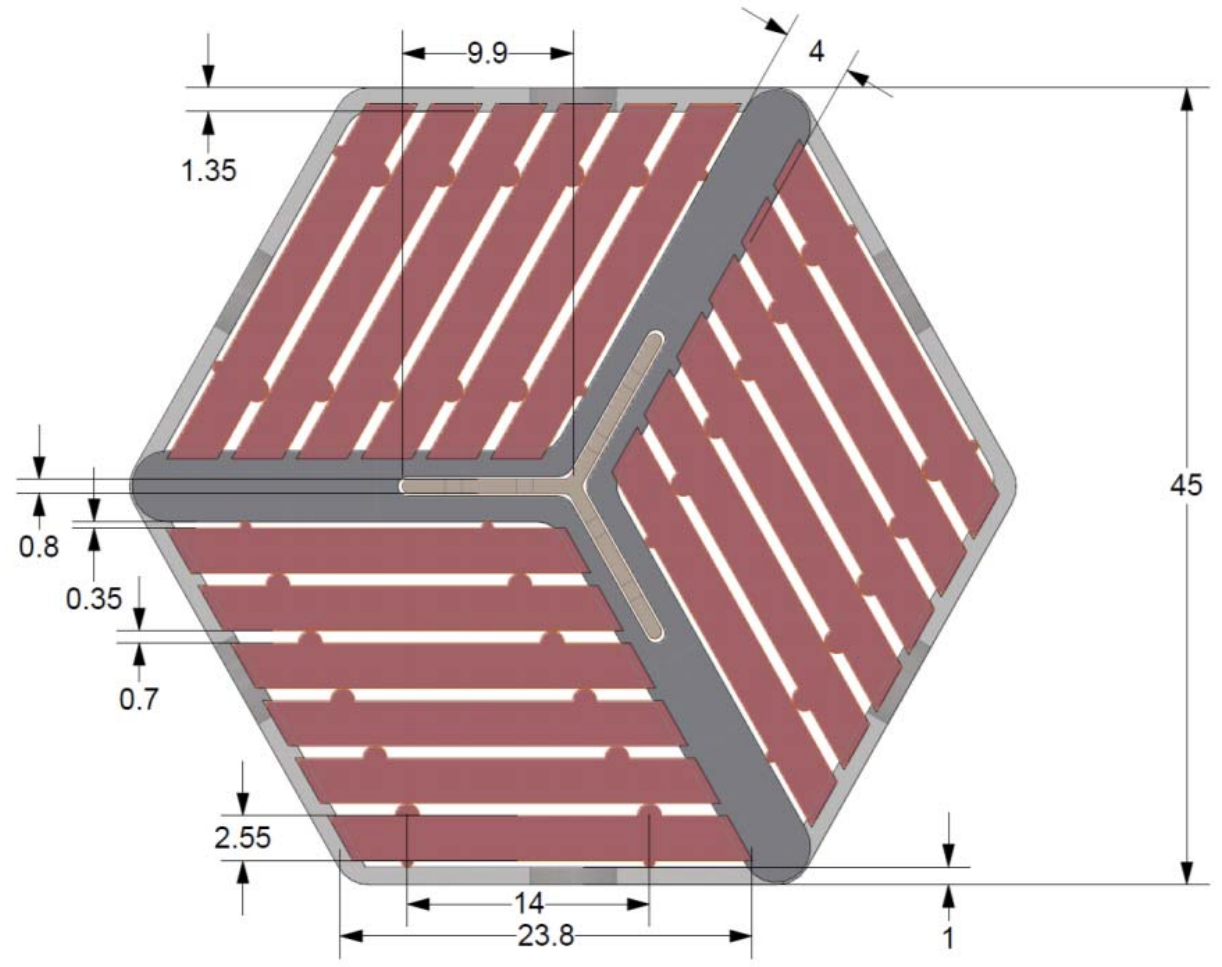

Fig. 2.3. Transverse cross section of the fuel assembly; dimensions in centimeters. 
Table 2.1. Key characteristics of the fuel assembly (18 fuel plates)

\begin{tabular}{lrl}
\hline Characteristic & Value & Units \\
\hline Total height & 600.00 & $\mathrm{~cm}$ \\
Fueled region height & 550.00 & $\mathrm{~cm}$ \\
Fuel assembly pitch & 46.75 & $\mathrm{~cm}$ \\
Outer apothem & 22.50 & $\mathrm{~cm}$ \\
Channel box wall thickness & 1.00 & $\mathrm{~cm}$ \\
Y-pillar thickness & 4.00 & $\mathrm{~cm}$ \\
Coolant thickness between plates & 0.70 & $\mathrm{~cm}$ \\
Coolant thickness between plate and wall & 0.35 & $\mathrm{~cm}$ \\
Control blade thickness & 1.00 & $\mathrm{~cm}$ \\
Control blade location wing length & 10.00 & $\mathrm{~cm}$ \\
Fuel plate thickness & 2.55 & $\mathrm{~cm}$ \\
\hline
\end{tabular}

\subsection{FUEL ASSEMBLY CHARACTERIZATION}

\subsubsection{Material Properties}

Each fuel assembly contains a combination of compressed TRISO particle fuel, carbon-carbon composite ("Y pillar" and channel box), matrix material (fuel plate sleeve and center section), silicon-carbide composite (upper and lower fuel assembly structures), and FLiBe (coolant). All of these materials would be considered somewhat exotic in comparison to typical steels, and their thermophysical properties are not nearly as well-known as those of common metals, gases, or water.

\subsubsection{Fluoride salts}

The knowledge base of fluoride salt properties and chemistry has been previously reviewed by Holcomb and Cetiner, ${ }^{6}$ who recommend a simple procedure for calculation of molten fluoride salt density that provides predictive accuracy better than 5\%. Using this approach and the thermal characteristics of the AHTR, a reference density of $1950.0 \mathrm{~kg} / \mathrm{m}^{3}$ was calculated for FLiBe salt.

Based on the review of Holcomb and Cetiner, viscosity is the molten salt property that varies most significantly with temperature and changes in $\mathrm{LiF}$ vs $\mathrm{BeF}_{2}$ composition. Sensitivity to other environmental conditions makes viscosity measurements difficult, and agreement between independent experiments is consequently difficult to obtain. For the purpose of these studies, a baseline dynamic viscosity of $6.091 \mathrm{mPa}$-s is used.

Holcomb and Cetiner consider two correlations that predict conductivities ranging from 0.79 to 1.1 $\mathrm{W} / \mathrm{m}-\mathrm{K}$ for $\mathrm{FLiBe}$ at $873 \mathrm{~K}$. The calculated value of $1.1 \mathrm{~W} / \mathrm{m}-\mathrm{K}$ is used for these analyses. A specific heat of $2.416 \mathrm{~kJ} / \mathrm{kg}-\mathrm{K}$ is used.

For CFD simulations of turbulent flows with conjugate heat transfer from the solid components to the fluid, an additional thermophysical parameter must be defined - the turbulent Prandtl number - the ratio of the eddy diffusivity for momentum transfer to the eddy diffusivity for heat transfer. This parameter is a strong function of the molecular Prandtl number, as well as the local flow geometry and conditions, and it is rarely equal to unity. Most CFD methods rely on a user input value of $\operatorname{Pr}_{t}$. For high molecular Prandtl number fluids such as gasles or organics, commercial CFD code vendors typically recommend a nominal value of $\operatorname{Pr}_{\mathrm{t}}=0.9$ as a starting point. Since FLiBe has a molecular Pr number between 10 and 20 under normal operating conditions, $\operatorname{Pr}_{t}=0.9$ was also chosen for the calculations presented here. The 
uncertainty in this property typically has lower impact on the solution than the uncertainty in molecular properties unless the fluid is extremely conductive or extremely insulating.

Fluoride salt properties used in the CFD simulations are summarized in Table 2.2.

Table 2.2. Thermophysical properties of fluoride salts used in CFD simulations

\begin{tabular}{lll}
\hline Density & 1950 & $\mathrm{~kg} / \mathrm{m}^{3}$ \\
Viscosity & 6.091 & $\mathrm{mPa}-\mathrm{s}$ \\
Thermal Conductivity & 1.1 & $\mathrm{~W} / \mathrm{m}-\mathrm{K}$ \\
Specific Heat & 2.416 & $\mathrm{~kJ} / \mathrm{kg}-\mathrm{K}$ \\
Turbulent Prandtl Number & 0.9 & \\
\hline
\end{tabular}

\subsubsection{TRISO fuel stripes}

Material properties of TRISO fuel compacts have recently been investigated by the Next Generation Nuclear Plant (NGNP) program of the US Department of Energy. Folsom ${ }^{7}$ recently found that conductivity of the fuel compact can vary greatly depending on packaging fraction, structural cracking, and temperature. For surrogate fuel samples, thermal conductivity varied from $40-50 \mathrm{~W} / \mathrm{m}-\mathrm{K}$ at $100^{\circ} \mathrm{C}$ to $25-30 \mathrm{~W} / \mathrm{m}-\mathrm{K}$ at $600^{\circ} \mathrm{C}$. Even greater uncertainty can be expected for irradiated fuel in which isotopic distributions of fission, activation, and decay products are widely varied. A reasonably conservative reference thermal conductivity of $24.0 \mathrm{~W} / \mathrm{m}-\mathrm{K}$ is carried forward from prior analyses.

While other thermophysical properties of the model's solid components have minimal impact on the solution outcome in steady state simulations, they can impact convergence characteristics, and reasonably representative properties are generally used. For the fuel stripes, a density of $2250 \mathrm{~kg} / \mathrm{m}^{3}$ and a specific heat of $708 \mathrm{~J} / \mathrm{kg}-\mathrm{K}$ are assumed.

\subsubsection{Carbon-carbon composite}

The material properties of carbon-carbon composites are highly dependent on manufacturing process. At this stage in the design, it is difficult to assign a realistic target value. Properties are assumed to be identical to those of the TRISO fuel compact but are varied separately in the parametric studies presented below.

\subsubsection{Silicon carbide composites.}

Katoh, et $\mathrm{al}^{8}$ recently completed a detailed review of the thermophysical properties of current nuclear grade silicon carbide $(\mathrm{SiC})$ composites and investigated the properties of new $\mathrm{SiC}$ fiber reinforced composites. Properties vary considerably with manufacturing process and with irradiation. At this stage in the design, nominal values were selected as shown in Table 2.3, and the impact of uncertainty was assessed as part of the parametric study.

Table 2.3. Assumed SiC composite properties in CFD simulations

\begin{tabular}{lll}
\hline Density & 3187 & $\mathrm{~kg} / \mathrm{m}^{3}$ \\
Thermal conductivity & 43.76 & $\mathrm{~W} / \mathrm{m}-\mathrm{K}$ \\
Specific heat & 1191 & $\mathrm{~J} / \mathrm{kg}-\mathrm{K}$ \\
\hline
\end{tabular}




\subsubsection{Coolant Channel Thermal Hydraulic Characteristics}

Prior to development of the CFD model, the assembly flow characteristics were assessed using conventional correlation-based methods and nondimensional scaling parameters.

\subsubsection{Assembly flow rates and inlet velocity}

For the purpose of the present analyses, the full core flow of $28,500 \mathrm{~kg} / \mathrm{s}$ is assumed to pass through the 252 fuel assemblies, and bypass flow routes are neglected. With $37.69 \mathrm{~kg} / \mathrm{s}$ flowing through $1 / 3$ of an assembly, the flow velocity in the lower plenum inlet region of each assembly (i.e., the open volume below the start of the fuel plates) is expected to be approximately $0.447 \mathrm{~m} / \mathrm{s}$.

\subsubsection{Turbulent transition}

The Reynolds number $\left(\mathrm{Re}=\rho \mathrm{vD}_{\mathrm{h}} / \mu\right)$ was evaluated based on hydraulic diameter of the nominal fullsize coolant channel of approximately $13.3 \mathrm{~mm}$ and a nominal velocity of $1.94 \mathrm{~m} / \mathrm{s}$. For this narrow rectangular channel, the Reynolds number is approximately 8300. Turbulent transition in rectangular channels is expected to occur between $2500>\operatorname{Re}<6000^{9}$, implying that the flow is well beyond turbulent transition and that turbulent flow should be expected throughout most of the channel under normal operating conditions. However, during some expected reactor transients, the flow may relaminarize, and impacts of laminar flow heat transfer and pressure drop will need to be considered during the design process.

\subsubsection{Pressure drop}

The pressure drop in a simple channel flow can be calculated using

$$
\Delta P=f_{D} \frac{L}{D_{e}} \frac{\rho V^{2}}{2}
$$

Based on the defined coolant properties and conditions, the friction factor, $\mathrm{f}_{\mathrm{D}}$, was calculated using the method recommended by Tung ${ }^{10}$ resulting in a friction factor of 0.0345 for graphite-walled channels. The expected pressure drop in the rectangular channel is $57.18 \mathrm{kPa}$.

\subsubsection{Heat rate and temperature rise}

With a total core power of $3400 \mathrm{MW}_{\text {th }}$, each of the 252 assemblies would produce13.5 MW on average. With 18 plates per assembly, each plate would produce $0.75 \mathrm{MW}$ on average. The expected temperature rise is given by

$$
\Delta T=T_{\text {out }}-T_{\text {in }}=\frac{q}{c_{p} \dot{m}}
$$

With an inlet temperature of $923 \mathrm{~K}$ and the conditions and thermophysical properties defined above, the expected channel temperature rise would be approximately $49.4 \mathrm{~K}$.

\subsubsection{Natural versus Forced Convection}

The Grashof number, a dimensionless parameter that approximates the ratio of buoyancy to viscous force acting on a fluid, is given by

$$
G r=\frac{g \beta\left(T_{s}-T_{\infty}\right) D_{e}^{3}}{v^{2}}
$$


Using the properties defined above and an approximate expansion coefficient of $2.5 \times 10^{-4} \mathrm{~K}^{-1}$, the Grashof number for the AHTR fuel assembly flow is 9680, while the core Reynolds number under normal operating conditions is 8300 . Some expected transient events will reduce the Reynolds number further. Although not investigated here, the possibility of mixed convection (forced and natural) must be addressed as the thermal hydraulic analysis progresses. Consideration of mixed convective conditions will include the core and will extend to other components as well (PHX, DRACS, etc.).

\subsubsection{Power Profile}

The power profile across a bank of six plates has been evaluated with conventional core design reactor physics methods using the SCALE code suite ${ }^{1}$ as shown in Fig. 2.4. Based on the conditions defined above, average volumetric heat rates were calculated for each fuel stripe in the assembly. Since the axial power profile has not yet been evaluated, a uniform axial heat rate was assumed.

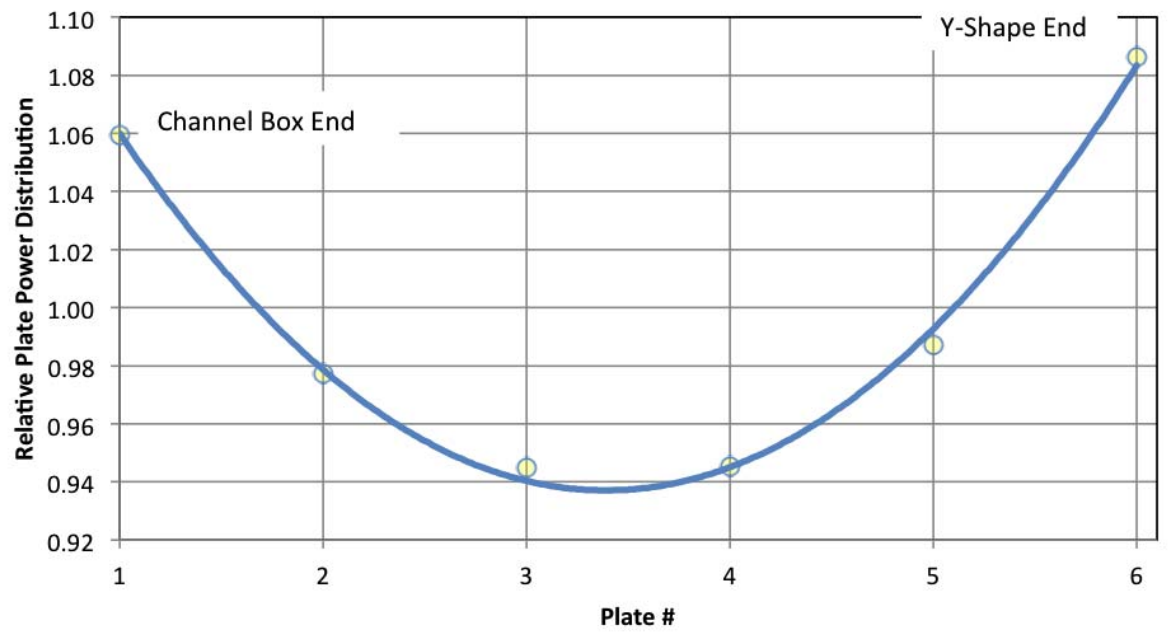

Fig. 2.4. Plate power distribution in AHTR fuel assembly. ${ }^{1}$

\subsection{CFD SIMULATION METHODOLOGY}

The commercial CFD code STAR-CCM $+{ }^{3}$ is a general-purpose analysis package for thermal and compressible/incompressible fluid flow phenomena based on the finite volume formulation.

STAR-CCM+ supports the use of generic polyhedral mesh elements and provides multiple approaches for fully parallel generation of conformal computational meshes describing complex geometries. Solutions are obtained via the semi-implicit method for pressure linked Equations (SIMPLE) algorithm with RhieChow interpolation for velocity-pressure coupling and with algebraic multi-grid preconditioning. Energyflow coupling is treated using a split operator methodology. A second order central differencing scheme is used, and all calculations in the present study are steady state. The convergence criteria were defined as the reduction of all equation residuals by four orders of magnitude, or, in other words, by reducing the normalized residuals below $10^{-4}$.

Turbulence is treated using the steady Reynolds-Averaged Navier-Stokes (RANS) method realizable $\mathrm{k}$-epsilon turbulence model in conjunction with the two-layer all $\mathrm{y}+$ wall treatment. In exploratory work, well-converged simulation results were difficult to obtain for the AHTR fuel assembly geometry with multiple parallel, narrow, high-aspect-ratio channels. Limiting residuals consistently occurred in the assembly outlet region above the fuel plates where the multiple rectangular jets merge. Since the focus of 
this study is the flow and heat transfer behavior within the channel, the jets themselves were not resolved. Instead, a more diffusive turbulence model, the standard k-epsilon model with the high-Reynolds number wall treatment, was used to generate a well-converged initial condition for the final simulation using the realizable k-epsilon turbulence model. The realizable model is much more sensitive, and local residuals in the outlet mixing region are not well behaved, but this approach prevents the oscillation between solutions observed in this region when starting from a more conventional zero velocity initial condition.

\subsection{MESH GENERATION AND MESH SENSITIVITY STUDIES}

All computational meshes were generated using the native mesh generation capabilities of STAR-CCM+. In all cases, a surface geometry definition was first generated in an external computeraided design (CAD) package and imported to STAR-CCM+. A polygonal surface mesh was generated and used as the basis for a prismatic extrusion layer along each liquid-solid interface and conformal polyhedral volume meshes in the adjacent liquid and solid regions. Specified target and minimum cell sizes, the number of points across a gap or around a circle, and the thickness and number of layers in the prismatic extrusion all constrain the sizes of individual mesh elements.

Initial simulations considered only a single coolant channel in order to provide guidelines for development of the computational mesh describing the assembly. A simple CAD model was developed with only the coolant channel and the fuel stripe on each side of the channel. The mesh was successively refined and simulation results were compared to expected pressure drop, surface heat flux, and channel temperature rise.

Meshing sensitivity studies separately considered variation of the target cell size in the bulk volumetric mesh, thickness of the extruded prismatic wall layer in fluid regions, and number of element layers in the prismatic wall layer. Although conformal mapping at the liquid-solid interface is generally preferred, integral mapping was allowed in this case since the interface is planar. The target cell size was varied from $2.5 \mathrm{~mm}$ to $0.25 \mathrm{~mm}$. Prism layer thicknesses of $0.8 \mathrm{~mm}$ or $1.6 \mathrm{~mm}$ were considered; the number of prism layers within that thickness was varied using 4, 8 or 16 layers. The standard deviation of pressure drop predictions for all cases was less than $2 \%$ of the expected value based on the friction factor calculation. The standard deviation of the outlet temperature distribution was less than $0.01 \%$ of the expected value based on the simple energy balance calculation.

Since the impact of mesh density and distribution on uncertainty in desired engineering quantities is small for this channel flow application, the course mesh characteristics were used for the following fuel assembly analysis. Excellent agreement (less than 2\%) with the calculated expected values could be obtained with the nominal coarse mesh distribution shown in Fig. 2.5. Nominal meshing parameters based on these results are summarized in Table 2.4. While the coarse mesh is minimally sufficient to evaluate the channel flow of interest in the present analysis, it should be noted that this coarse mesh will be inadequate to resolve mixing behaviors above the fuel plates in future models.

Using these parameters, a reference computational mesh was developed to describe $1 / 3$ of an AHTR fuel assembly with the associated fraction of the channel box, Y pillar, and the interassembly coolant space. A cross sectional view of the model geometry is shown in Fig. 2.6. The final polyhedral computational mesh uses a total of $7.1 \mathrm{M}$ computational cells to describe this geometry. A cross sectional view of the computational mesh distribution is shown in Fig. 2.7. 


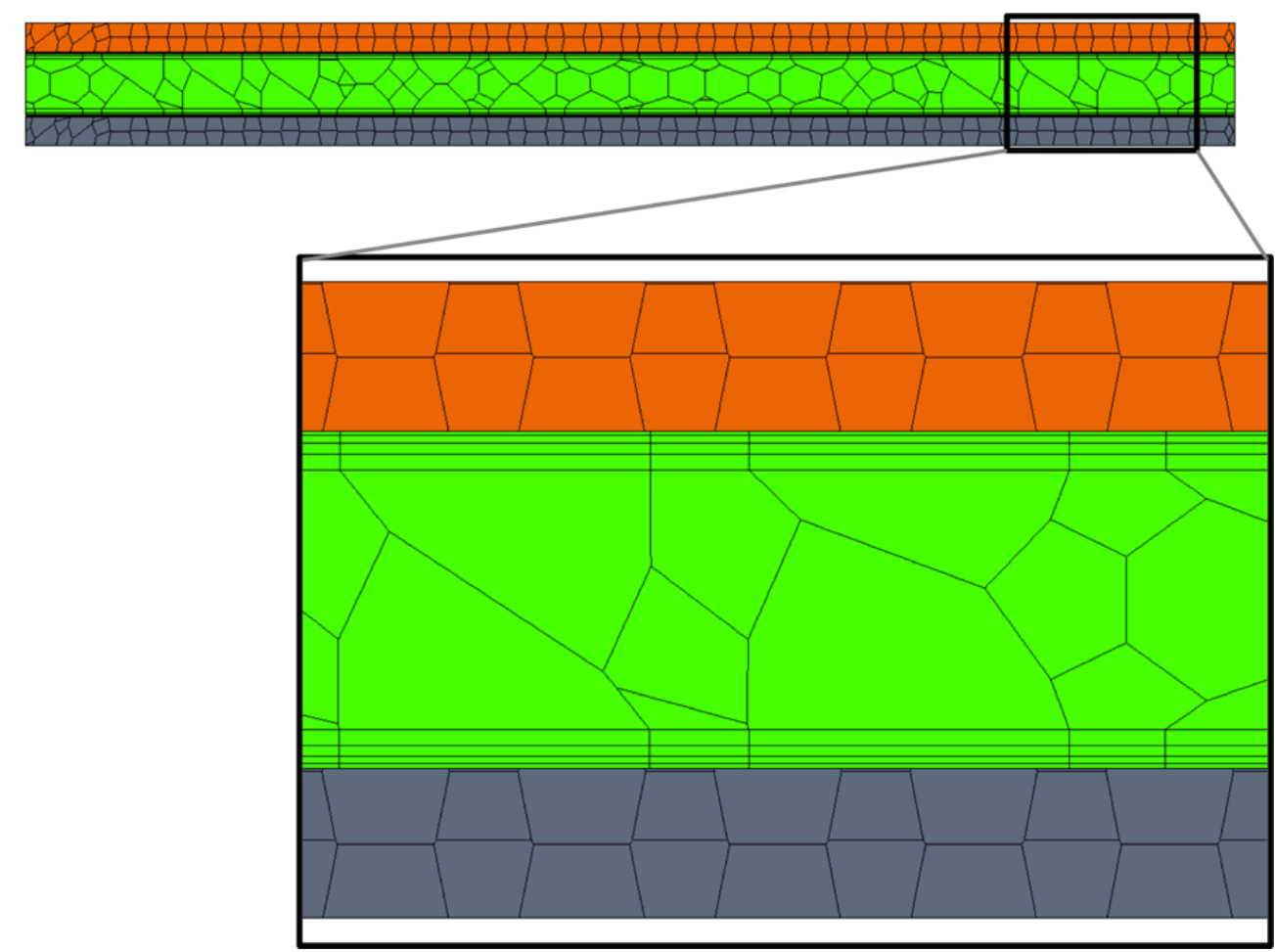

Fig. 2.5. Computational mesh distribution at mid-height cross section of the single channel model.

Table 2.4. Meshing parameters used in CFD model development

\begin{tabular}{ll}
\hline Target mesh size & $2.5 \mathrm{~cm}$ \\
Minimum mesh size & $0.1 \mathrm{~cm}$ \\
& 2 \\
Points across gap & 36 \\
Points on a circle & 1 \\
Tet/poly density & 1 \\
Tet/poly growth factor & 1 \\
Tet/poly blending factor & 4 \\
& $0.0813 \mathrm{~cm}$ \\
Number of prism layers (fluid only) & 1.5 \\
Prism layer thickness & \\
Prism layer stretching factor &
\end{tabular}




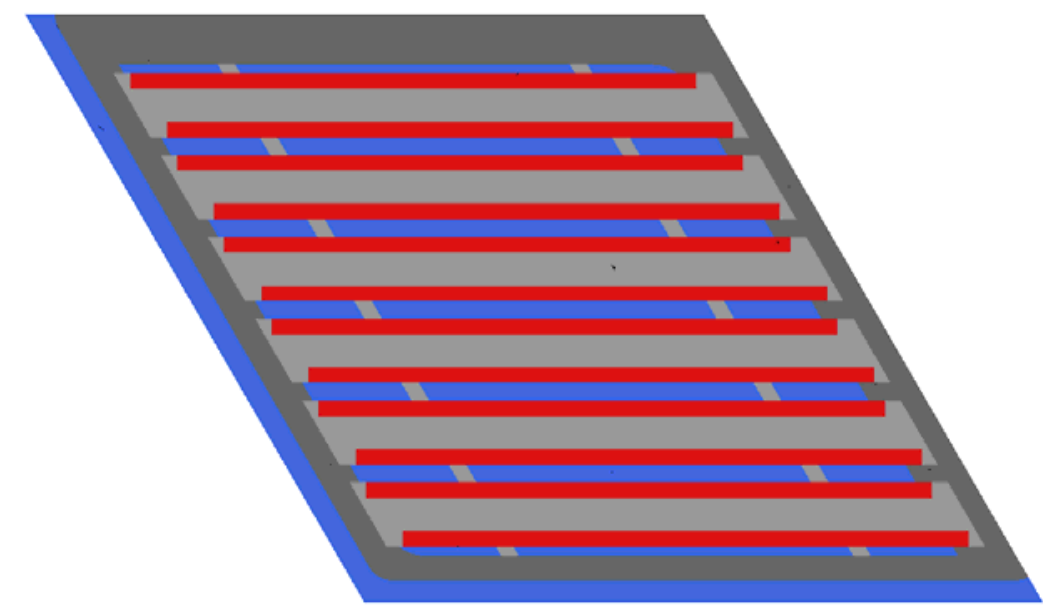

(a)

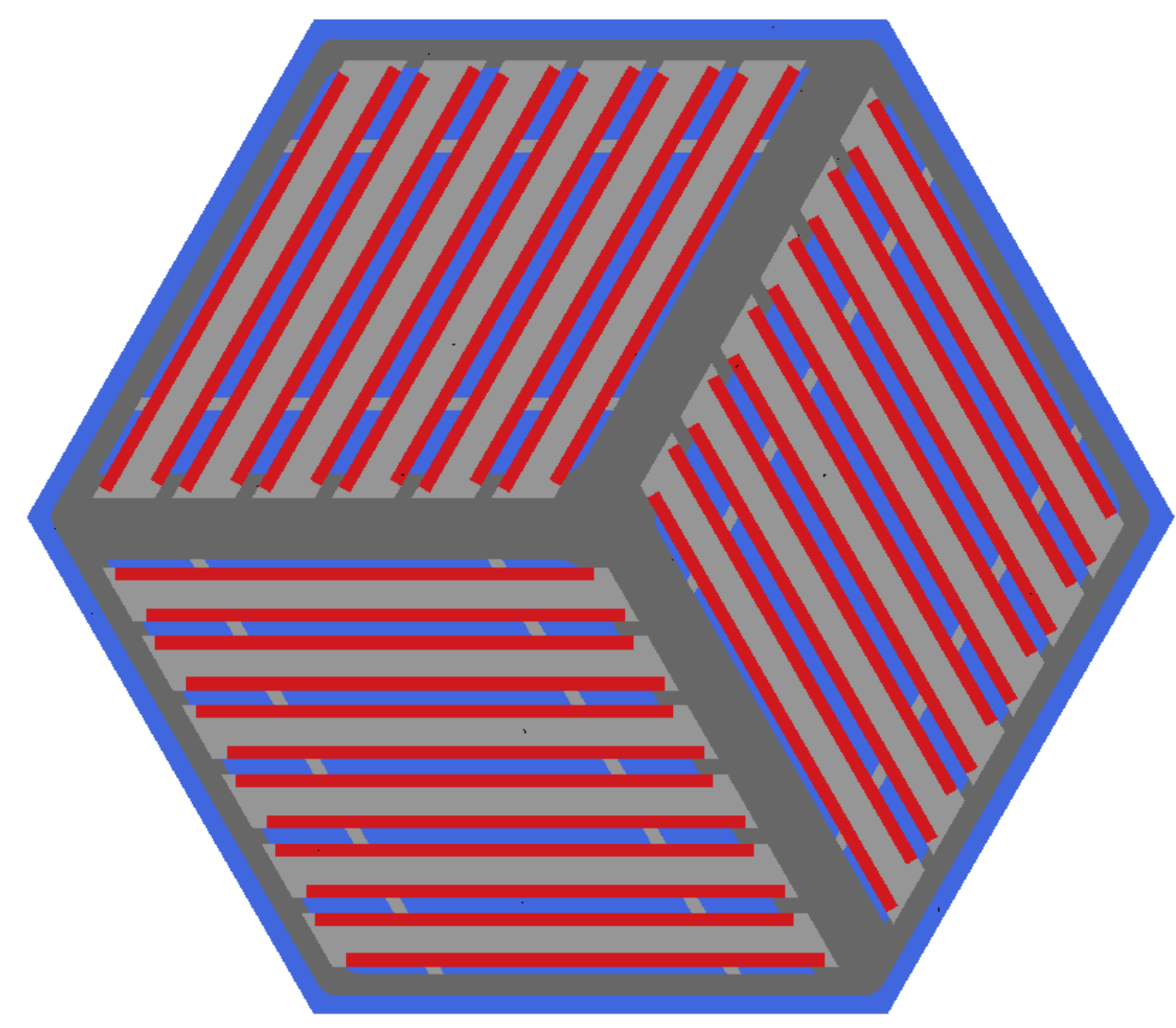

(b)

Fig. 2.6. The CFD model used in these studies considers $1 / 3$ of an AHTR fuel assembly, as shown in (a). Periodic rotational coupled boundaries are used on the upper and right side faces of the model to replicate the interactions with the other $2 / 3$ of the assembly, as illustrated in (b). 


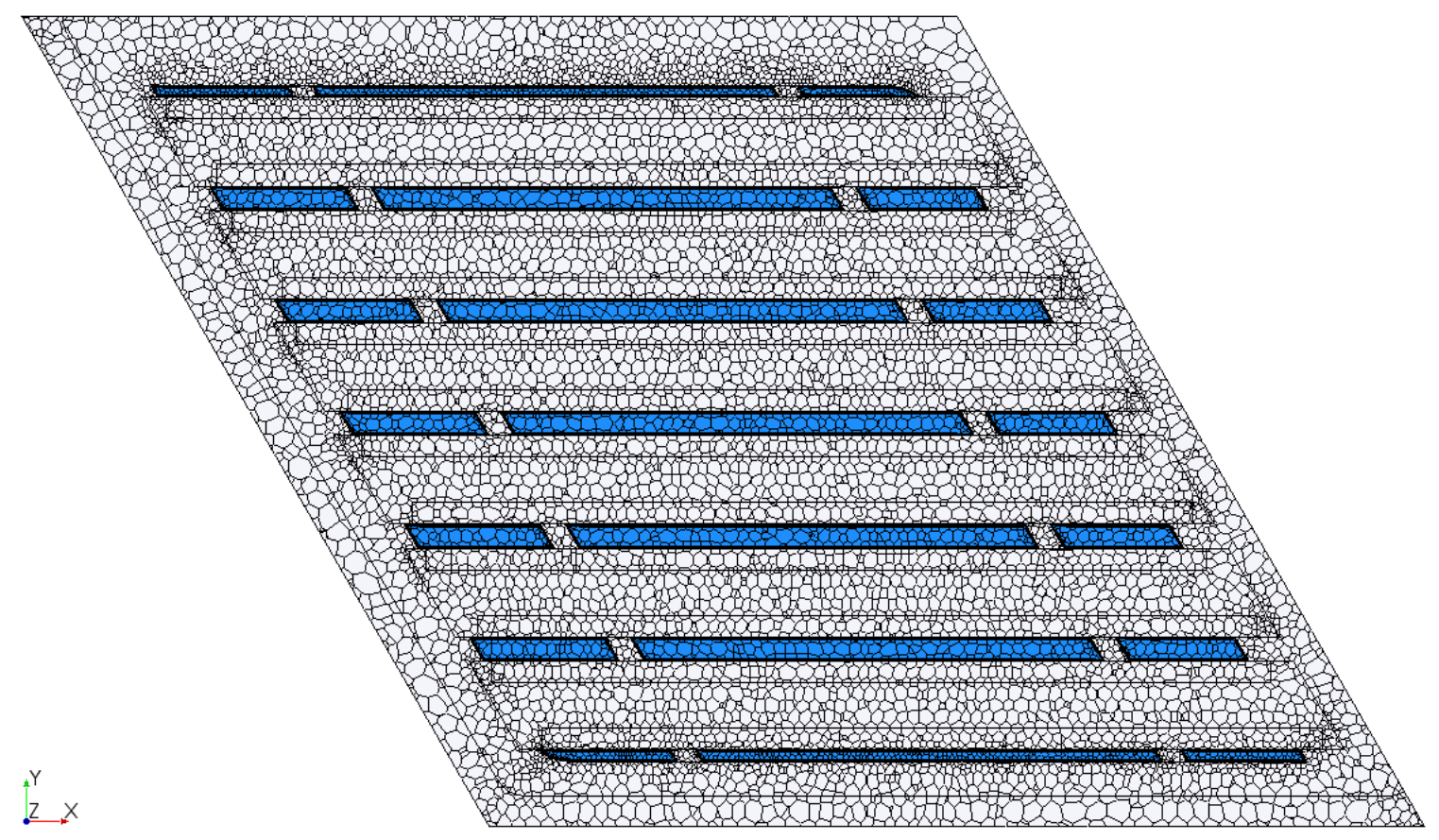

Fig. 2.7. Computational mesh distribution used in the CFD simulations of heat transfer. Solids are shown as gray, and coolant is shown as blue.

\subsection{SIMULATION RESULTS}

\subsubsection{Baseline Reference Model}

A baseline simulation of fluid flow and heat transfer in one rotationally periodic third of the AHTR fuel assembly was completed using the computational mesh and simulation methodology described above. Spacers were simplified to quadrilateral projections to reduce mesh counts and computational cost at this stage in the design analysis. The thin graphite fuel plate skin is also neglected for this reason. All simulations were completed using a 16 core desktop workstation and could typically be completed overnight.

Flow enters the model through a common inlet with a fixed mass flux and exits through a common outlet with a fixed pressure. The distribution of flow to individual channels is simulated rather than specified. The predicted velocity profile near the outlet of the fueled region is shown in Fig. 2.8. The velocity profile across the larger $0.7 \mathrm{~cm}$ gap channel is a typical flattened turbulent flow profile, while the profile across the smaller gap is not as well developed. The predicted turbulent kinetic energy profile near the outlet of the fueled region is shown in Fig. 2.9. A significant level of turbulence is being generated near the walls of the larger channels and may contribute some enhancement of heat transfer in those channels.

Temperature profiles are shown near the outlet of the fueled region in Fig. 2.10. The surface temperatures of the individual fuel plates are shown in Fig. 2.11. The temperature is clearly peaked in the innermost plate in each set of six. The location of the peak is a combination of the peaked power profile, which results from the presence of a significant moderator/reflector in the Y pillar and reduced flow in the narrow gap width of the innermost channel. The peak is further enhanced by the fact that a segment of the fuel stripe is embedded within the wall of the Y pillar and is not directly cooled by the cooling channel. 


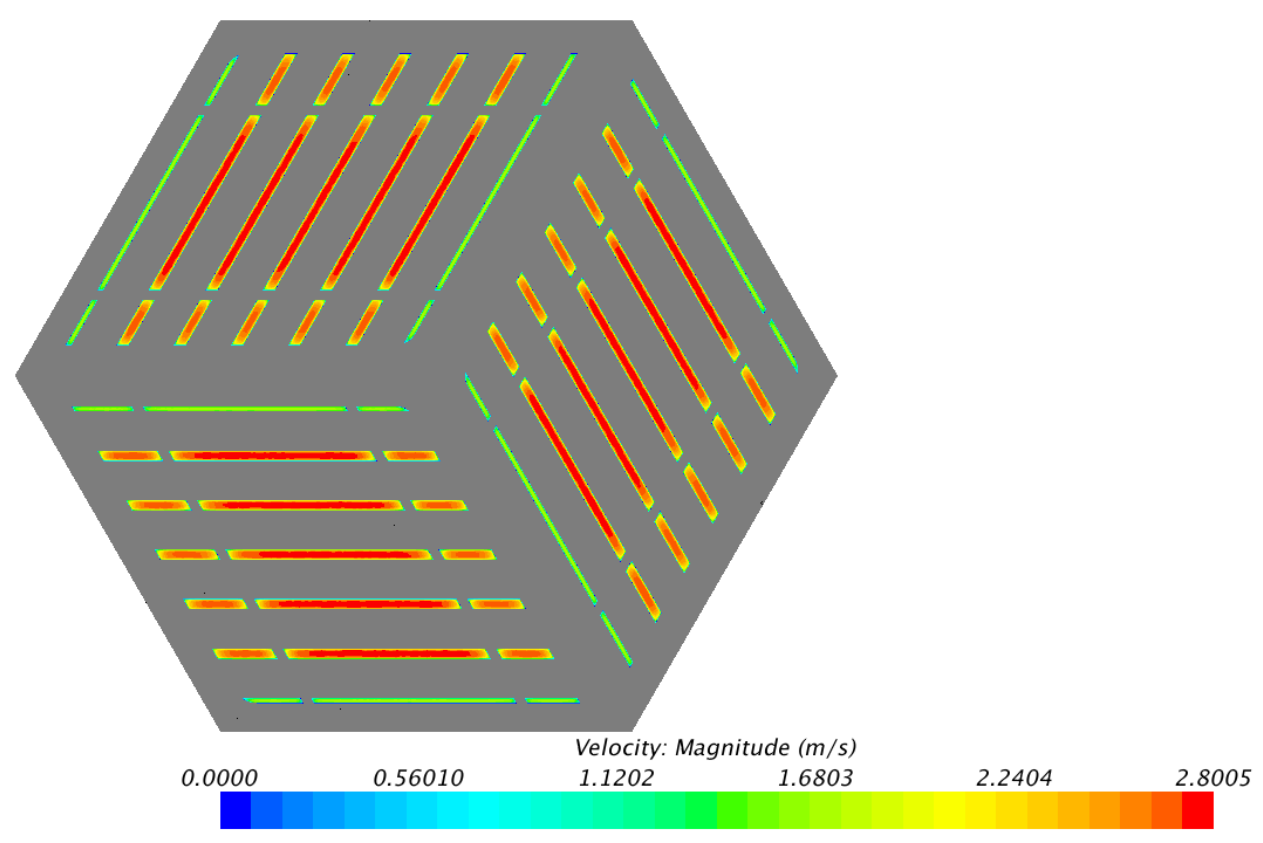

Fig. 2.8. Predicted velocity profile in coolant channels at top of fueled region for baseline case. Results are duplicated across rotationally periodic boundaries to form the complete assembly.

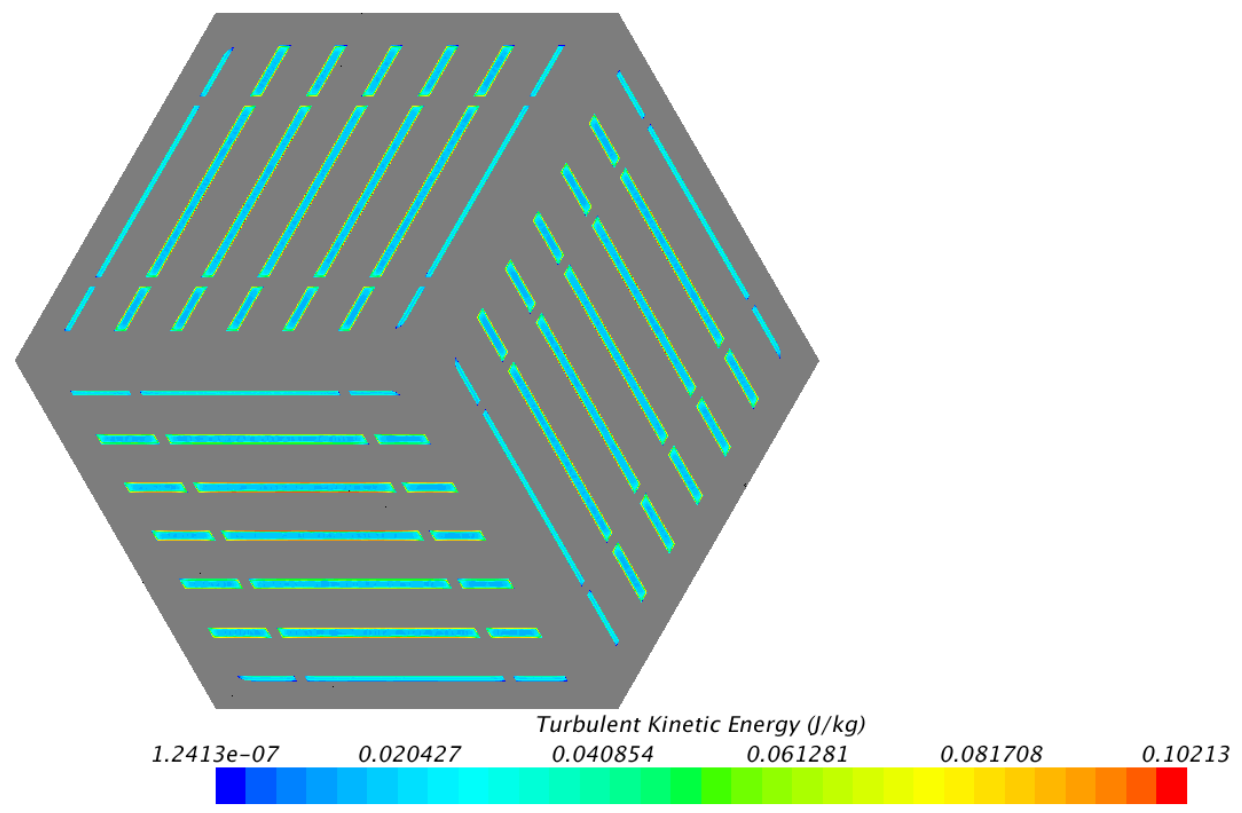

Fig. 2.9. Predicted turbulent kinetic energy profile in coolant channels for baseline case. Results are duplicated across rotationally periodic boundaries to form the complete assembly. 


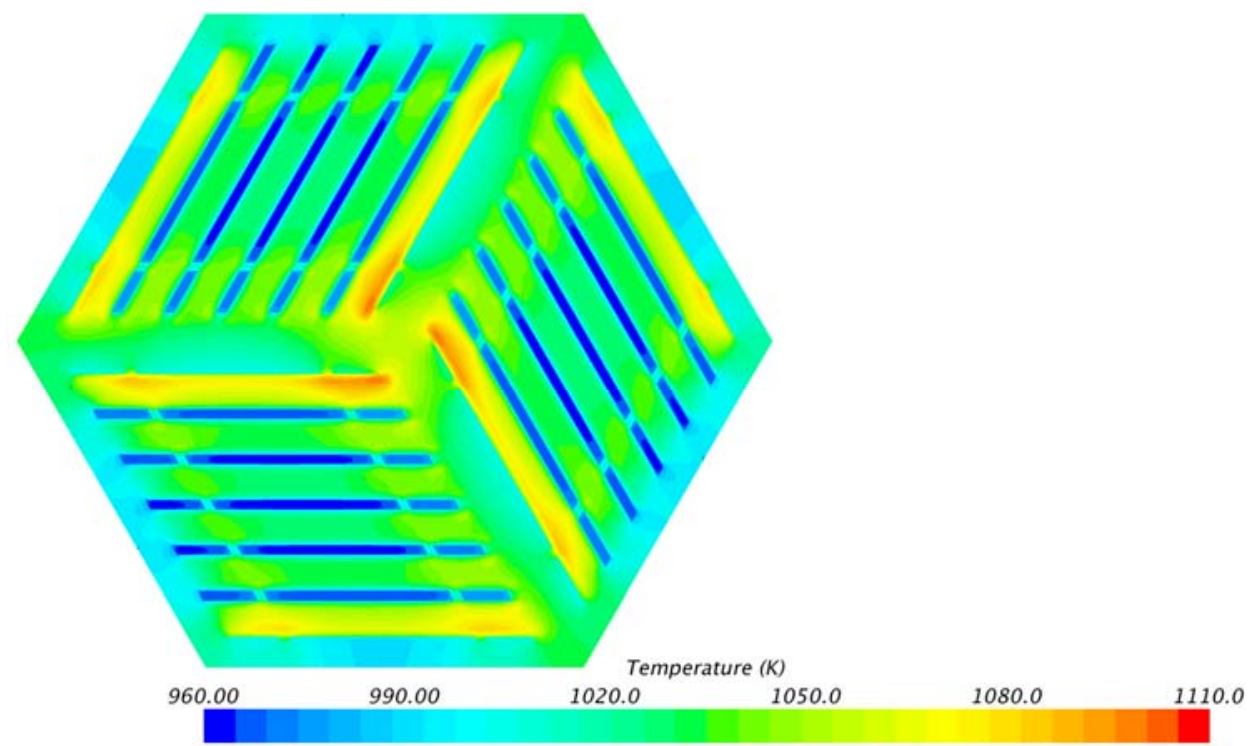

Fig.2.10. Predicted temperature profile for baseline case. Results are duplicated across rotationally periodic boundaries to form the complete assembly.

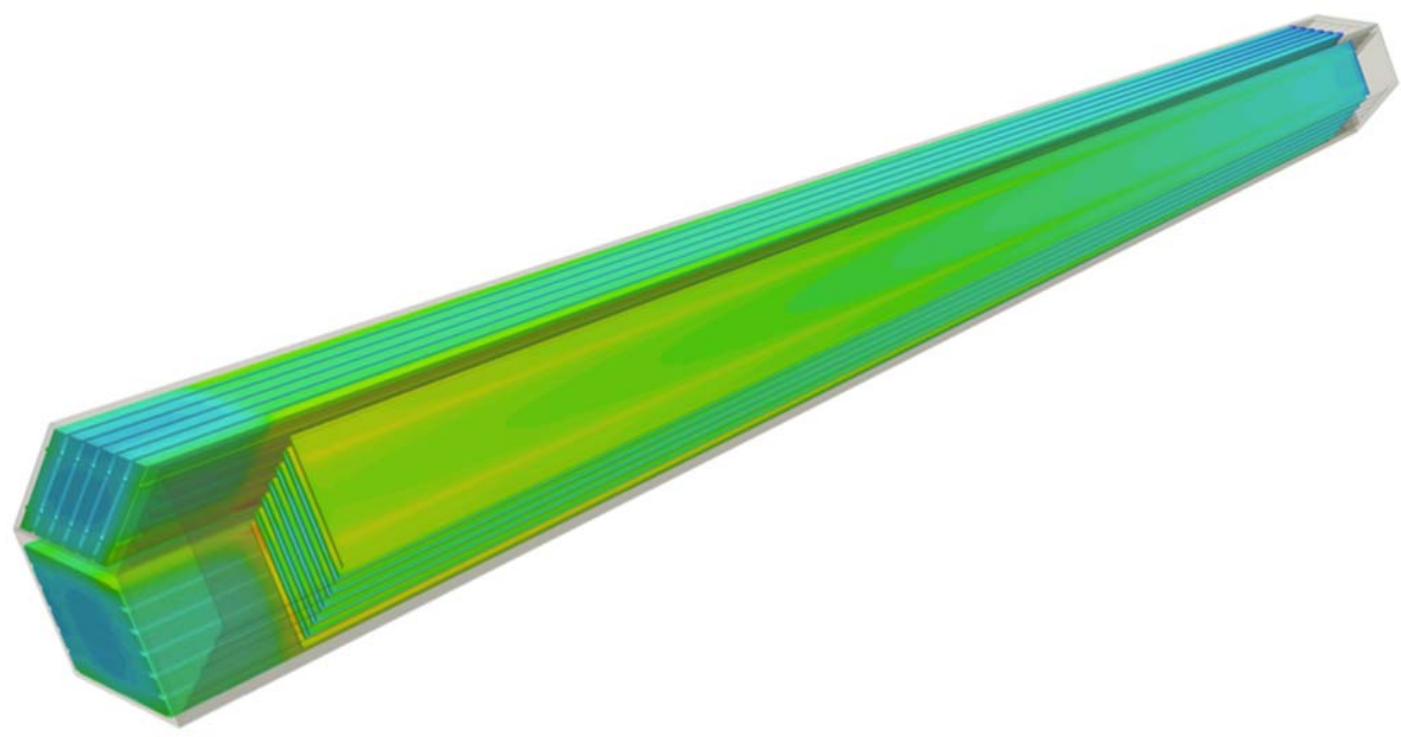

Fig. 2.11. Predicted surface temperatures of the AHTR fuel plates. In the upper right third of the assembly, only the fuel stripes are shown. 


\subsubsection{Conductivity Sensitivity Studies}

While significant effort has already been invested in understanding the thermophysical properties of FLiBe, the properties of the novel solid materials used in the AHTR are not as well known. Using the baseline model, the sensitivity of the simulation result to the uncertainty in the thermal conductivity of the solid materials has been investigated. Since these simulations are steady state, the impact of other properties such as density and specific heat cannot be evaluated.

In order to assess the sensitivity more quantitatively, temperature data are extracted along a sample line extending from the centerline of the assembly out to the corner of the fuel channel box, as shown in Fig. 2.12. Data are collected at uniformly distributed points along this line. The bias in the data associated with the number of points collected was investigated. Data collection using 100 versus 500 samples is shown in Fig. 2.13. The only significant differences occur in the locations where the sample line just passes through a corner of a coolant channel. Since plate temperatures are unaffected, a data density of 100 samples per line was collected for all comparisons.

In addition to the nominal case using the property data defined in 2.2.1, an extreme condition case was defined in which solid material conductivities were reduced to only $5 \mathrm{~W} / \mathrm{m}-\mathrm{K}$. This case is not intended to be representative of anticipated physical conditions but is intended to enable the reader to better assess the scale of the impact for the more physical cases considered below. The temperature profile extracted for the nominal and minimum reference cases is shown in Fig. 2.14.

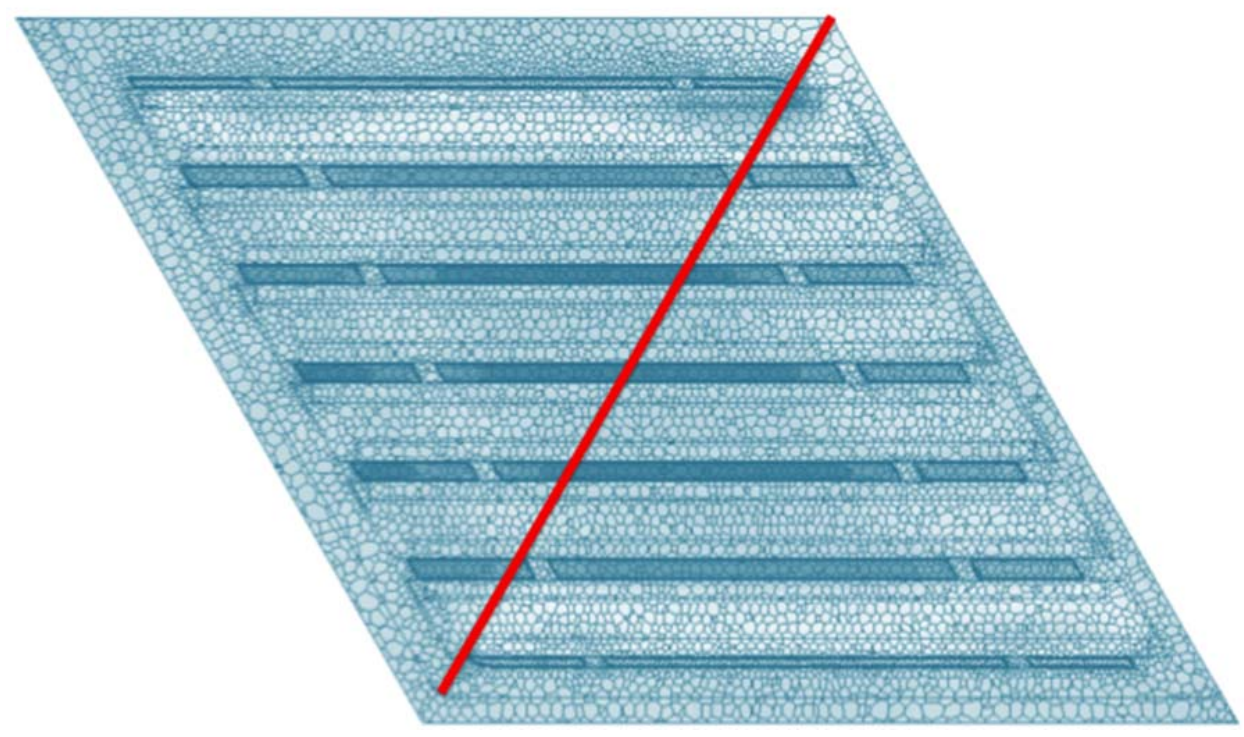

Fig. 2.12. Location of data sampling line in $1 / 3$ AHTR assembly model. 


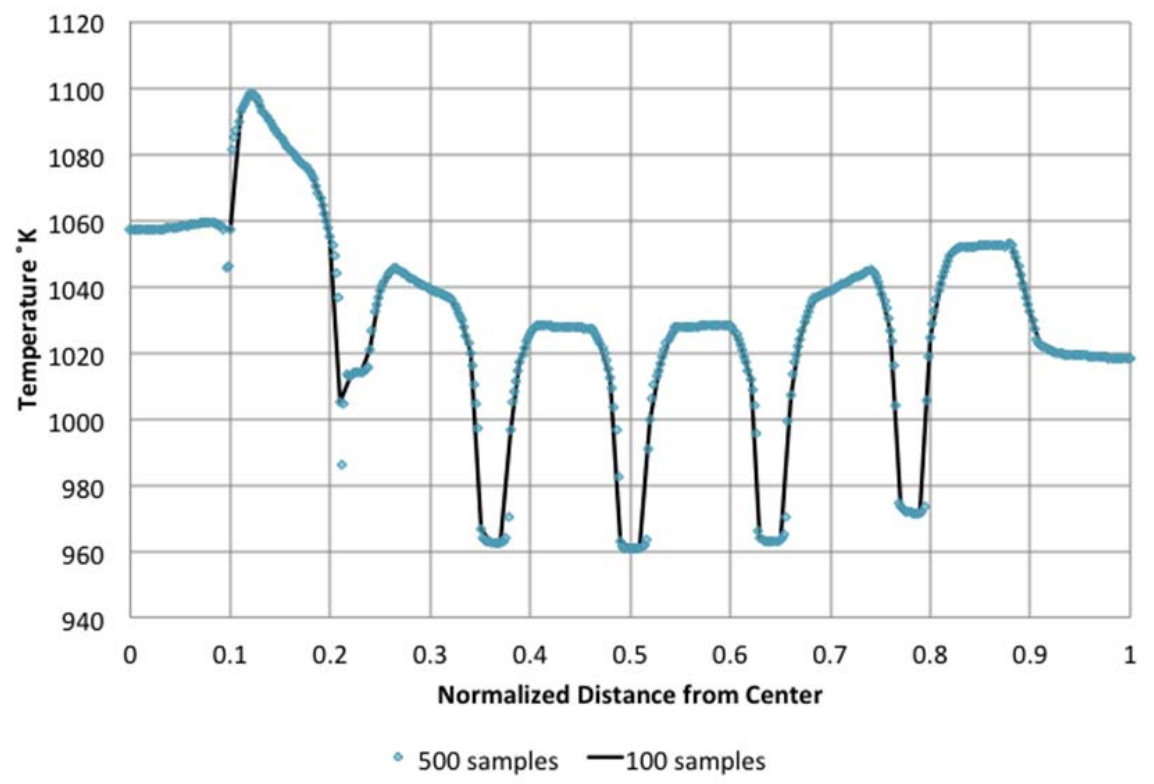

Fig. 2.13. Comparison of sample data extracted along the line shown in Fig. 2.12 using 100 vs. 500 uniformly spaced sampling points.

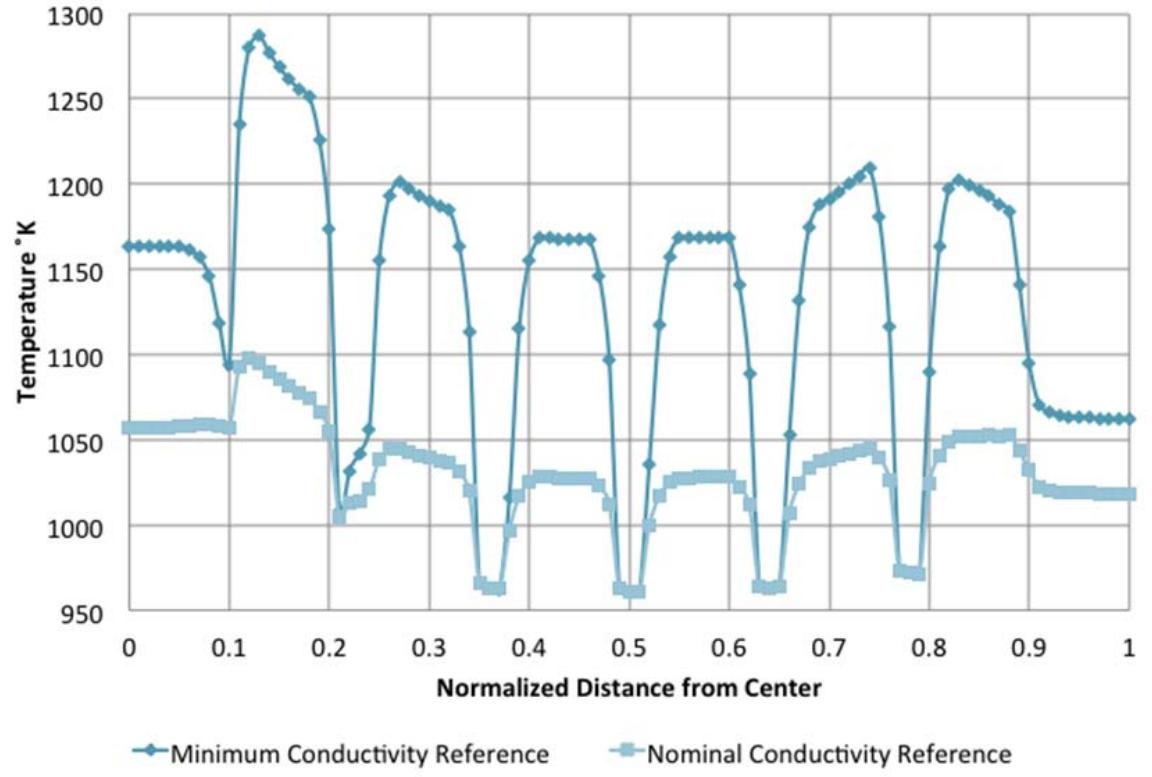

Fig. 2.14. Comparison of nominal and minimum conductivity cases.

\subsubsection{Fuel box thermal conductivity sensitivity}

In order to evaluate the sensitivity of the predicted temperature field to the uncertainty in the thermal conductivity of the fuel box carbon-carbon composite material, two cases were considered. In the first case, the baseline or nominal thermal conductivity was reduced by $25 \%$. In the second, it was increased by $25 \%$. Predicted temperature profiles are shown for these two cases plus the nominal and minimum baseline cases in Fig. 2.15. In the present model, the interassembly gap space is treated as stagnant FLiBe, so the fuel box conductivity has virtually no impact on the predicted temperature profile. If bypass flow is 
considered or if the interassembly coolant is needed as a heat sink or source during transient, the fuel box conductivity may be more impactful.

\subsubsection{Fuel plate thermal conductivity sensitivity}

As with the fuel box, the thermal conductivity of the fuel plate carbon-carbon composite material was increased and decreased by $25 \%$ to generate two new cases. All other material properties were left unchanged. Predicted temperature profiles are shown for these two cases plus the nominal and minimum baseline cases in Fig. 2.16. Since the fuel plate material is mostly locked between the two fuel stripe regions, it impacts heat transfer only by conducting additional heat through the side edges or to the unheated regions above or below the core. Changes of $\pm 25 \%$ in the thermal conductivity of this material have virtually no impact on temperature distribution.

\subsubsection{Fuel strip thermal conductivity sensitivity}

Conventional wisdom dictates that the thermal conductivity of the fuel itself should be well qualified. The thermal conductivity of the fuel stripe TRISO compact material was also increased and decreased by $25 \%$ to generate two new cases. Predicted temperature profiles along the data sampling line for these two cases, plus the nominal and minimum baseline cases, are shown in .Fig. 2.17. The uncertainty in the fuel compact conductivity has a more significant impact on predicted fuel temperatures, but the uncertainty band is still fairly small. A $25 \%$ uncertainty in fuel conductivity results in approximately $2 \%$ uncertainty in temperature. It is worth noting that these temperature predictions are for homogenized fuel compacts and do not account for local peaking within the fuel particle itself.

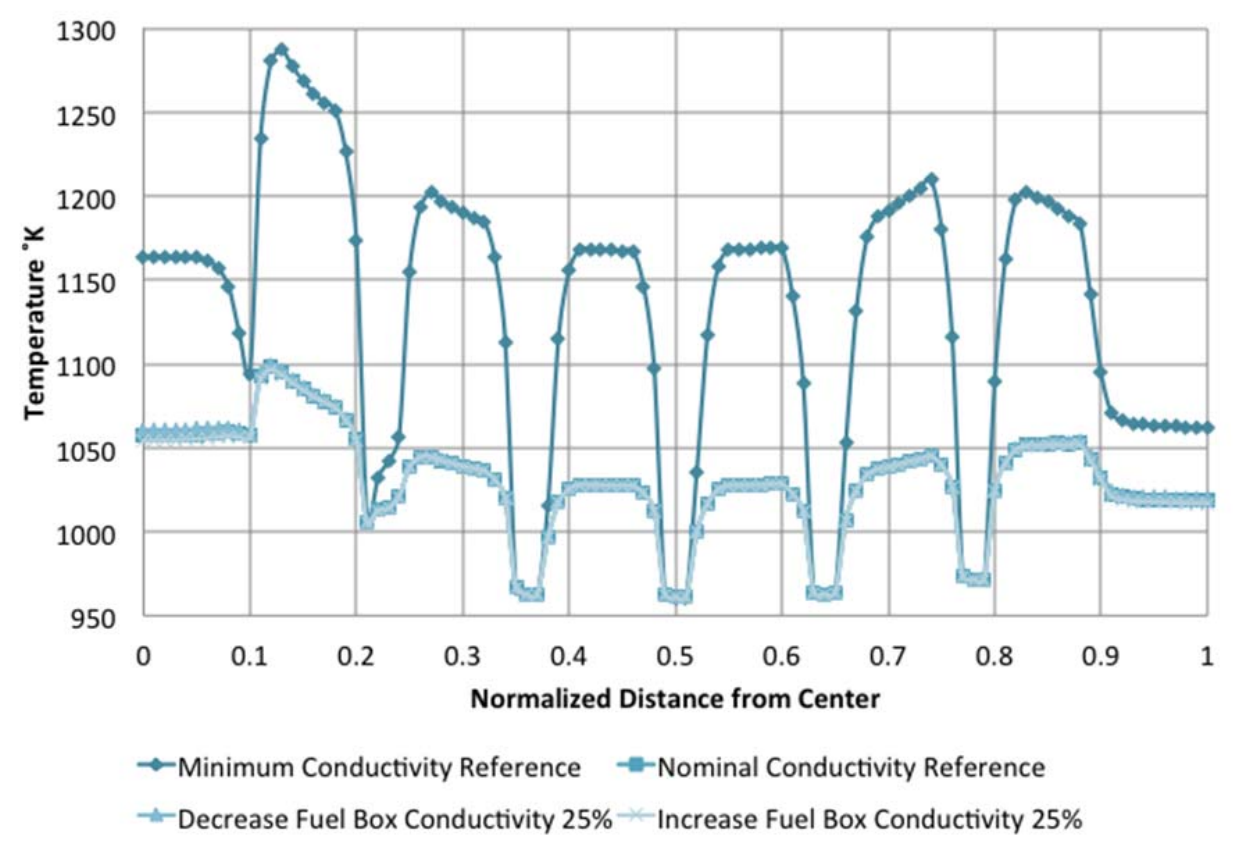

Fig. 2.15. Impact of uncertainty in the fuel box thermal conductivity on predicted temperature distributions. 


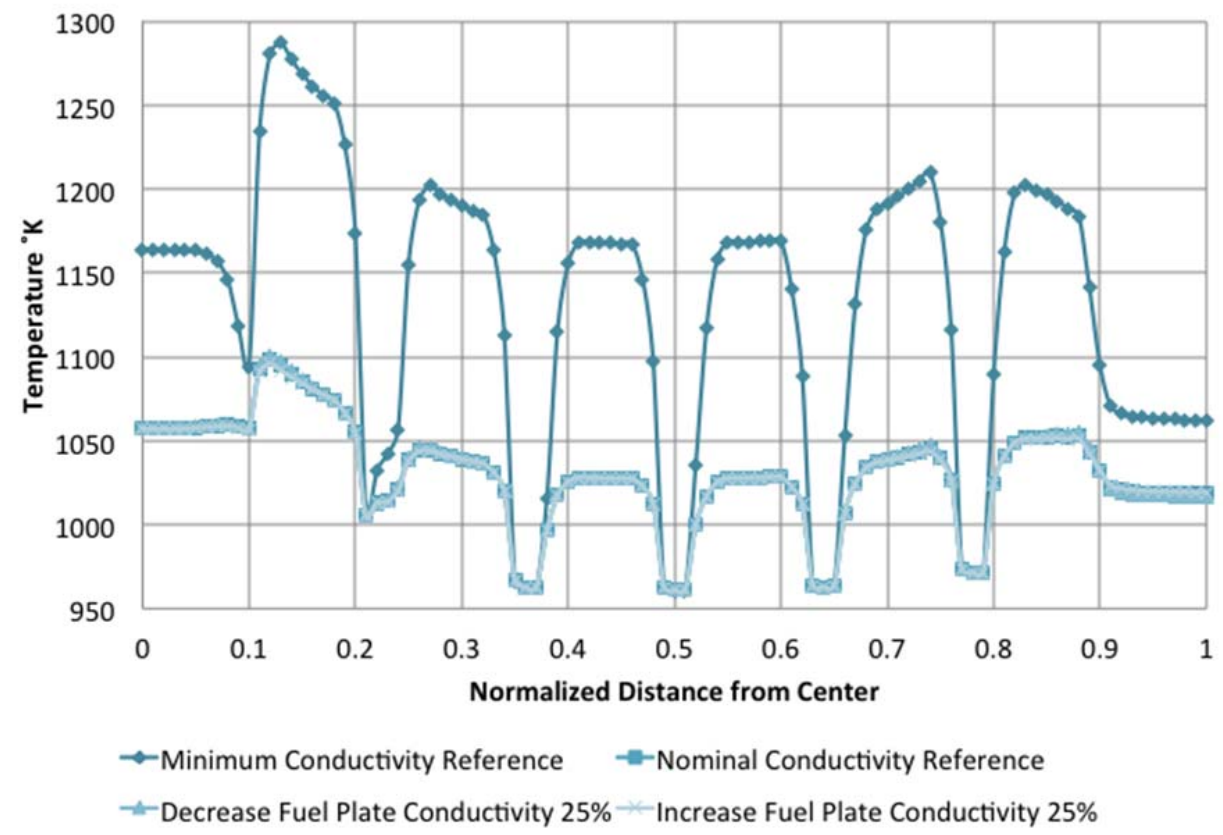

Fig. 2.16. Impact of uncertainty in the fuel plate thermal conductivity on predicted temperature distributions.

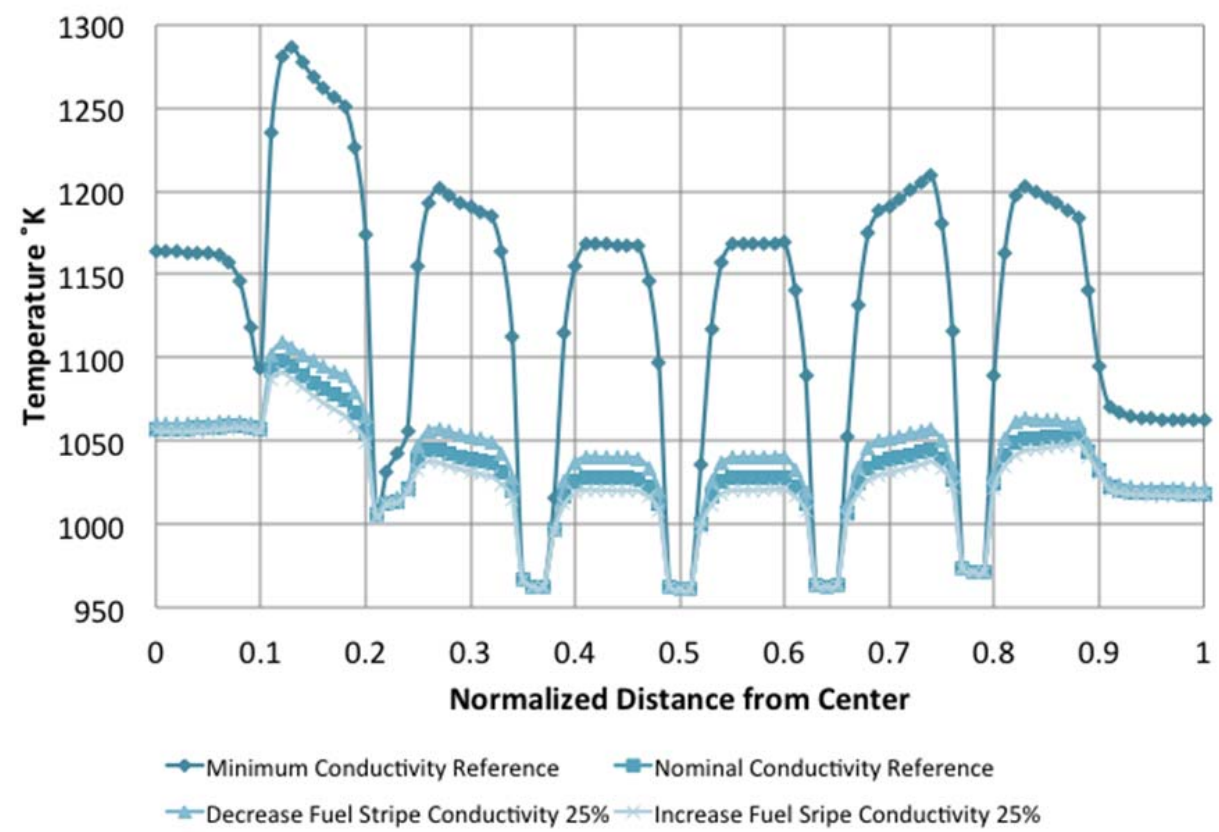

.Fig. 2.17. Impact of uncertainty in the fuel strip thermal conductivity on predicted temperature distributions.

\subsubsection{Initial Full Assembly Flow Studies}

In the AHTR fuel assembly, coolant moves from the reactor's lower plenum into one of three open volumes formed by the Y pillar and fuel box just below the fuel plates before splitting between the 21 available coolant channels. After passing through the coolant channels, the channel flows merge in three 
open volumes formed by the Y pillar and fuel box. The flows from these three volumes then mix inside the grappling ring at the top of the fuel assembly.

As noted in the discussion of the baseline case above, the flows exiting the coolant channels form turbulent rectangular jets that interact with one another in the upper volumes of the assembly. To better explore the flow behaviors in this region, an alternate model has been developed which considers the full fuel assembly and attempts to resolve these flow fields, but the model neglects some geometric details of the solid components such as the spacers between plates. A preliminary velocity field prediction in the outlet region is shown in Fig. 2.18. This solution is not well converged, with residuals only decreasing three orders of magnitude in a steady-state simulation before stagnating.

Both single rectangular jet problems and multiple jet problems of any kind are difficult to capture with either steady or unsteady RANS. Expensive, highly resolved, time-dependent simulations using large eddy simulation (LES) or direct numerical simulation (DNS) are likely required to obtain a clearer understanding of the phenomena occurring in this region. Since the mixing that occurs as a consequence of the jet interactions is likely beneficial and it seems unlikely that they introduce sufficiently large pressure oscillations to alter the distribution of flow between channels, the preferred approach to address this uncertainty is likely to alter the design of the coolant channel outlet to improve the stability of the jets or to at least introduce a more predictable form of instability.

The preliminary velocity field solution has been included herein as a reference case for future studies.

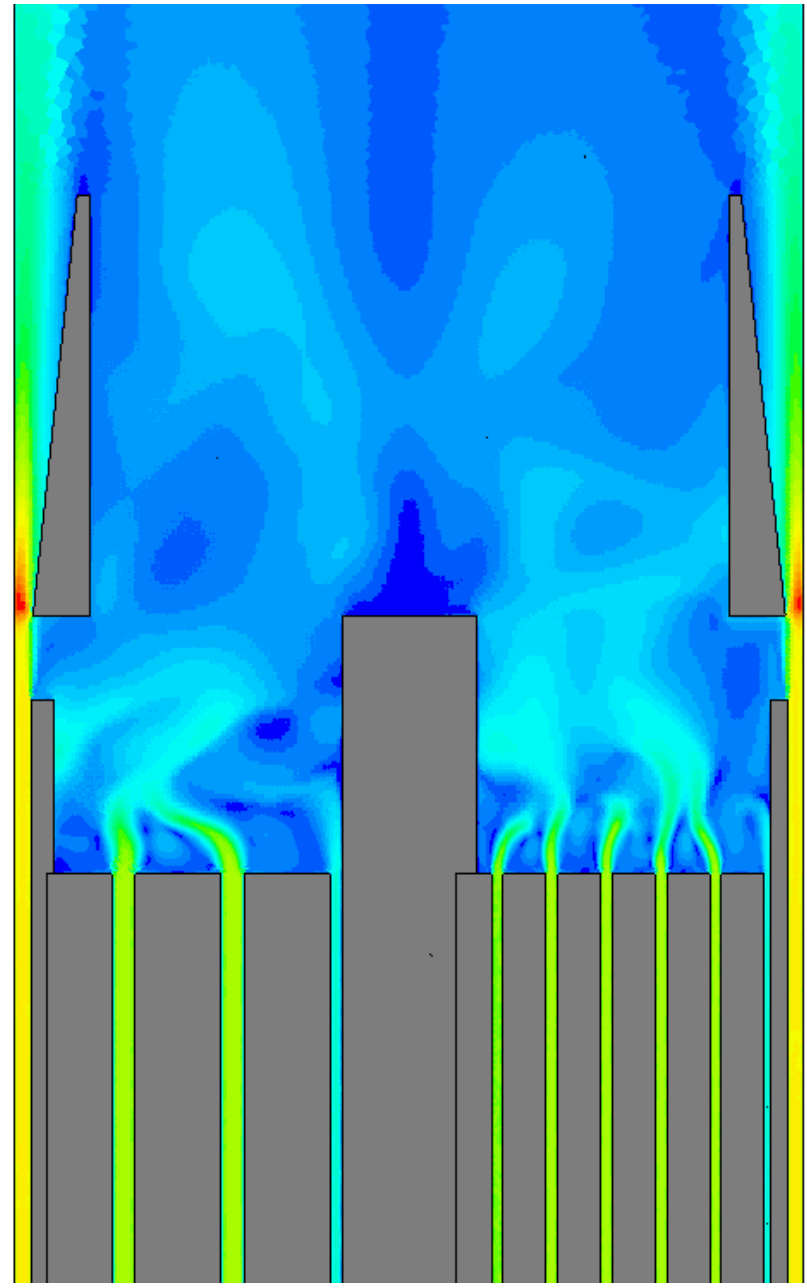

Fig. 2.18. Initial velocity predictions in the upper regions of the AHTR fuel assembly. 


\subsection{FUEL ASSEMBLY DESIGN RECOMMENDATIONS AND FUTURE WORK}

A series of preliminary CFD studies has been completed to better understand the features and performance of the AHTR fuel assembly design. The following recommendations have been compiled based on the analyses presented above.

- The present AHTR fuel assembly design does not account for the non-uniform power distribution within the assembly. The gap width of the smaller edge channels should be increased to account for the power distribution and to attempt to encourage turbulent heat transfer in those channels. A uniform distribution of coolant within the assembly is recommended as a starting point.

- The fuel stripe of each fuel plate is wider than the adjacent coolant channel. As a result, a small segment of the fuel stripe is embedded within the wall of the fuel box or central Y pillar, and a localized hot spot occurs on each fuel stripe. This effect will be further exacerbated when the additional local moderation in this region is accounted for in future reactor physics simulations to provide more detailed radial power distributions. The fuel stripe width should be reduced so that the entire fuel stripe is in contact with the coolant channel.

- The design of the cooling channel outlet should be further evaluated to determine if outlet nozzle design modifications might improve the predictability of thermal hydraulic performance in the entire fuel assembly without resorting to higher fidelity methods.

In addition to the recommended design considerations above, the following recommendations for the path of future work have been compiled based on the analysts' experience to date.

- Analyses to date consider only standard operating conditions in the reactor. Steady-state simulations should be completed for conditions that result in peak temperatures in transient system analyses. The need for time-dependent CFD analyses should be determined based on these results.

- Nondimensional analysis suggests that a mixed convection flow occurs within the coolant channel. More detailed analyses should be completed to better understand the natural convection contributions to the heat transfer within the coolant channel. Particular attention should be given to the potential for relaminarization of the flow and any negative impacts that may result. 


\title{
3. AHTR THERMAL HYDRAULIC SYSTEM ANALYSIS
}

\author{
Dean Wang
}

\subsection{TRACE MODELING AND SIMULATION OF AHTR}

This chapter documents the development of a TRACE plant system model for the AHTR, including the reactor vessel, three primary coolant loops, and three DRACSs. The TRACE AHTR model developed has been employed to optimize the component design and investigate system safety performance of the AHTR. Simulations for steady-state conditions and a loss of forced flow accident were carried out, and the results are discussed and documented. Based on system modeling and analysis, some remarks and recommendations about the AHTR design have been summarized at the end of this chapter.

The AHTR is a fluoride-salt-cooled high-temperature reactor design concept which features low-pressure liquid fluoride salt cooling, coated-particle fuel, a high-temperature power cycle, and fully passive decay heat rejection. The development of the TRACE AHTR model is largely based on the design characteristics and parameters presented in the referenced report ${ }^{1}$ which are intended to be useful for concept evaluation but do not reflect the optimization necessary to form a realistic design.

\subsubsection{Overall Plant Features}

The AHTR concept is designed with the thermal power of 3,400 $\mathrm{MW}_{\text {th. }}$. The reactor core contains 252 fuel assemblies with a hexagonal lattice configuration. The primary coolant is $2 \mathrm{LiF}_{-} \mathrm{BeF}_{2}(\mathrm{FLiBe})$, and $\mathrm{KF}-\mathrm{ZrF} 4$ is employed for the DRACS and intermediate loops. The primary loop coolant flow rate is $28,500 \mathrm{~kg} / \mathrm{s}$ and the intermediate salt flow rate is $43,200 \mathrm{~kg} / \mathrm{s}$. Under normal operation, the primary salt transfers heat to the salt in the intermediate loop, and from this loop, the heat is transferred to the power cycle. The three DRACS systems are designed to remove decay heat under abnormal conditions. On each DRACS loop there is a DRACS heat exchanger (DHX) in the downcomer region above the core. The DRACS loop transfers heat from the primary salt to the DRACS circuit that in turn transfers heat to the atmosphere by natural convection through the air cooling tower. The main heat transfer paths for the AHTR are illustrated in Fig. 1.1. The detailed design features and parameters of the AHTR can be found in reference 1 .

\subsubsection{TRACE Model Description}

The development of the AHTR design is still at the early preconceptual stage. The mechanical design of the reactor fuel and core is relatively complete. However, there is lack of detailed design of the DRACS system and primary and intermediate loops and the power cycle. One objective of the TRACE AHTR model development is to design and optimize system components where necessary based on system performance. For example, the DRACS system has been redesigned and optimized based on performance during a loss of forced flow (LOFF) transient. For the DRACS heat exchanger and air cooler components, the correlations of the shell-side heat transfer and pressure drop are implemented in the TRACE model. In addition, a preliminary design of the primary heat exchanger has been developed.

The TRACE AHTR model is shown in Fig. 3.1. The three DRACS loops are explicitly modeled. The DHX is a tube-shell design with three passes in the tube side. In this model, the intermediate loops and steam lines are not included. 


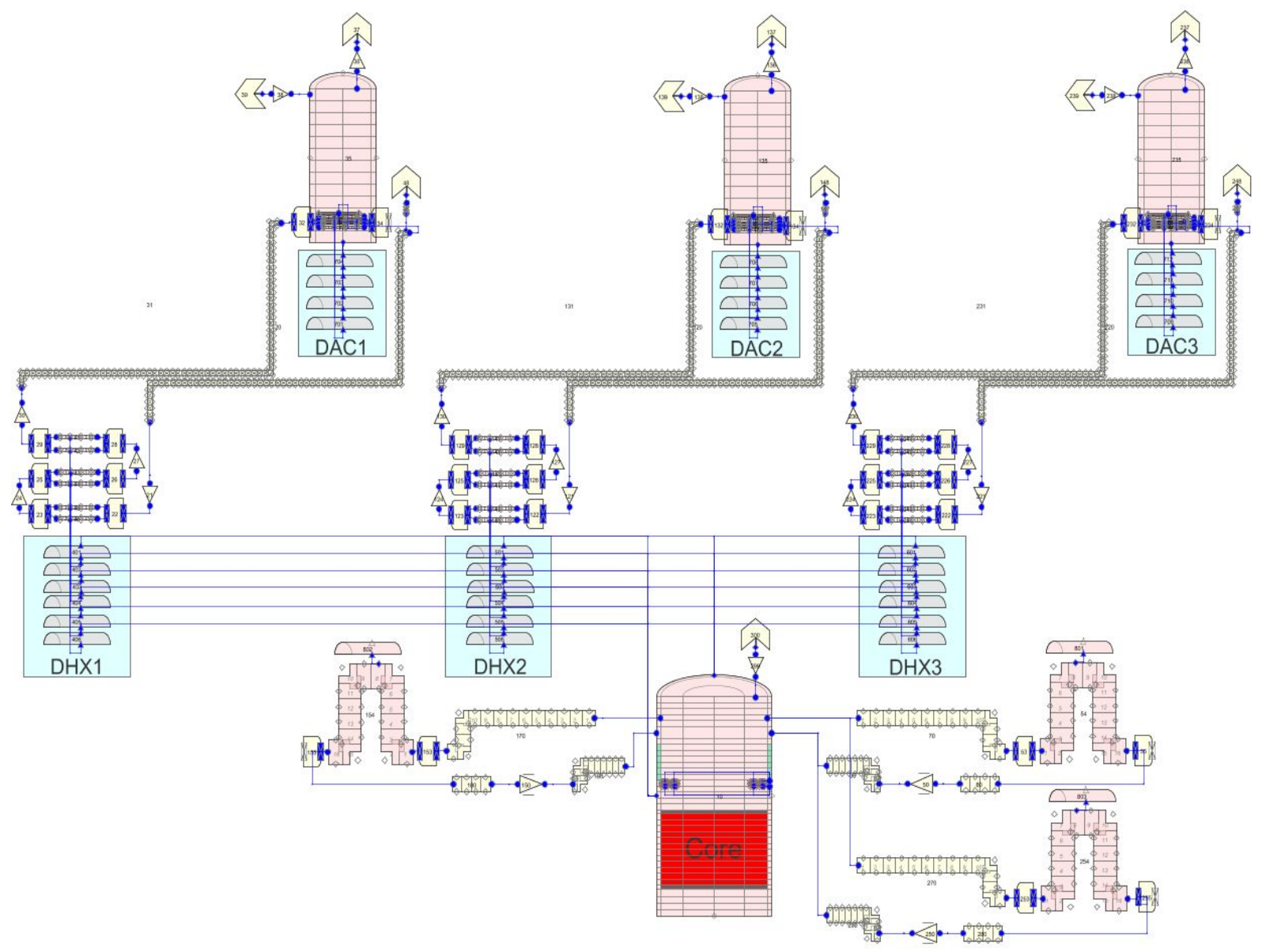

Fig. 3.1. TRACE SNAP model of AHTR.

The major TRACE components are discussed and described below.

\subsubsection{Reactor vessel and internal components}

The reactor vessel is cylindrical with a height of $\sim 19 \mathrm{~m}$ and an inside diameter of $10.4 \mathrm{~m}$, as shown in Fig. 3.2. The vessel wall is made of $800 \mathrm{H}$ with Hastelloy $\mathrm{N}$ cladding and a clad thickness is $0.05 \mathrm{~m}$. The core barrel made of $\mathrm{C}-\mathrm{C}$ composite, has an internal diameter (ID) of $9.6 \mathrm{~m}$, and a thickness of $0.03 \mathrm{~m}$. The reactor vessel is modeled in TRACE with 36 axial levels (\#1 at the bottom of the vessel and \#36 at the top), three radial rings, and eight azimuthal sectors. The two inner rings ( 1 and 2$)$ are the core region. The radius of ring 1 is $2.76614 \mathrm{~m}$ and the radius of ring 2 is $4.83 \mathrm{~m}$. The outermost ring 3 is the downcomer region. The core ranges from levels 6 through 17. The three DRACS heat exchangers (HXs) are located between levels 24 and 29 in three azimuthal sectors of ring 3 . The primary loop cold legs are connected to the reactor vessel level 31, and the hot legs are connected to level 33. 


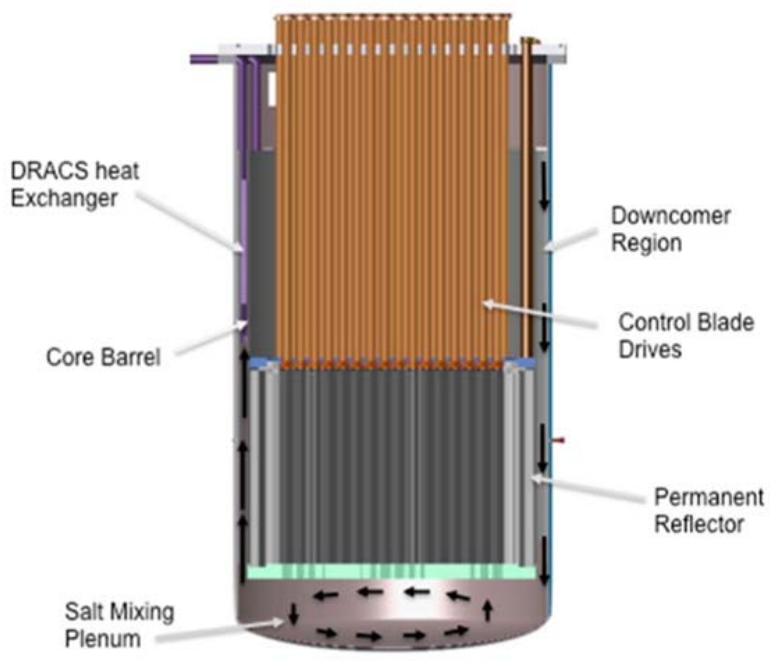

Single fuel assembly FA* $\left(\mathrm{m}^{2}\right)$ : $\quad 0.02831$

Core fuel assembly FA fraction in ring 1: 0.14959

Core fuel assembly FA fraction in ring 2: $\quad 0.07243$

Single fuel assembly HD** $(\mathrm{m})$ : $\quad 0.01180$

fuel assembly bypass FA $\left(\mathrm{m}^{2}\right)$ : $\quad 0.01391$

Core fuel assembly bypass FA fraction: $\quad 0.07347$

Core fuel assembly bypass HD (m): $\quad 0.03568$

Core total FA $\left(\mathrm{m}^{2}\right)$ : $\quad 7.13512$

Core total bypass FA $\left(\mathrm{m}^{2}\right)$ : $\quad 3.50409$

*Flow area

** Hydraulic diameter

Fig. 3.2. Sectional view of the reactor vessel.

The reactor core consists of 252 fuel assemblies supported by the upper and lower support plates. The geometric dimensions of a fuel assembly are shown in Fig. 2.3.

The core region is modeled with two radial rings in the TRACE model. The inner ring consists of 127 fuel assemblies, and the outer ring has 125 fuel assemblies. The TRACE input parameters for the core flow areas and hydraulic diameters are summarized in Fig. 3.2.

The core bottom support plate is shown in Fig. 3.3. There are flow channels cut on the lower support to direct the flow into the fuel assemblies. An indexing hole and guides on the plate are used to align the fuel assemblies.

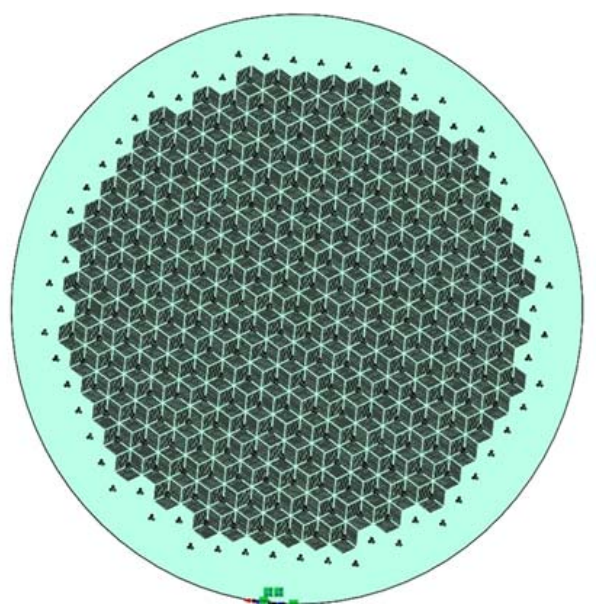

$\begin{array}{lr}\text { Bottom plate total FA }\left(\mathrm{m}^{2}\right) \text { : } & 7.29775 \\ \text { Bottom plate FA fraction in ring 1: } & 0.15240 \\ \text { Bottom plate FA fraction in ring 2: } & 0.07379 \\ \text { Bottom plate axial HD }(\mathrm{m}) \text { : } & 0.01180 \\ \text { Bottom plate height }(\mathrm{m}): & 0.3\end{array}$

Fig. 3.3. Core bottom support plate.

TRACE input parameters for the lower core support plate are summarized in Fig. 3.3.

The core upper support plate is shown in Fig. 3.4. There are 313 flow channels cut through the plate in a hexagonal shape. The bottom inlet flow area is slightly larger than the exit flow area. 

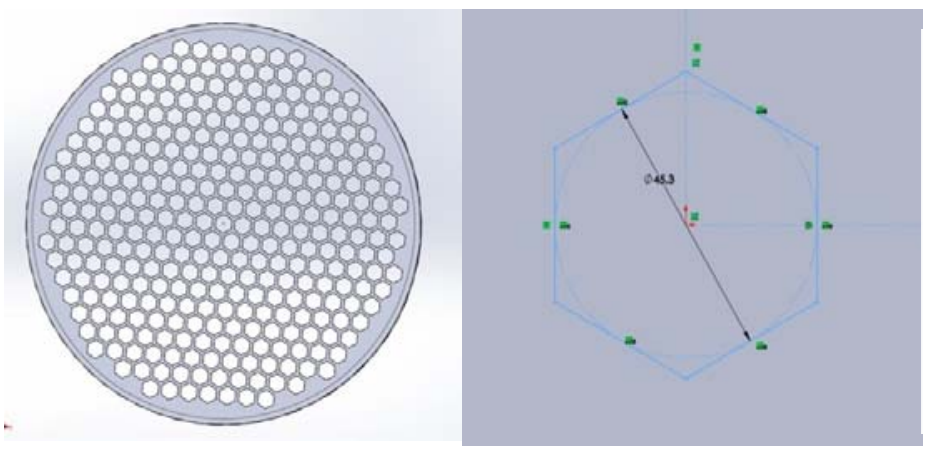

Upper plate bottom FA $\left(\mathrm{m}^{2}\right)$ :

Upper plate FA fraction in ring 1:

Fig. 3.4. Core upper support plate.

TRACE input parameters for the upper core support plate are shown in Fig. 3.4.

The AHTR employs one control blade per fuel assembly. There are 252 control blade guide tubes sitting above the core upper plate. The ID of each tube is $0.24 \mathrm{~m}$, and the outer diameter (OD) is $0.3 \mathrm{~m}$. TRACE input parameters for the guide tubes are given in Table 3.1.

Table 3.1. Guide tube design parameters

\begin{tabular}{lc}
\hline \multicolumn{1}{c}{ Region } & Value \\
\hline Guide tube region FA fraction in ring 1: & 0.86556 \\
Guide tube region FA fraction in ring 2: & 0.93490 \\
Guide tube region HD in ring 1 (m): & 0.69531 \\
Guide tube region HD in ring 2 (m): & 1.23686 \\
\hline
\end{tabular}

\subsubsection{Primary loops}

The AHTR has three primary coolant loops, each consisting of the primary piping, the primary heat exchanger, and the primary salt pump, as shown in Fig. 3.5. The FLiBe salt mass flow rate of each loop is $9,500 \mathrm{~kg} / \mathrm{s}$. The design temperature drop through the primary heat exchanger is $50 \mathrm{~K}$.

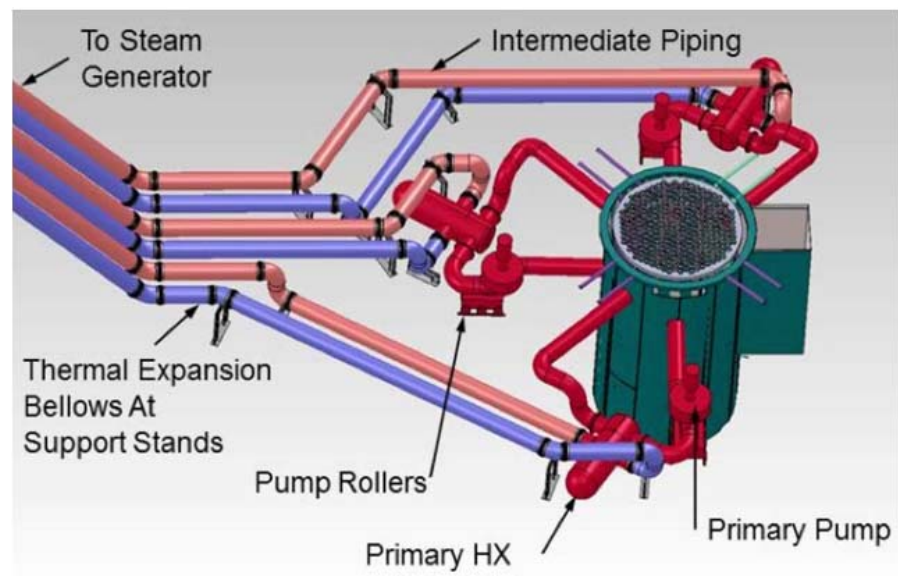

Hot leg length (m):

Hot leg HD (m):

Cold leg length (m):

Fig. 3.5. Primary coolant loop (in red). 
The preliminary design parameters of the hot and cold legs are given in Fig. 3.5.

\subsubsection{Primary heat exchanger design and modeling}

The PHX is a tube-and-shell design as shown in Fig. 3.6. For simplicity, one pass is employed for both shell and tube sides. The temperature change and coolant thermal properties of the PHX design are given in Table 3.2.

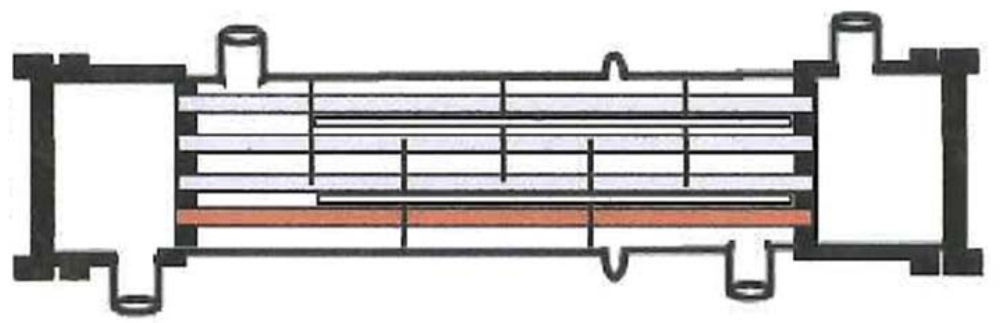

Fig. 3.6 Schematic drawing of tube-and-shell exchanger.

Table 3.2. PHX design parameters and coolant thermal properties

\begin{tabular}{lccc}
\hline \multicolumn{1}{c}{ Parameter } & \multirow{2}{*}{ Primary loop } & \multicolumn{2}{c}{ Intermediate loop } \\
\cline { 3 - 4 } & & Salt 1 & Salt 2 \\
\hline Coolant salt & $\mathbf{2 L i F - B e F _ { 2 }}$ & KF-ZrF & FLiNaK \\
HX inlet temperature $\left({ }^{\circ} \mathrm{C}\right)$ & 700 & 600 & 600 \\
HX outlet temperature $\left({ }^{\mathrm{O}} \mathrm{C}\right)$ & 650 & 675 & 675 \\
Coolant flow rate $(\mathrm{kg} / \mathrm{s})$ & 9,500 & 14,400 & 7,518 \\
Coolant density* $\left(\mathrm{kg} / \mathrm{m}^{3}\right)$ & 1,950 & 2,850 & 2,064 \\
Coolant viscosity* $(\mathrm{Pa}-\mathrm{s})$ & 0.00609 & 0.00522 & 0.00390 \\
Coolant thermal conductivity* $(\mathrm{W} / \mathrm{m}-\mathrm{K})$ & 1.1 & 0.42 & 0.89 \\
Coolant-specific heat capacity* $(\mathrm{J} / \mathrm{kg}-\mathrm{K})$ & 2416 & 1804 & 2010 \\
Coolant Pr* & 13.32 & 12.95 & 8.85 \\
\hline
\end{tabular}

Evaluated at average temperature.

A Microsoft Excel spreadsheet for the tube-and-shell HX design was developed according to Kern's method $^{11}$ This method is based on experimental work on commercial exchangers and will give a reasonably satisfactory prediction of the heat transfer coefficient for standard designs. The pressure drop prediction is less satisfactory since pressure drop is more affected by leakage and bypass than heat transfer. ${ }^{12}$ The shell-side heat transfer factor $\left(\mathrm{j}_{\mathrm{h}}\right)$ and the friction factor $\left(\mathrm{j}_{\mathrm{f}}\right)$ as a function of the Reynolds number $(\mathrm{Re})$ are implemented in the spreadsheet HX model. The tube-side heat transfer coefficient is calculated based on the Gnielinsky correction, and the friction factor is calculated using the McAdams correlation.

In the PHX design, the first decision is fluid allocation on the shell or tube sides. In general, there are a few factors in determining the allocation of the fluid streams to the shell or tube side (e.g., corrosion, fouling, fluid temperatures, operating pressures, pressure drop, viscosity, flow rates, etc.) ${ }^{12}$ Table 3.3 summarizes major parameters of the three PHX design options developed based on the spreadsheet HX model. Option 1 has the primary loop on the tube side and the intermediate loop on the shell side.

Option 3 uses FLiNaK as the coolant fluid for the intermediate loop. It shows that Option 2 is better than Option 1 in terms of the size of the heat exchanger and the PHX pumping power. However, if the FLiNak salt is used for the intermediate loop, the PHX pumping power of Option 3 is almost half that of Option 2. It should be noted that the PHX designs are very preliminary, and further study is needed to develop a more optimum design. 
Table 3.3. PHX design options

\begin{tabular}{|c|c|c|c|c|c|c|}
\hline \multirow{2}{*}{ Parameter } & \multicolumn{2}{|c|}{ Option 1} & \multicolumn{2}{|c|}{ Option 2} & \multicolumn{2}{|c|}{ Option3 } \\
\hline & Tube & Shell & Tube & Shell & Tube & Shell \\
\hline Loop allocation & Primary & Interm. & Interm. & Primary & Primary & Interm. \\
\hline Coolant salt & FLiBe & $\mathrm{KF}-\mathrm{ZrF}_{4}$ & $\mathrm{KF}-\mathrm{ZrF}_{4}$ & FLiBe & FLiBe & FLiNaK \\
\hline Tube length (m) & \multicolumn{6}{|c|}{20.0} \\
\hline Tube ID (m) & \multicolumn{6}{|c|}{0.019735} \\
\hline Tube wall thickness (m) & \multicolumn{6}{|c|}{0.001245} \\
\hline \# of tubes & \multicolumn{2}{|c|}{20000} & \multicolumn{2}{|c|}{18000} & \multicolumn{2}{|c|}{12000} \\
\hline Tube pitch $(\mathrm{m})$ & \multicolumn{6}{|c|}{$1.5 \mathrm{OD}$} \\
\hline Tube arrangement & \multicolumn{6}{|c|}{ Square } \\
\hline Shell inside diameter (m) & \multicolumn{2}{|c|}{5.44} & & & & \\
\hline Baffle spacing $(\mathrm{m})$ & \multicolumn{6}{|c|}{2.0} \\
\hline Baffle cut & \multicolumn{6}{|c|}{$25 \%$} \\
\hline $\begin{array}{l}\text { Heat transfer coefficient } \\
\left(\text { HTC) }\left(\mathrm{W} / \mathrm{m}^{2}-\mathrm{K}\right)\right.\end{array}$ & 2853.3 & 2530.5 & 2116.9 & 5044.3 & 4768.8 & 4387.4 \\
\hline Pressure drop $(\mathrm{Pa})$ & $2.10 \mathrm{E}+04$ & $1.23 \mathrm{E}+6$ & $3.55 \mathrm{E}+04$ & $8.92 \mathrm{E}+5$ & $5.26 \mathrm{E}+04$ & $6.04 \mathrm{E}+5$ \\
\hline $\begin{array}{l}\text { PHX pumping power } \\
\text { (MW) }\end{array}$ & 0.10 & 6.24 & 0.18 & 4.35 & 0.26 & 2.20 \\
\hline
\end{tabular}

In the TRACE model, Option 2 has been implemented for the PHX. Control systems are developed to calculate the heat transfer coefficient and friction factor for the shell side of the PHX based on the correlations given in reference 12 .

\subsubsection{DRACS design and modeling}

Decay heat removal is provided by three DRACS cooling loops. A schematic drawing of the DRACS loops is shown in Fig. 3.7. The DRACS is a fully passive safety system. The flow in each intermediate DRACS loop is driven by the gravity head difference between the hot leg and cold leg of the DRACS, taking heat from the primary loop through the DRACS HX and transferring it to the atmosphere by the air cooler installed at the bottom of each DRACS cooling tower. All heat transfer in the DRACS system occurs through conduction and natural convection.

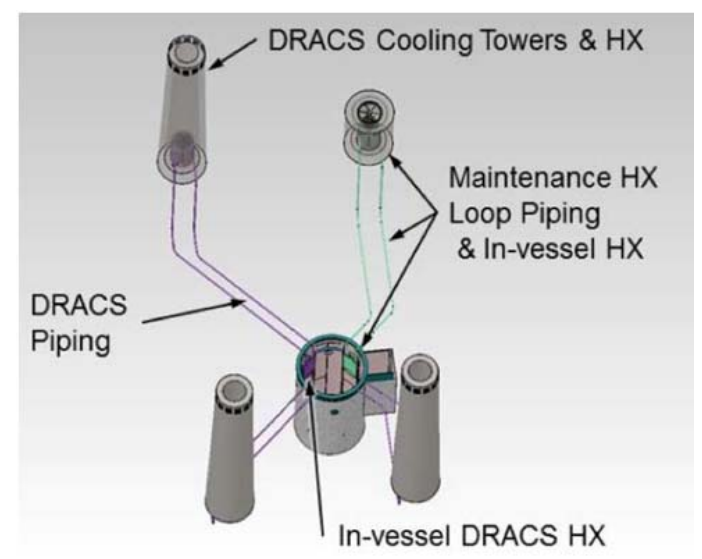

Fig. 3.7. Schematic drawing of the DRACS loops. 
The preliminary design parameters of the DHX are summarized in Table 3.4.

Table 3.4. Preliminary design parameters of DHX

\begin{tabular}{rc}
\hline DHX design: & Shell and tube \\
\hline Tube arrangement: & Staggered \\
\hline Primary side: & Shell \\
DRACS side: & Tube \\
\# of tubes: & 1078 \\
\# of tube rows: & 98 \\
\# of tube passes: & 3 \\
Tube length (m): & 3.6 \\
Tube OD (m): & 0.0254 \\
Tube wall thickness (m): & $1.651 \mathrm{E}-3$ \\
Tube material: & Hastelloy N \\
\hline
\end{tabular}

The DRACS air cooler (DAC) plays an important role in passive decay heat removal. Decay heat is transferred out of the DRACS by natural convection air flow passing through the DAC outside surface. Because of the low volumetric heat capacity of the air, it requires a large flow rate to efficiently remove decay heat from the DAC. However, the flow rate is determined by the balance between the pressure drop through the DAC and the available buoyancy driving head in the air tower. In addition, the temperature change through the DAC should not be too high in order to prevent significant thermal impact on the DAC structure. The TRACE system model has been employed to perform design optimization of the DAC by varying a few design parameters such as fin height and spacing, number of tubes, and tube size. The preliminary design parameters of the DAC are given in Table 3.5.

Table 3.5. Preliminary design parameters of DAC

\begin{tabular}{rc}
\hline DAC design: & Horizontal finned tube \\
\hline Tube arrangement & Inline \\
DRACS loop side: & tube \\
\# of tubes: & 200 \\
\# of tube rows: & 4 \\
\# of tube passes: & 1 \\
Tube length $(\mathrm{m}):$ & 4.0 \\
Tube OD $(\mathrm{m}):$ & 0.0254 \\
Fin height $(\mathrm{m}):$ & $1.651 \mathrm{E}-3$ \\
Fin spacing $(\mathrm{m}):$ & 0.0254 \\
Transe wall thickness $(\mathrm{m}):$ & 0.015 \\
Longitudinal tube spacing $(\mathrm{m}):$ & 0.0802 \\
Tube material: & 0.0802 \\
\hline
\end{tabular}

\subsection{An analytical approach to optimizing the DRACS design}

In order to have a better understanding of the natural circulation flow in the DRACS and obtain insights about the design of the DRACS loop, it would be helpful to perform a simplified theoretical analysis of the DRACS natural circulation flow. A schematic drawing of the DRACS loop is shown in Fig. 3.8. 


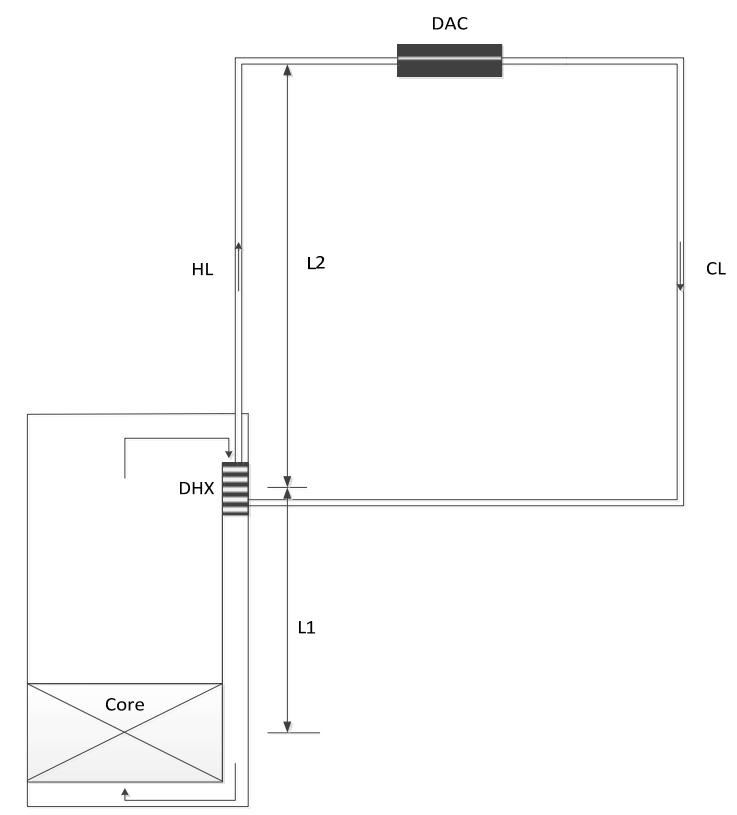

Fig. 3.8. Simplified schematic drawing of a DRACS loop.

For a given constant heat load, it is assumed the flow in the DRACS will eventually stabilize at a constant flow rate, that is, the loop pressure drop will be balanced by the buoyancy driving head, $\Delta P_{f}=\Delta P_{B}$. The total pressure drop along the DRACS loop is calculated in Eq (3.1), and the buoyancy head is calculated in Eq (3.2). Note that the pressure drop due to form loss is not considered since it is assumed negligible compared with friction losses.

$$
\begin{aligned}
& \Delta P_{f}=\left(f \frac{L}{D} \frac{\rho v^{2}}{2}\right)_{C L}+\left(f \frac{L}{D} \frac{\rho v^{2}}{2}\right)_{H L}+\left(f \frac{L}{D} \frac{\rho v^{2}}{2}\right)_{D H X}+\left(f \frac{L}{D} \frac{\rho v^{2}}{2}\right)_{D A C} \\
& =\left\{\left[a\left(\frac{D}{\mu A}\right)^{-n} \frac{L}{D} \frac{1}{2 A^{2}}\right]_{C L}+\left[a\left(\frac{D}{\mu A}\right)^{-n} \frac{L}{D} \frac{1}{2 A^{2}}\right]_{H L}+\left[a\left(\frac{D}{\mu A}\right)^{-n} \frac{L}{D} \frac{1}{2 A^{2}}\right]_{D H X}+\left[a\left(\frac{D}{\mu A}\right)^{-n} \frac{L}{D} \frac{1}{2 A^{2}}\right]_{D A C}\right\} \frac{(\dot{m})^{2-n}}{\bar{\rho}} \\
& =b \frac{(\dot{m})^{2-n}}{\bar{\rho}} . \\
& \Delta P_{B}=\beta \Delta T g L_{2}=\beta \frac{\dot{Q}}{\dot{m} \bar{c}_{P}} g L_{2} \\
& b=\left[a\left(\frac{D}{\mu A}\right)^{-n} \frac{L}{D} \frac{1}{2 A^{2}}\right]_{C L}+\left[a\left(\frac{D}{\mu A}\right)^{-n} \frac{L}{D} \frac{1}{2 A^{2}}\right]_{H L}+\left[a\left(\frac{D}{\mu A}\right)^{-n} \frac{L}{D} \frac{1}{2 A^{2}}\right]_{D H X}+\left[a\left(\frac{D}{\mu A}\right)^{-n} \frac{L}{D} \frac{1}{2 A^{2}}\right]_{D A C}
\end{aligned}
$$

From Eqs (1) and (2), the mass flow rate can be computed as

$\dot{m}=\left(\frac{\beta \rho g L_{2}}{b \bar{c}_{P}}\right)^{\frac{1}{3-n}} \dot{Q}^{\frac{1}{3-n}}=d \dot{Q}^{\frac{1}{3-n}}$

where

$d=\left(\frac{\beta \rho g L_{2}}{b \bar{c}_{P}}\right)^{\frac{1}{3-n}}=$ flow coefficient 
Eq (3.4) implies that the natural circulation flow rate in the DRACS loop is dependent on the overall flow coefficient $d$, which is also a function of loop friction factor $b$. Therefore, this equation can be used to optimize the DRACS design.

In order to obtain favorable high mass flow rate assuming fixed DHX and DAC designs, the overall friction factor $b$ should be reduced as much as possible. As shown in Eq (3.3), the overall friction factor $b$ consists of four friction loss contributors: cold leg, hot leg, DHX, and DAC. The friction losses through the DHX and DAC can be estimated based on their design parameters. The lengths of the cold and hot legs of the DRACS are estimated to be $35 \mathrm{~m}$. The diameter for the hot and cold legs is still not known. The cold leg and hot leg are assumed to have the same diameter.

The total flow coefficient as a function of the diameter of the hot and cold legs is shown in Fig. 3.9. It is seen that the total coefficient $\mathrm{d}$ becomes insensitive to the diameter of the hot and cold legs when it is larger than $0.35 \mathrm{~m}$, which means the friction loss in the hot and cold legs becomes small relative to the losses in the tubes of the DHX and DAC. In the TRACE model, the diameter of $0.4 \mathrm{~m}$ is used for both hot and cold legs of the DRACS.

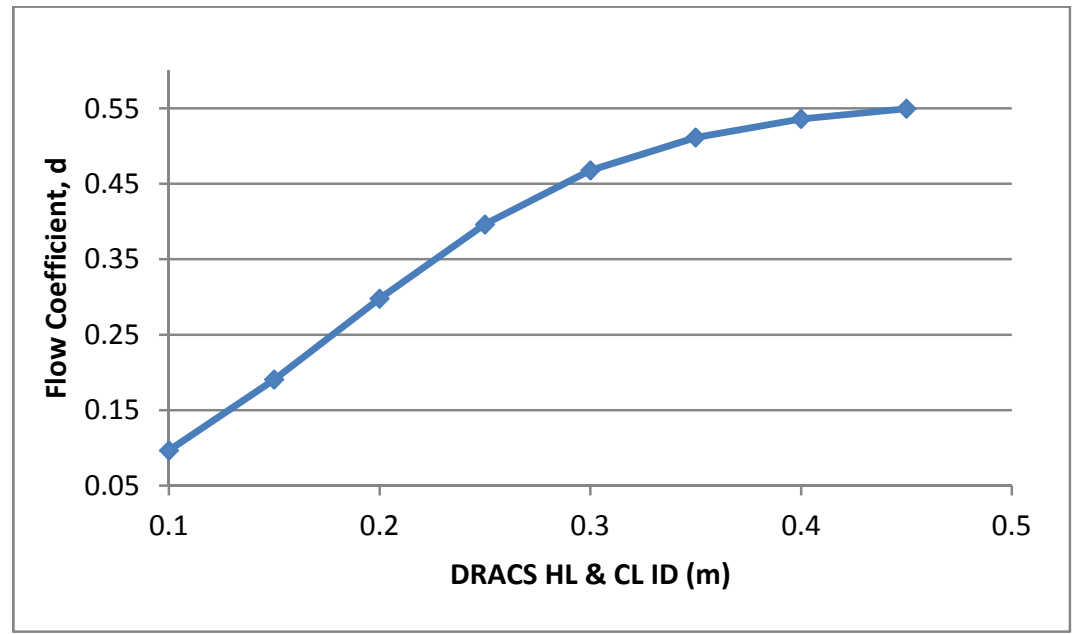

Fig. 3.9. Flow coefficient d vs. ID.

\subsection{TRACE model of DRACS}

The DHX consists of 1078 tubes configured in three tube passes. Each pass is modeled with two pipe components. Each pipe component models 179 or 180 tubes. The pressure drop and heat transfer coefficient of the DHX shell side are calculated by the control logic systems developed based on the empirical correlations for cross flow. The TRACE input values of the pipe and the downcomer region of the DHX are given in Table 3.6.

Table 3.6. TRACE input values of pipe and downcomer region of the DHX

\begin{tabular}{lc}
\hline \multicolumn{1}{c}{ Parameter } & Value \\
\hline DHX tube length (m): & 3.6 \\
DHX tube ID (m): & 0.022098 \\
DHX tube thickness (m): & 0.001651 \\
\# of tubes: & 1078 \\
\# of tube passes: & 3 \\
DHX region volume fraction: & 0.42172 \\
DHX region FA fraction: & 0.11262 \\
DHX region HD (m): & 0.02540 \\
\hline
\end{tabular}


The DAC employs one pass for the tubes, which are modeled with four pipe components. Each pipe models 50 tubes. The air cooling towers are modeled with TRACE vessel components. The height of each vessel component is $12.92 \mathrm{~m}$ with the radius of $3 \mathrm{~m}$. The vessel components have two radial rings and 18 axial levels. The inside ring has the radius of $2.5 \mathrm{~m}$, and the outside ring provides the downward flow path for the incoming cooling air. The DACs are located at the bottom of the air cooling towers (Level 36). The pressure drop and heat transfer coefficient of the DAC shell side are calculated by the control logic systems developed based on the empirical correlations for finned tube cross flow. A surface multiplier is applied to the shell side in accounting for the total area of the finned tubes. The TRACE input values of the pipe component and the vessel DAC region are given in Table 3.7.

Table 3.7. TRACE input values of pipe component and vessel DAC region

\begin{tabular}{lc}
\hline \multicolumn{1}{c}{ Parameter } & Value \\
\hline DAC tube length (m): & 4.0 \\
DAC tube ID (m): & 0.022098 \\
DAC tube thickness (m): & 0.001651 \\
\# of tubes: & 200 \\
\# of tube passes: & 1 \\
DAC region volume fraction: & 0.9147 \\
DAC region FA fraction: & 0.5371 \\
Shell side surface multiplier: & 7.854 \\
\hline
\end{tabular}

\subsubsection{Decay power and heat structures}

\subsection{Decay power}

A typical pressurized water reactor (PWR) decay power curve is used for the TRACE AHTR model since the actual decay curve for the AHTR core is not available at this writing (see Fig. 3.10).

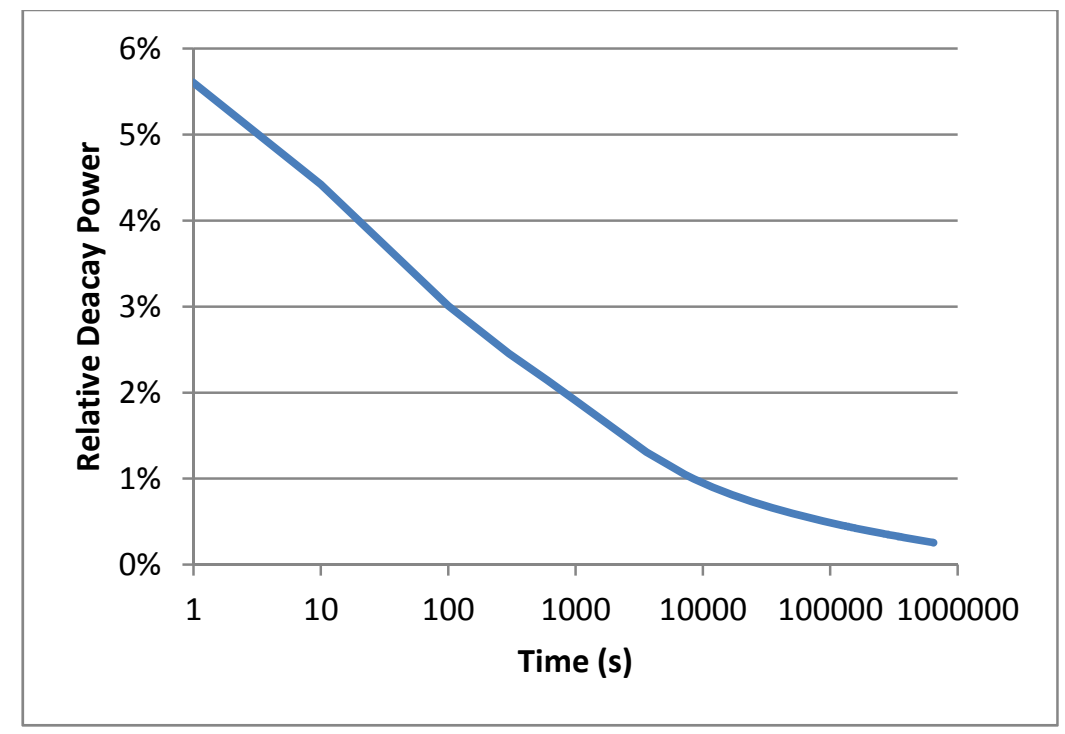

Fig. 3.10 Decay power curve. 


\subsection{Thermophysical properties of Hastelloy N, SiC-SiC, and graphite}

Hastelloy $\mathrm{N}$ is the material proposed for all of the HX tubes. Specific heat capacity and thermal conductivity as a function of temperature are shown in Table 3.8. Note that a constant density of 8,860 $\mathrm{kg} / \mathrm{m}^{3}$ for Hastelloy $\mathrm{N}$ is used in the TRACE model since its dependence on temperature is not available.

Table 3.8. TRACE input of thermal properties of Hastelloy $\mathrm{N}^{12}$

\begin{tabular}{ccc}
\hline Temp $(\mathbf{K})$ & $\mathbf{C}_{\mathbf{p}} \mathbf{( J / k g - K )}$ & $\mathbf{k}(\mathbf{W} / \mathbf{m}-\mathbf{K})$ \\
\hline 373.15 & 419 & 11.5 \\
473.15 & 440 & 13.1 \\
573.15 & 456 & 14.4 \\
673.15 & 469 & 16.5 \\
753.15 & 477 & 17.7 \\
813.15 & 485 & 18.92 \\
843.15 & 523 & 19.61 \\
863.15 & 565 & 20.07 \\
893.15 & 586 & 20.96 \\
933.15 & 582 & 22.28 \\
953.15 & 578 & 22.94 \\
973.15 & 578 & 23.6 \\
\hline
\end{tabular}

The upper and lower core support plates are made of SiC-SiC composite. Although these plates are actually honeycomb structures in the present design, they have been modeled as solid plates with holes in the TRACE model. The values for density, thermal conductivity, and specific heat capacity assumed in the TRACE model for SiC-SiC are summarized in Table 3.9.

Table 3.9. TRACE input of thermal properties of $\mathrm{SiC}_{-} \mathrm{SiC}^{13}$

\begin{tabular}{|c|c|c|c|}
\hline $\begin{array}{c}\text { Temp } \\
\text { (K) }\end{array}$ & $\begin{array}{c}\text { Density } \\
\left(\mathrm{kg} / \mathrm{m}^{\wedge} 3\right)\end{array}$ & $\begin{array}{c}\mathbf{K}^{14 *} \\
(\mathbf{W} / \mathbf{m}-\mathbf{K})\end{array}$ & $\begin{array}{c}\mathrm{C}_{\mathrm{p}}{ }^{15 *} \\
(\mathrm{~J} / \mathrm{kg}-\mathrm{K})\end{array}$ \\
\hline 300 & 3214.96 & 112.63 & 676.72 \\
\hline 400 & 3212.37 & 94.76 & 864.19 \\
\hline 500 & 3209.05 & 80.48 & 966.65 \\
\hline 600 & 3205.19 & 69.18 & 1034.70 \\
\hline 700 & 3200.93 & 60.33 & 1085.66 \\
\hline 800 & 3196.42 & 53.41 & 1126.77 \\
\hline 900 & 3191.74 & 48.01 & 1161.49 \\
\hline 1000 & 3186.98 & 43.76 & 1191.65 \\
\hline 1200 & 3177.41 & 37.50 & 1241.97 \\
\hline 1400 & 3167.81 & 32.84 & 1282.08 \\
\hline 1600 & 3158.21 & 28.97 & 1313.79 \\
\hline 1800 & 3148.61 & 26.01 & 1337.95 \\
\hline 2000 & 3139.01 & 24.97 & 1355.03 \\
\hline 2200 & 3129.42 & 24.97 & 1365.28 \\
\hline 2400 & 3119.82 & 24.97 & 1368.85 \\
\hline 2600 & 3110.22 & 24.97 & 1369.13 \\
\hline 2800 & 3100.62 & 24.97 & 1369.40 \\
\hline
\end{tabular}


The AHTR fuel is in the form of TRISO particles, with a UCO kernel enclosed in a layer of pyrolytic graphite, a silicon carbide cladding layer, and another layer of pyrolytic graphite. Pyrolytic graphite has higher thermal conductivity in the direction parallel to the layers than in the direction perpendicular to the layers ${ }^{16}$. The fuel plates themselves are a carbon-carbon matrix material; however, for the present analysis, the properties have been assumed to be those of graphite. In this model, a conservative thermal conductivity of $6 \mathrm{~W} / \mathrm{m}-\mathrm{K}$ is used for the carbon-carbon matrix material. The density is assumed constant at $2210 \mathrm{~kg} / \mathrm{m}^{3}$. Specific heat capacity as a function of temperature is summarized in Table 3.10 .

\section{Table 3.10. TRACE input of specific heat of Graphite ${ }^{14}$}

\begin{tabular}{cc}
\hline Temp $(\mathbf{K})$ & $\mathbf{C}_{\mathbf{p}}(\mathbf{J} / \mathbf{k g}-\mathbf{K})$ \\
\hline 300 & 709 \\
400 & 992 \\
500 & 1215.2 \\
600 & 1406 \\
645 & 1485.2 \\
800 & 1650 \\
1000 & 1793 \\
1200 & 1890 \\
1500 & 1974 \\
2000 & 2130 \\
2500 & 2190 \\
3000 & 2230 \\
\hline
\end{tabular}

\subsection{Heat structures for fuel plates}

A fuel assembly consists of 18 fuel plates. A cross sectional view of the fuel plate is shown in Fig. 2.2. TRISO fuel particles are dispersed in the carbon composite stripes, which are located very close to the fuel plate surface. In this model, the fuel meat is analyzed assuming SiC properties. As discussed in Chapter 2, this assumption has little effect on plate thermal performance. With this fuel design, the fuel operates at a relatively low temperature with a flat profile. Therefore, the fuel temperature is not very sensitive to fuel thermal conductivity, which is very favorable from a safety point of view since it will largely reduce initial stored energy.

In the TRACE model, the fuel plates are modeled with the slab component. The reactor core region consists of 2 radial rings, 8 azimuthal sectors, and 12 axial levels. There are in total 16 slab components in the TRACE model, 8 of which are used to represent the fuel assemblies in the inside ring, while the other 8 slab components model the assemblies in the outside ring. The fuel plates are divided into 12 axial nodes which are coupled to the hydraulic flow channels in the reactor vessel. The fuel stripe region is modeled with $\mathrm{SiC}$, and the central matrix is modeled with graphite. Each slab component has a surface multiplier to account for all of the fuel plates in that sector.

\subsection{Heat structures for DHX and DAC, and PHX tubes}

The tubes of the DHX, DAC, and PHX are modeled with the TRACE cylindrical heat structure component. The shell side heat transfer coefficient and friction factor are calculated by the control blocks, which are developed based on the empirical correlations for cross flow. Those control blocks are discussed in detail in the following control system portion of this report. 


\subsection{Heat structures for other vessel internal components}

In the AHTR TRACE model, other vessel internal components such as the core barrel, core reflector, and control guide tubes are also modeled with different heat structures.

\subsubsection{Control systems}

\subsection{Heat Transfer and Pressure Drop Correlations for DHX}

Each DHX consists of 1078 small tubes horizontally configured in 98 rows. Each DHX is located in one of the downcomer sectors. The tubes are configured in a staggered array. The heat transfer and pressure drop correlations on the shell side are summarized as follows. ${ }^{17}$

Heat transfer correlation for staggered tube bundle:

$\begin{array}{ll}N u=1.04 \operatorname{Re}^{0.4} \operatorname{Pr}^{0.36}\left(\frac{P r}{P r_{w}}\right)^{0.25} & 1 \leq R e<5 \times 10^{2} \\ N u=0.71 \operatorname{Re}^{0.5} \operatorname{Pr}^{0.36}\left(\frac{P r}{P r_{w}}\right)^{0.25} & 5 \times 10^{2} \leq R e<10^{3} \\ N u=0.35(a / b)^{0.2} \operatorname{Re}^{0.6} \operatorname{Pr}^{0.36}\left(\frac{P r}{P r_{w}}\right)^{0.25} & 10^{3} \leq \operatorname{Re}<2 \times 10^{5} \\ N u=0.031(a / b)^{0.2} \operatorname{Re}^{0.8} \operatorname{Pr}^{0.36}\left(\frac{P r}{P r_{w}}\right)^{0.25} & 2 \times 10^{5} \leq \operatorname{Re}<2 \times 10^{6}\end{array}$

Pressure drop correlation for staggered configuration:

$\Delta P=\xi N_{r}\left(\rho V_{n}^{2} / 2\right)$

Where,

$$
\begin{aligned}
& \xi=\xi_{i, l} f_{z n, l}+\left(\xi_{i, t} f_{z, t}+f_{n, t}\right)\left[1-\exp \left(-\frac{R e+200}{1000}\right)\right] \\
& \xi_{i, l}=\frac{f_{a, l}}{R e} \\
& f_{a, l}=\frac{280 \pi\left[\left(b^{0.5}-0.6\right)^{2}+0.75\right]}{(4 a b-\pi) c^{1.6}} \\
& f_{z n, l}=\left\{\begin{array}{cc}
\left(\frac{\mu_{w}}{\mu}\right)^{\frac{0.57\left(N_{r} / 10\right)^{0.25}}{\left[\left(\frac{4 a b}{\pi}-1\right) R e\right]^{0.25}}} & \text { for } N_{r}<10 \\
f_{z, l} & \text { for } N_{r} \geq 10
\end{array}\right. \\
& f_{z n, l}=f_{z, l} \\
& f_{z, l}=\left(\frac{\mu_{w}}{\mu}\right) \frac{0.57}{\left[\left(\frac{4 a b}{\pi}-1\right) R e\right]^{0.25}} \\
& \xi_{i, t}=\frac{f_{a, t, v}}{R e^{025}} \\
& f_{a, t, v}=2.5+\frac{1.2}{(a-0.85)^{1.06}}+0.4\left(\frac{b}{a}-1\right)^{3}-0.01\left(\frac{a}{b}-1\right)^{3} \\
& f_{z, t}=\left(\frac{\mu_{w}}{\mu}\right)^{0.14} \\
& f_{n, t}=\left\{\begin{array}{lr}
\xi_{0}\left(\frac{1}{N_{r}}-\frac{1}{10}\right) & \text { for } 5 \leq N_{r}<10 \\
0 & \text { for } N_{r} \geq 10
\end{array}\right. \\
& \xi_{0}=\left[\frac{2(c-1)}{a(a-1)}\right]^{2}
\end{aligned}
$$


The above correlations for the heat transfer coefficient (HTC) and pressure drop factor (K-loss) on the tube outside surface (shell side) are developed and implemented in the TRACE model using the control system components (signal variables, control blocks, tables). A SNAP schematic of the control systems for calculating HTC and K-loss factor is shown in Fig. 3.11.

\subsection{Heat transfer and pressure drop correlations for the DAC}

Each DAC consists of 200 small finned tubes horizontally configured in four rows at the bottom of each air cooling tower. The tubes are configured in an inline fashion. The heat transfer correlations and pressure drop correlations on the shell side are summarized as follows. ${ }^{18}$

\section{Heat transfer correlation for finned tube bundle:}

$N u=0.192\left(X_{t}^{*} / X_{l}^{*}\right)^{0.2}\left(S / d_{o}\right)^{0.18}\left(e_{f} / d_{o}\right)^{-0.14} \operatorname{Re}^{0.65} \operatorname{Pr}^{0.36}\left(\frac{P r}{P r_{w}}\right)^{0.25} \quad 100<R e \leq 2 \times 10^{4}$

$N u=0.0507\left(X_{t}^{*} / X_{l}^{*}\right)^{0.2}\left(S / d_{o}\right)^{0.18}\left(e_{f} / d_{o}\right)^{-0.14} \operatorname{Re}^{0.8} \operatorname{Pr}^{0.36}\left(\frac{P r}{P r_{w}}\right)^{0.25} \quad 2 \times 10^{4}<R e \leq 2 \times 10^{5}$

$1.1<X_{t}^{*}<4.0,1.03<X_{l}^{*}<2.5, \quad 0.006<\frac{s}{d_{o}}<0.36, \quad 0.07<\frac{e_{f}}{d_{o}}<0.715$

$N u=0.0081\left(X_{t}^{*} / X_{l}^{*}\right)^{0.2}\left(S / d_{o}\right)^{0.18}\left(e_{f} / d_{o}\right)^{-0.14} \operatorname{Re}^{0.95} \operatorname{Pr}^{0.4}\left(\frac{P r}{P r_{w}}\right)^{0.25} \quad 2 \times 10^{5}<R e \leq 2 \times 10^{6}$

$2.2<X_{t}^{*}<4.2, \quad 1.27<X_{l}^{*}<2.2, \quad 0.125<\frac{s}{d_{o}}<0.28, \quad 0.125<\frac{e_{f}}{d_{o}}<0.6$

\section{Pressure drop correlation for a finned tube bundle:}

$\Delta P=E u N_{r}\left(\rho V_{n}^{2} / 2\right)$

$E u=67.6 R e^{-0.7} X_{t}^{*-0.55} X_{l}^{*-0.5} F^{0.5}$

$$
100<R e \leq 1000
$$

$E u=3.2 R e^{-0.25} X_{t}^{*-0.55} X_{l}^{*-0.5} F^{0.5}$

$1000<R e \leq 10^{5}$

$E u=0.18 X_{t}^{*-0.55} X_{l}^{*-0.5} F^{0.5}$

$10^{5}<R e \leq 1.42 \times 10^{6}$

Where the fin factor, $\mathrm{F}$, is given by:

$F=\frac{1}{S}\left[\frac{2 e_{f}}{l}\left(1+\frac{e_{f}}{d_{o}}\right)+\frac{\delta_{f}}{l}\left(1+\frac{2 e_{f}}{d_{o}}\right)+1\right]$

$$
l=S-\delta_{f}
$$

Note that the definitions for the other parameters are the same as those for the bare tube bundle. The correlations given above for the HTC and K-loss on the tube's outside surface (shell side) are developed and implemented in the TRACE model using the control system components (signal variables, control blocks, tables). A SNAP schematic of the control systems for calculating HTC and K-loss factor is shown in Fig. 3.12. 


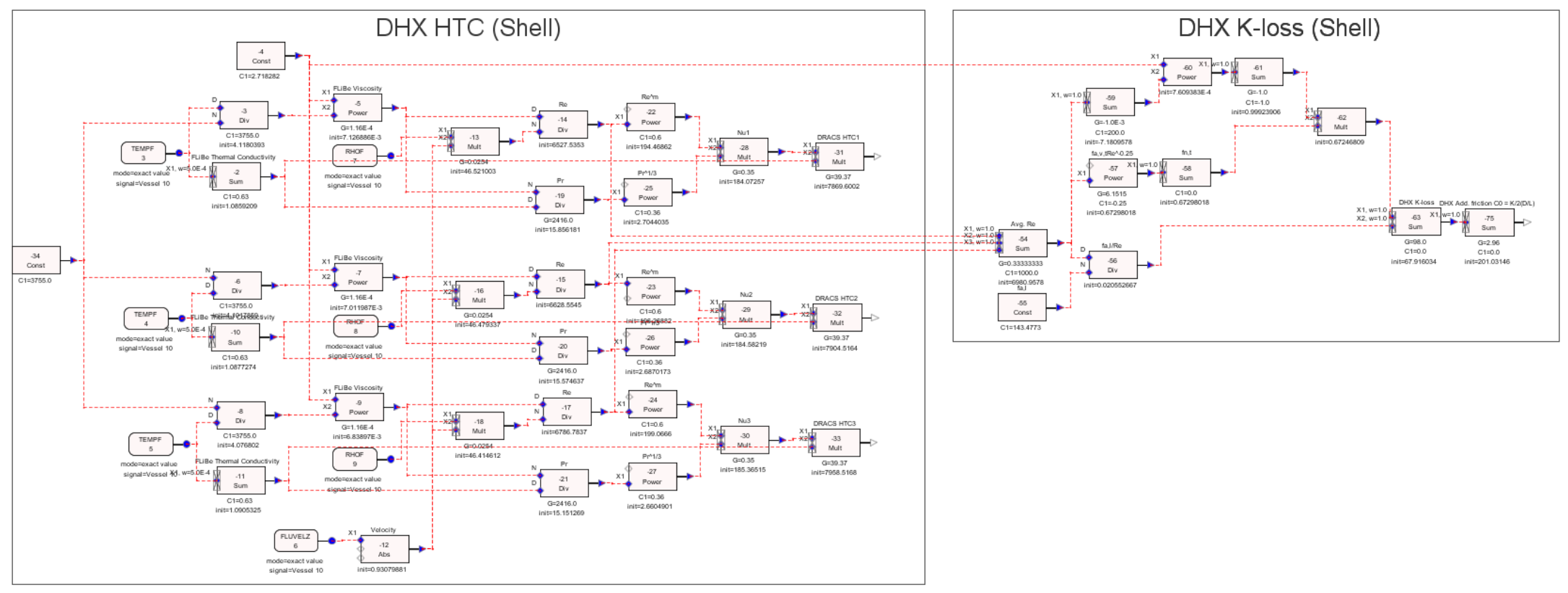

Fig. 3.11. Control systems for calculating HTC and K-loss of DHX. 


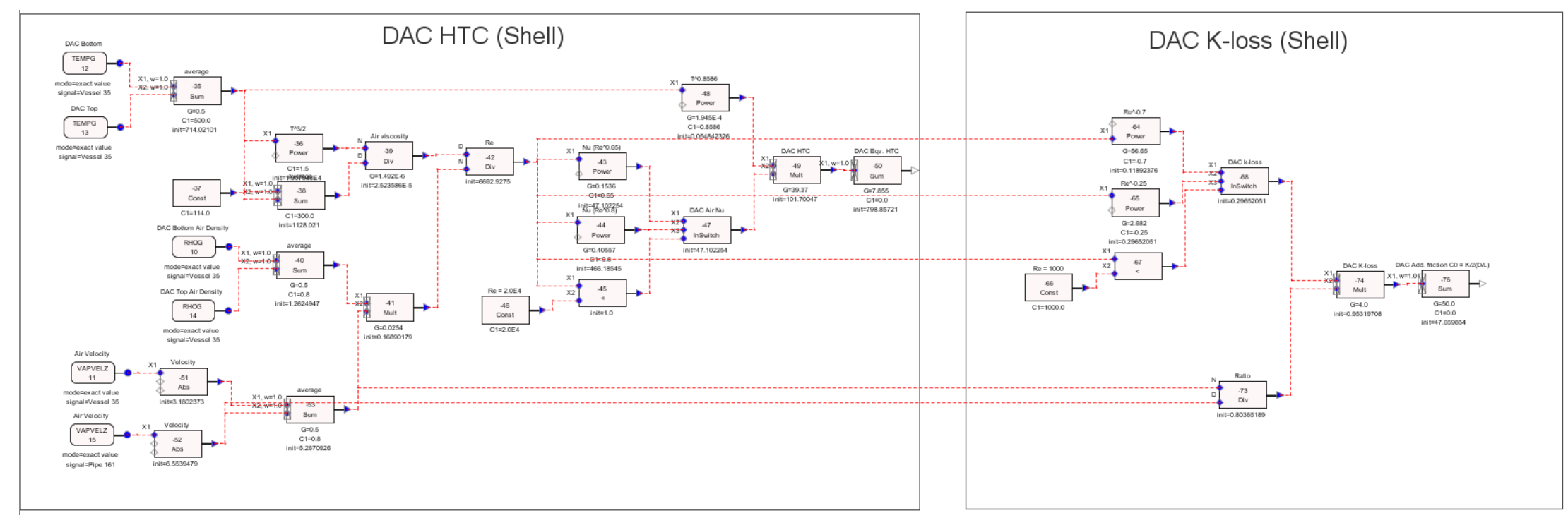

Fig. 3.12. Control systems for calculating HTC and K-loss for DAC. 


\subsubsection{Simulations}

Calculations of steady state and a LOFF transient were carried out with the TRACE AHTR model. The steady-state simulation was performed to obtain initial conditions for the transient simulation. In the LOFF transient, all the primary coolant pumps are assumed to fail at the beginning of transient without any pump coastdown.

\subsubsection{Steady-state}

Table 3.11 summarizes the calculated steady-state conditions of the AHTR. It shows that TRACE calculated core inlet and outlet temperatures are in very good agreement with the AHTR design values. Note that the shell-side flow of the DHX is only about 3.9\% of the total core flow rate. This indicates that the heat loss through the DRACS during normal operation is insignificant. Nevertheless, some amount of heat is needed to prevent freezing during normal operation.

Table 3.11. Steady-state initial conditions of AHTR

\begin{tabular}{lcc}
\hline Parameter & $\begin{array}{c}\text { AHTR design } \\
\text { values }\end{array}$ & TRACE \\
\hline Rated thermal power $(\mathrm{MWt})$ & 3,400 & 3,400 \\
Core flow $(\mathrm{kg} / \mathrm{s})$ & 28,500 & 28,500 \\
Relative DHX shell side flow ${ }^{\mathrm{a}}$ & $\mathrm{N} / \mathrm{A}$ & $3.9 \%$ \\
Core inlet temperature $\left({ }^{\circ} \mathrm{C}\right)$ & 650 & 651 \\
Core outlet temperature $\left({ }^{\circ} \mathrm{C}\right)$ & 700 & 701 \\
Core pressure drop $(\mathrm{Pa})$ & $\mathrm{N} / \mathrm{A}$ & $3.903 \mathrm{E}+5^{\mathrm{b}}$ \\
DRACS loop flow rate $\left(\mathrm{kg} / \mathrm{m}^{3}\right)$ & $\mathrm{N} / \mathrm{A}$ & 351 \\
DRACS lot leg temperature $\left({ }^{\circ} \mathrm{C}\right)$ & $\mathrm{N} / \mathrm{A}$ & 586 \\
\hline DRACS cold leg temperature $\left({ }^{\circ} \mathrm{C}\right)$ & $\mathrm{N} / \mathrm{A}$ & \\
\hline a. $\quad$ Relative to total core flow & & \\
b. Friction loss $(62,900$ Pa) + form loss through lower and upper core support plates $(6,300 \mathrm{~Pa})+$ gravity
\end{tabular}

\subsubsection{Loss of forced flow}

The LOFF transient was simulated to evaluate the DRACS design and its safety performance. In this transient, the DRACS is the only means available for decay heat removal. Figures 3.13 through 3.15 illustrate TRACE animation snapshots at three time points. Figure 3.16 plots the maximum fuel plate surface temperature.

Before the transient occurs $(\mathrm{t}=0 \mathrm{~s})$, the reactor system was running under normal operating conditions as shown in Fig 3.13. The core average coolant velocity was $1.93 \mathrm{~m} / \mathrm{s}$, and the calculated core Reynolds number Re was about 7400, so the core flow was in the turbulent regime. The DRACS coolant circulated at a speed of $1 \mathrm{~m} / \mathrm{s}$, with the mass flow rate at about $351 \mathrm{~kg} / \mathrm{s}$ in each loop.

When the transient occurs, the three primary coolant pumps are shut down at time $0 \mathrm{~s}$, resulting in an immediate reduction of core flow, and the reactor is shut down immediately, as well. Within a few seconds, the DHX shell side flow reverses from upwards to downwards, and natural circulation flow is established in the reactor vessel thereafter. The core starts to heat up.

At about 700s into the transient (Fig. 3.14), the coolant temperature reaches the maximum value $1040 \mathrm{~K}$ at the exit of the core (red curve in the figure). After that, the coolant begins to gradually cool down as the decay heat decreases. The hot FLiBe coolant moves upwards through the core under natural circulation and mixes with the relatively cooler coolant in the guide tube region. The peak temperature 
seen by the tubes of the DHXs is about $996 \mathrm{~K}$ (green curves). Fig. 3.15 shows that after 5 hours into the transient, the primary coolant temperature drops below $973 \mathrm{~K}$ (the nominal core outlet temperature). In a general, the system temperatures and core flow decrease as the decay heat continues decreasing.

The air temperature of the DAC exit during the transient is shown in Fig. 3.15. The peak temperature reaches $650 \mathrm{~K}$. The air inlet temperature is about $303 \mathrm{~K}$. Fig. 4.1 shows that the nominal DAC exit air temperature is about $624 \mathrm{~K}$. Such a significant temperature change of $>300 \mathrm{~K}$ through the DAC poses some concern about its thermal impact on the DAC structure. Therefore, further study on the DAC system design is needed.

The maximum fuel plate surface temperature is predicted as shown in Fig. 3.16, which shows that the peak temperature of the fuel surface is about $1050 \mathrm{~K}$, which occurs at $701 \mathrm{~s}$. It should be noted that the fuel temperature profile is very flat inside the fuel plate, and the center line temperature is close to the plate surface temperature because of its very unique fuel stripe design in which the fuel is placed near the plate surface. TRACE would tend to over predict the fuel plate surface temperature for this transient because the code does not have the HTC correlation for the narrow rectangular channel, which generally has higher HTC than the circular flow channel when the flow is laminar. 


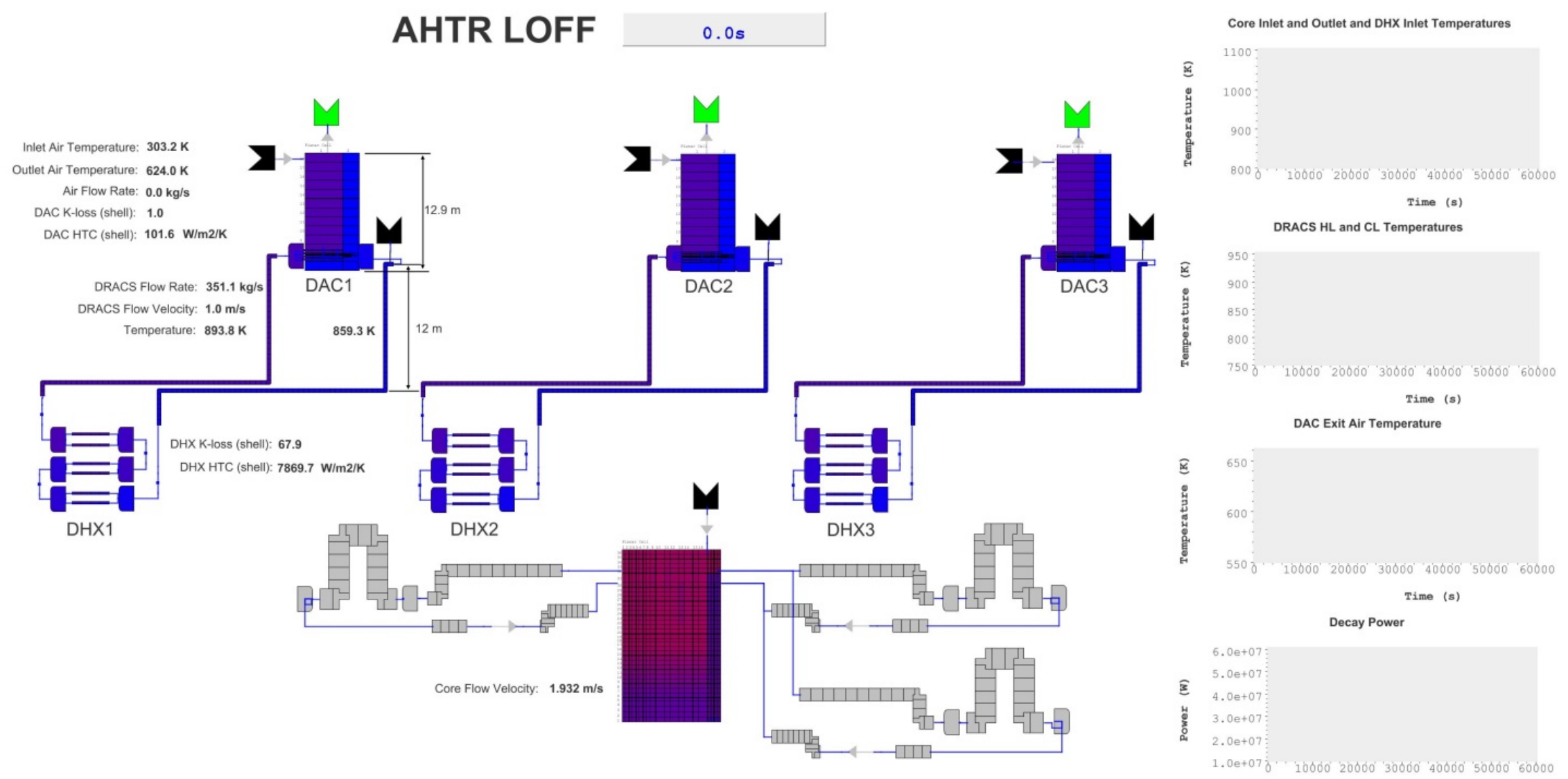

Time (s)

Fig. 3.13. TRACE animation of AHTR LOFF $(t=0 \mathrm{~s})$. 


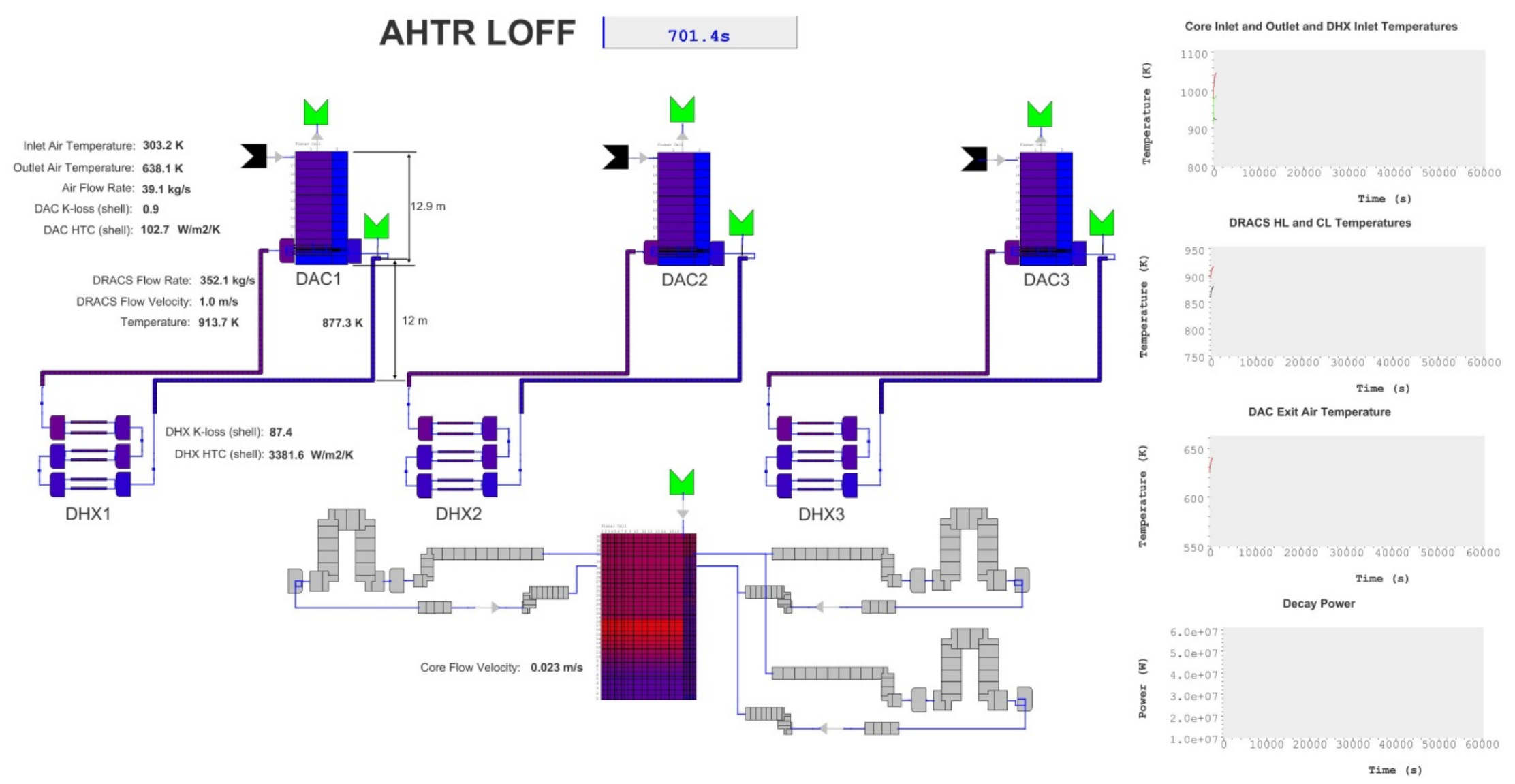

Fig. 3.14. TRACE animation of AHTR LOFF $(t=701.4 \mathrm{~s})$. 


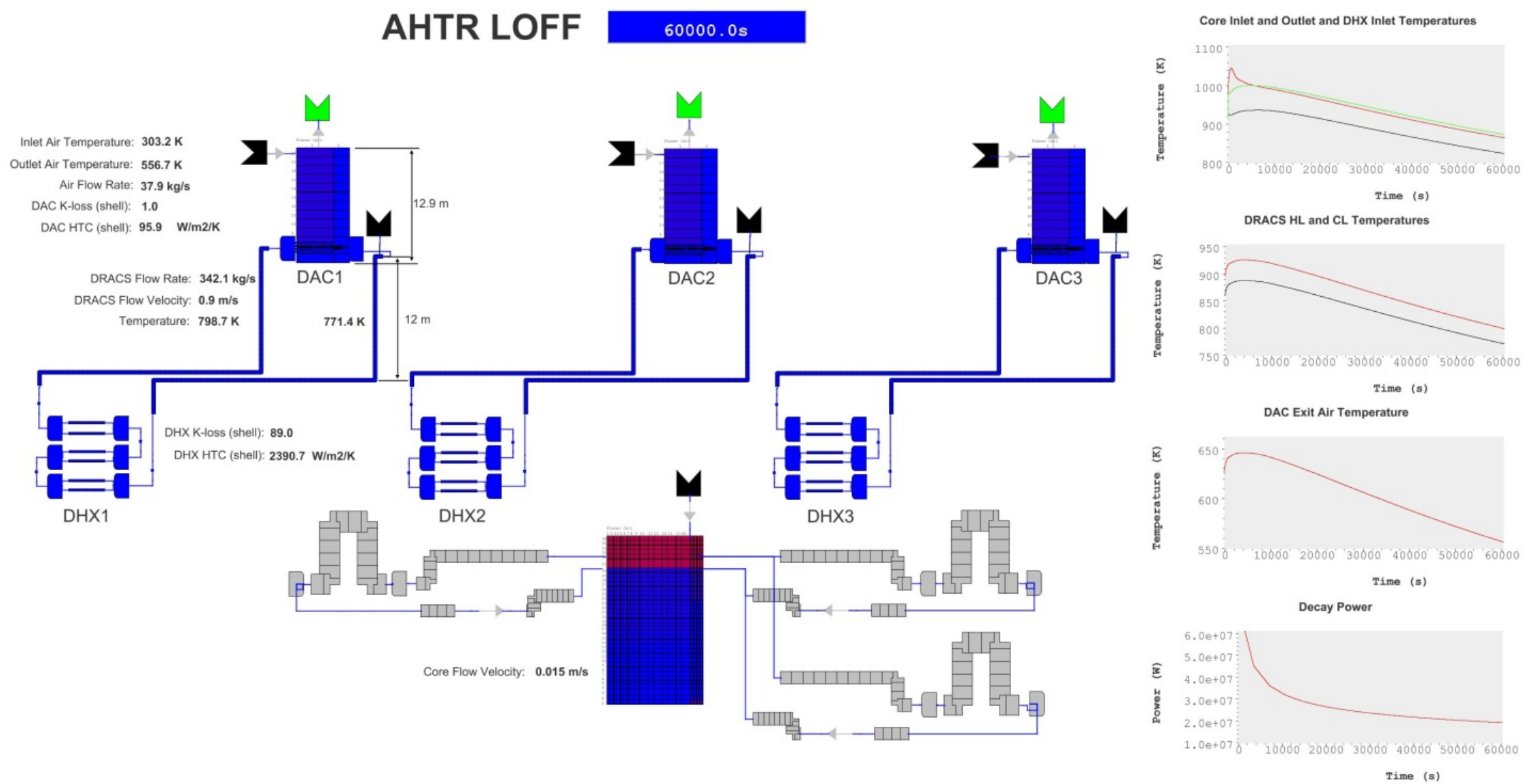

Fig. 3.15. TRACE animation of AHTR LOFF $(t=60,000 \mathrm{~s})$. 


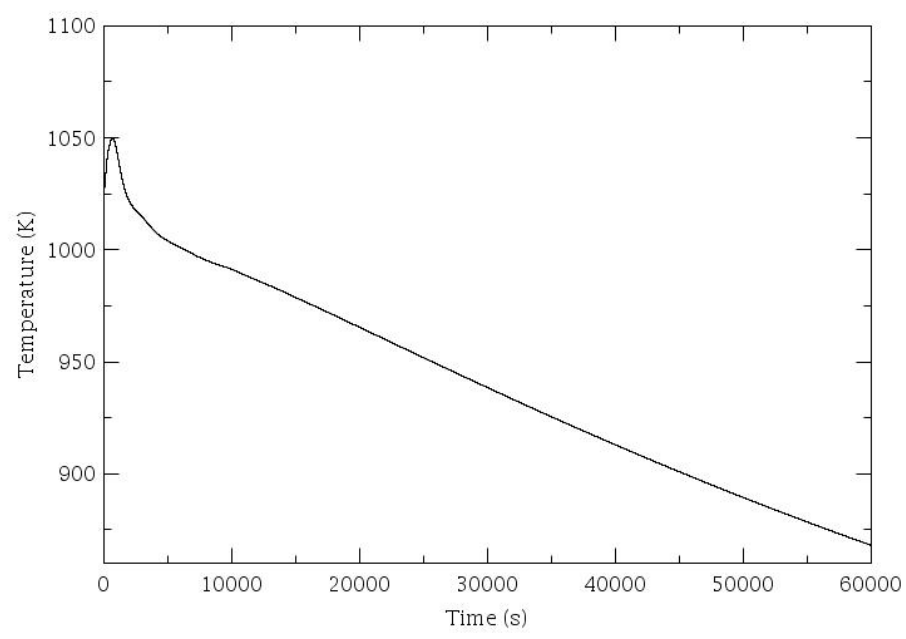

Fig. 3.16. Maximum fuel plate surface temperature.

\subsubsection{Summary of TRACE Model Development}

A TRACE ATHR system model has been developed to analyze the safety performance of the AHTR. The TRACE model is a detailed representation of the AHTR plant system, including the reactor core, reactor vessel, three primary loops, and three DRACS loops. The TRACE model consists of 124 hydraulic components, 206 control components (signal variables, control logic blocks, trips, and tables), 117 heat structures, and 1 power component. The intermediate loops, steam generators, and steam lines will be developed in the future.

The empirical correlations of heat transfer and pressure drop for the shell side of the DHX and DAC have been implemented in the TRACE model using TRACE control systems. The TRACE model has been employed to do an initial optimization of the DRACS design. A study on the PHX design has been performed and preliminary design characteristics are discussed.

A steady-state calculation was carried out and the calculated initial conditions are in very good agreement with the nominal design values. A loss of forced flow transient was simulated, and the results show that the DRACS can effectively remove all decay heat from the primary loop under this extreme accident scenario.

Based on the study, some concluding remarks are summarized as follows:

1. In the DHX preconceptual design, a fluidic diode is installed underneath the DHX to limit the coolant flow through the DHX tubes during normal operation. The calculation shows that the reverse flow rate is only about $3.9 \%$ of the total core flow rate, and at least for this design, a fluidic diode may not be necessary. Additional design trade studies will be needed to confirm this as a general conclusion.

2. The primary heat exchanger employs a simple tube-and-shell type design. The primary side of the heat exchanger is FLiBe, and the intermediate side of the heat exchanger is a less expensive salt. A preliminary analysis of the PHX design shows that FLiNak performs much better than $\mathrm{KF}^{-} \mathrm{ZrF}_{4}$ as an intermediate coolant in terms of the HX size and the pressure drop through the heat exchanger. The $\mathrm{FLiBe}-\mathrm{FLiNaK} \mathrm{HX}$ requires only $60 \%$ the number of tubes of the $\mathrm{FLiBe}-\mathrm{KF}-\mathrm{ZrF}_{4} \mathrm{HX}$, and the pumping power for the $\mathrm{FLiBe}-(\mathrm{FLiNaK} \mathrm{HX})$ is only about half that of the $\mathrm{FLiBe}-\mathrm{KF}_{-} \mathrm{ZrF}_{4} \mathrm{HX}$.

3. If the primary coolant system is not pressurized, the primary pumps should be installed on the hot legs instead of cold legs because of the significant pressure drop through the primary heat exchangers.

4. Although not discussed in this report, a sensitivity study was performed to investigate the effect of pump coastdown on core heatup during the LOFF transient. It was found that a short period of pump 
coastdown can effectively reduce the coolant peak temperature at the very beginning of the accident. Therefore, it is suggested that a fly-wheel be considered for the primary and intermediate pumps.

5. The correlations of heat transfer and pressure drop for the HX shell side cross flow should be further investigated. Perhaps experimentation is needed for a specific HX design.

6. The predicted HTC values for fluoride salts show large discrepancies when different correlations are used since the fluoride salts have relatively large Pr numbers ( 13). For example, the Dittus-Boelter correlation would significantly under predict HTC as compared with the Gnielinsky correlation. It is recommended that the Gnielinsky correlation be used for AHTR analysis.

7. In addition, the HTC correlation for the rectangular flow channel for both laminar and turbulent flow regimes should be implemented in the TRACE code in the future. 


\title{
4. FHR PRIMARY COOLANT CLEANING OVERVIEW
}

\author{
David Holcomb
}

This chapter provides an early-phase design overview of the primary coolant cleanup system for an FHR. The principal purpose for this chapter of the report is to provide guidance on the remaining research, development, and demonstration (RD\&D) activities necessary to design and construct FHR salt cleanup components and systems. A secondary purpose is to provide an integrated reference to the diverse salt cleaning technology developments over the past several decades. This chapter builds upon the "Fluoride Salt-Cooled High-Temperature Reactor Technology Development and Demonstration Roadmap" that was produced in 2013..$^{5}$

This chapter focuses on technologies for removing dissolved or entrained materials from the primary coolant. It includes:

- an overview of the cleanup system performance requirements,

- potential mechanisms for the salt to acquire contamination,

- an overview of technologies to remove contaminants from the primary coolant salt,

- technologies required to integrate the cleanup system into an FHR are described,

- a preconceptual salt cleaning system layout is then described, and

- remaining RD\&D tasks.

The salt cleanup system technologies are intended to be generally applicable to any FHR. The AHTR, as described in the 2012 mechanical, structural, and neutronic preconceptual design report ${ }^{1}$, is employed as a system evaluation template.

\subsection{PERFORMANCE REQUIREMENTS}

Detailed FHR coolant cleanup system performance requirements cannot yet be directly developed from plant characteristics due to the overall concept immaturity. However, general FHR primary coolant cleanup system performance requirements can be developed through comparison with those of more mature reactor classes. The chemistry and volume control system (CVCS) for PWRs has significant performance requirements that are similar to an FHR's primary coolant cleanup system, as both reactor classes employ single-phase, low-activation liquid cooling of low-leakage solid reactor fuels. Furthermore, the chemistry for removing contamination from FHR primary coolant salt is closely related to the fission product removal steps of molten salt reactor (MSR) fuel processing. Fission product removal for dissolved fuel MSRs was intended to be performed following uranium removal from the salt, thus increasing the similarity of the chemical environment. Consequently, the process thermodynamics that were determined during the MSR program are directly applicable to FHRs. However, MSR fuel processing involves small volumes of highly radioactive salt, whereas FHRs will process much larger amounts of mildly contaminated salt, necessitating distinctive processing technology implementation.

The requirements for cleaning the primary coolant salt derive from the potential impacts of and mechanisms for contaminating the salt. First, tritium can escape from the primary coolant into the cover gas, containment atmosphere, or intermediate coolant, thereby increasing the plant's radionuclide release potential. Second, some contaminants (e.g., tellurium) will increase the corrosiveness of the primary coolant, which could eventually challenge the integrity of the salt-wetted portions of the primary containment boundary. Third, higher levels of coolant radioactivity will increase the nearby dose level, potentially increasing maintenance worker dose and damaging nearby electronics and components. FHR fuel leakage, however, is less significant from an environmental release perspective than PWR or hightemperature gas-cooled reactor (HTGR) fuel leakage due to the low system pressure and the radionuclide retention characteristics of the fuel bodies and primary coolant salt. 
The size of the FHR primary coolant cleanup system cannot yet be optimized, as detailed fuel performance modeling, radioactive waste handling assessment, and concept-of-operations planning has not yet been performed. However, given the high degree of similarity between FHRs and PWRs in terms of their overall physical layout and required capability to accommodate fuel leakage, FHR preconceptual design and layout will rely upon the design choices made for PWRs. In large PWRs, 4-5 L/s (75 gpm) of primary coolant is continuously routed through the CVCS to maintain the purity of the coolant and minimize the amount of radioactive material in the coolant. The preconceptual design for the AHTR's primary salt cleanup system will have similar volumetric capabilities. Smaller FHRs will have proportionally smaller primary coolant cleanup systems.

\subsection{POTENTIAL CONTAMINATION MECHANISMS}

FHR primary coolant loops will interface with a number of different systems, and the fuel and in-core structures will need to be periodically replaced. Consequently, FHRs will have a number of potential routes to acquire contamination. Contamination vulnerabilities and available avoidance and mitigation mechanisms will vary with the plant status. For example, the metallic primary coolant boundary will have an oxide layer on its surface that will dissolve into the primary coolant upon initial salt heat-up. Redeveloping a surface oxide layer would require draining the salt as might occur for component maintenance or inspection. Sparging the primary coolant salt with a mixture of hydrogen fluoride (HF) and $\mathrm{H}_{2}$ is the intended method to remove dissolved oxygen as water vapor. However, will only be performed while the plant is not at power to avoid mixing the added hydrogen with the neutron capturegenerated tritium. Further, the sparging will be performed in a dedicated tank on extracted batches of the primary coolant, as introducing HF into the reactor coolant piping would produce substantial corrosion.

\subsubsection{Tritium}

Tritium production is an especially important safety issue because it is the only radionuclide with the potential for significant release under normal operating conditions without failed fuel. Further, FHRs will produce substantially more tritium than light water moderated reactors (albeit substantially less than heavy water moderated plants). At high temperatures, tritium readily permeates structural alloys, potentially enabling it to spread beyond the otherwise sealed primary coolant boundary.

Tritium is formed in FLiBe through neutron interactions with both lithium and beryllium. The tritium will either exist in the salt as tritium fluoride (TF), a dissolved ion $\left(\mathrm{T}^{+}\right)$, or as dissolved tritium gas (HT or $\mathrm{T}_{2}$ ). Shifting the redox potential of the fluoride salt to a more reducing condition shifts the chemical equilibrium away from tritium-fluoride. Metallic beryllium contact has been shown to effectively reduce $\mathrm{TF}$ to $\mathrm{T}^{+}$in FLiBe. ${ }^{19}$ Providing excess beryllium in the salt has been estimated to enable keeping the FLiBe TF concentration below 20 ppt. ${ }^{20}$ Tritium gas has a very low solubility in FLiBe. The equilibrium partial pressure of tritium gas over FLiBe with $1 \mathrm{ppm} \mathrm{T}_{2}$ is $10^{5} \mathrm{~Pa}^{21}$

Tritium is directly generated by neutron reactions in the primary coolant, and as such, tritium production and transport in FHRs will be nearly identical to that exhibited at the Molten Salt Reactor Experiment (MSRE) with the notable exception that the MSRE sprayed its fuel salt in the primary pump bowl to remove the xenon-135 neutron poison. The spraying also removed a significant fraction of the generated tritium. The generated tritium can be trapped by the carbonaceous materials in the primary loop, escape through the primary coolant surface into the cover gas, or permeate through the reactor vessel, piping and the heat exchanger tubing. The large surface area and thin tubing walls combined with the turbulent mixing within the heat exchanger makes tritium escape through the heat exchanger tubes, a significant tritium escape mechanism.

Tritium has been calculated ${ }^{22,23}$ and experimentally demonstrated at MSRE to significantly transfer from FLiBe under turbulent flow through heat exchanger tubes. At the MSRE 48\% of the tritium was discharged in the fuel off-gas system (i.e., it was removed through the droplet spray in the primary pump), 
$2 \%$ was discharged in the intermediate coolant loop off-gas system, 7\% discharged in the coolant radiator air, $9 \%$ appeared in the cell atmosphere, and 14\% was retained in the core graphite. Much of the remaining $20 \%$ was believed to be retained in the oil residues of the fuel salt off-gas system. ${ }^{24}$ Significant uncertainty remains in the amount of tritium rejected through the radiator air (due to the technical challenges of measuring the dilute tritium airstream) with more than an order of magnitude variance in measured amounts. ${ }^{25}$

\subsubsection{Fuel Leakage or External Contamination}

FHRs will unavoidably contain some imperfect fuel particles, and some fuel assemblies may have uranium contamination or larger-than-anticipated amounts of defective fuel that is only revealed in service. Some of the resultant radionuclides will leak into the primary coolant. The ability to remove circulating radionuclides from leaking or contaminated fuel enables FHRs to rely upon the precedents established for acceptable fuel leakage characteristics at PWRs. While properly manufactured TRISO fuel has a very low in-service failure potential, verifying that each fuel kernel deployed to the core has been properly manufactured greatly increases the cost of fuel manufacturing. Thus the primary coolant salt radionuclide cleanup capability directly reduces the TRISO particle fuel quality assurance requirements. This may substantially reduce the fuel fabrication and in-service inspection costs.

The fission product transport at MSRE provides the technical basis necessary to understand radionuclide migration at FHRs. Fuel and fission product transport was a complex issue at MSRE. Consequently, significant effort was devoted to understanding the radionuclide transport and deposition phenomena. ${ }^{26}$ A significant complicating factor for fission product transport at MSRs involves the multiple steps along the fission product decay chain. (Direct fission products have an excess of neutrons resulting in a series of beta decays.) The different elements along the decay chain each have different transport characteristics. Additionally, leaking radionuclides must pass through the carbon fuel bodies to enter the salt at FHRs. For some radionuclides, the carbon will have a significant filtering effect. As the fuel temperature at FHRs will be lower than at HTGRs, diffusion through the carbon materials will be slower, and more effective retention by graphite will be expected.

\subsubsection{Cover Gas Handling System Contamination}

The primary coolant cover gas will contain small amounts of moisture and oxygen contamination. The oxygen permeation rate into FLiBe from the cover gas is small. Consequently, the most significant impact of oxygen cover gas impurities could be enhanced corrosion of the reactor vessel at the salt-toliquid interface due to repeated oxide formation at the interface, which is subsequently and repeatedly fluxed off by the coolant. This might also cause corrosion products (principally $\mathrm{Ni}, \mathrm{Fe}, \mathrm{Cr}$ ) that would be free to circulate in the salt, potentially activating and depositing at undesirable locations. Exposing the surface of the primary coolant pool to moisture and/or oxygen will shift the redox condition of the coolant to a more oxidizing condition, thus increasing its corrosiveness.

\subsubsection{Vessel Gasket Leakage}

The reactor vessel lid will be sealed using gaskets. The containment atmosphere will likely be at slightly higher pressure than the vessel upper plenum. Improper sealing of the vessel lid would result in leakage of the containment atmosphere into the vessel upper plenum. The containment atmosphere will be of lower purity than the cover gas. Consequently, containment gas in-leakage is a potential route for cover gas contamination. 


\subsubsection{Initial Material Loading}

All of the metallic surfaces of the primary coolant boundary will initially have a thin oxide coating, and the structural and functional elements within the primary coolant will likely have some oxygen and/or moisture on their exposed surfaces. The oxygen and moisture will be removed from the surfaces by the primary coolant as it heats up, resulting in dissolved oxygen (and/or or $\mathrm{BeO}$ ) or moisture in the primary coolant. A small amount of circulating $\mathrm{BeO}$ is not especially deleterious and may be left to circulate with the primary coolant. The carbon materials may also have dust on their surfaces that becomes entrained in the primary coolant.

\subsubsection{Maintenance Access}

Each time the primary coolant boundary is breached to perform maintenance or inspection activities, it presents an opportunity to introduce moisture and/or oxygen into the primary coolant. Replacement components and/or structures also may have surface contamination such as oils or solvents that would dissolve into the primary coolant upon flooding with hot salt.

\subsubsection{PHX or DHX Tube Leakage}

At some point during the life of the plant, heat exchanger tubes will almost certainly leak. Both the DRACS and the intermediate coolant loops will be at somewhat higher pressure than the primary coolant loop, resulting in in-flow of the intermediate $\mathrm{KF}-\mathrm{ZrF}_{4}$ coolant. $\mathrm{KF}-\mathrm{ZrF}_{4}$ activates, is a neutron poison, and has a higher vapor pressure than FLiBe, resulting in increased vapor deposition onto upper plenum structures. Other fluoride salts could be used as alternative intermediate coolants. While the challenges for alternate salts will be somewhat different (notably avoiding the comparatively high $\mathrm{ZrF}_{4}$ volatility and tendency to recrystallize on cooler surfaces above the melt), $\mathrm{KF}-\mathrm{ZrF}_{4}$ is employed as a representative material.

\subsubsection{Fuel Moisture Contamination}

FHR fuel, reflector, and moderator structures are composed primarily of carbon. Carbon has a strong tendency to absorb and retain moisture and oxygen from air. As such, carbon structures arriving at the plant have high potential to be contaminated with moisture or oxygen. Moisture or oxygen that is released into the primary coolant will shift the salt's redox condition to a more oxidative state, resulting in increased corrosion. Water retained on carbon structures would chemically react locally upon being introduced into hot salt, forming carbon monoxide or carbon dioxide and hydrogen. Carbonate and carbides can subsequently be formed. The gases would be transported with the salt. The carbon monoxide and/or carbon dioxide will either escape from the surface of the pool or be reduced to an entrained carbon atom within the salt stream. Substantial amounts of water within carbon pieces would result in a phase change pressure build-up, mechanically damaging the structure.

\subsubsection{Primary Coolant Pump Shaft Seal Leakage}

FHRs will employ dry gas shaft seals. Some seal gas will leak into the primary coolant pump bowl. The pump may entrain the seal gas into the primary coolant flow. Large amounts of bubble entrainment could increase the core reactivity.

\subsubsection{Thermowell Breakage}

FHR primary loops will employ thermowells for temperature measurement. If a thermowell were to break (as in the Monju incident) the primary coolant would be contaminated with the thermal conduction paste (primarily boron nitride) and electrical insulation (magnesium oxide). Both the thermowell and 
thermocouple sheath (both nickel alloy pieces) would also then be free to circulate as loose parts in the primary coolant.

\subsubsection{Material (Bismuth) Carryover from the Primary Salt Cleanup System}

FHRs will employ a molten bismuth-lithium based reductive extraction salt cleanup system. If the system performs online cleanup rather than batch clean up, bismuth that carries over from the salt cleanup system would itself become a contaminant in the primary coolant loop. Bismuth is especially deleterious as it dissolves into nickel structural alloys, potentially significantly decreasing the performance of the primary coolant boundary.

\subsubsection{Dissolved or Entrained Corrosion Product Activation}

The alloy material components can become activated once dissolved into the coolant salt. Even if activated materials are subsequently reduced and deposited onto the container walls, they represent potential sources for worker exposure.

\subsubsection{Fluorine Transmutation}

Fluorine has a fast neutron cross section for transmutation into ${ }^{16} \mathrm{~N}$, which decays into stable oxygen. Fluorine also has a somewhat smaller cross section for fast neutron transmutation into ${ }^{19} \mathrm{O}$, which decays into stable neon. The oxygen will shift the salt's redox condition increasing its corrosivity.

\subsubsection{Reserve Shutdown System Activation}

If the reserve shutdown system uses a soluble poison, its activation will release large amounts of $\mathrm{EuF}_{2}$ or $\mathrm{GdF}_{3}$ into the primary coolant. Both europium and gadolinium are strongly salt-seeking elements and thus anticipated to remain in solution until removed by the salt cleanup system. Examinations of surveillance specimens exposed in the core of the MSRE showed only 0.1 to $0.2 \%$ of the salt-seeking isotopes without noble-gas precursors on salt-wetted structures. The bulk of the amount present stemmed from fission recoils and was generally consistent with the flux pattern ${ }^{26}$.

The lack of poison deposition on the salt-wetted structures within the core decreases the operational impact of inadvertent deployment of the reserve shutdown system. Cleaning up the primary coolant becomes a dilution issue that primarily impacts that design size of the coolant cleanup system rather than requiring replacing and/or cleaning the salt-wetted structures.

\subsection{FLUORIDE SALT CLEANING TECHNOLOGIES}

The MSR program planned to remove accumulating fission product neutron poisons from the reactor fuel salt. Consequently, the chemical processes necessary to strip fission products from fluoride salts are reasonably well known. However, the MSR program had a number of only partially resolved technical issues when it was closed down in the 1970s. Material science, chemical engineering, and control system technology have all advanced over the intervening decades. Furthermore, the requirements for an FHR salt cleanup system and those for an MSR fuel salt processing system are somewhat different both in terms of which elements are separated and the required salt processing volume. FHRs, like light-water reactors (LWRs), employ a low-activation liquid coolant and minimize the amount of circulating radioactivity. As the plant staff dose limits will be common to LWRs and FHRs, and as the heat capacity of FLiBe and water are similar, FHRs will have similar volumetric scale coolant cleanup systems. In contrast, a single fluid thermal spectrum MSR was intended to have a volumetric salt processing rate of only about $6 \%\left(0.2 \mathrm{~L} / \mathrm{s}[3 \mathrm{gpm}] \text { for } 2250 \mathrm{MW}_{\mathrm{t}}\right)^{27}$ of that planned for FHRs. The following discussion provides an overview of the technologies for a modern FHR salt cleanup system. 


\subsubsection{Tritium}

\subsubsection{Stripping}

The potential for tritium release was a key technical element given in the decision to close the US MSR program in the early 1970s. ${ }^{28}$ Over the years, several mechanisms have been proposed to strip tritium from the salt, all of which rely on diffusion of tritium to a surface. Previously proposed tritium stripping techniques include helium-hydrogen sparging, ${ }^{29}$ ultrasonic degassing ${ }^{30}$ spray-droplet based disengagement, ${ }^{31}$ and cathodic stripping. ${ }^{32}$ However, all of the previously proposed mechanisms are impractical for power plants, principally due to the slow diffusion of the tritium in the FLiBe under laminar conditions. Evaluations performed during the design of the Molten Salt Breeder Reactor (MSBR) indicated that an adequate sparging-based tritium stripping system "can be expected to increase significantly the cost and complexity of an MSBR." ${ }^{31}$ Similarly, "the spray disengager process to recover tritium from molten salt seems discouraging due to the large jet velocity, the number of nozzles, and the droplet size needed for mass transfer of tritium fluoride from salt." ${ }^{\text {, }}$

However, tritium can be stripped from flowing FLiBe using a membrane reactor into an inert sweep gas from which it can be readily extracted and captured. ${ }^{33}$ Both palladium and silver are a chemically compatible with FLiBe under the redox conditions useful for a reactor. ${ }^{34}$ Palladium has very high affinity for disassociating molecular tritium into the atomic state (enabling fast absorption and desorption), absorbs large amounts of tritium while maintaining its physical properties, has an acceptable coefficient of thermal expansion match with stainless steel, and has a high tritium diffusion rate. Palladium and palladium-silver alloy films are commercially used as gaseous hydrogen separation membranes.

Tritium, which impinges on a palladium or palladium alloy membrane, will rapidly absorb into and diffuse through the membrane. Turbulent FLiBe flow across a palladium-based surface ensures that all of the tritium within the flowing salt rapidly impinges upon the substrate. Interposing a thin (few microns) palladium-based material layer between turbulent FLiBe and an inert sweep gas thus enables tritium to be removed from the salt. However, thin membranes are not mechanically robust, and unsupported membranes would be rapidly destroyed by turbulent salt flow. Mechanical membrane support can be provided by affixing the membrane to a backing plate. Sintered metal porous structures (often 316 stainless steel) are commonly employed to provide membrane backing. The interconnected porosity of the support structure enables rapid tritium gas permeation. A thin, adherent palladium (or palladium alloy) coating layer can be deposited uniformly on steel surfaces via an electroless deposition process. ${ }^{35}$ However, intermetallic diffusion between the SS316 substrate and the Pd-Ag alloy at high temperatures is known to degrade permeation of hydrogen through palladium alloys. ${ }^{36}$ Also, the large pores and rough surface of porous stainless steel (PSS) make depositing thin, defect-free membranes difficult. Recently, Zhang et $\mathrm{al}^{37}$ demonstrated that interposing a thin, sol-gel-derived, mesoporous, yttria-stabilized zirconia (YSZ) layer between the PSS and the palladium membrane inhibits intermetallic diffusion, thereby preserving the membrane permeance at high temperatures and providing a suitably smooth substrate for subsequent electroless deposition of defect-free palladium alloy membranes. Fig. 4.1 shows the layer structure of the tritium stripping system, and Fig. 4.2 shows a tritium stripping system for a larger pipe in a tube and shell configuration. 


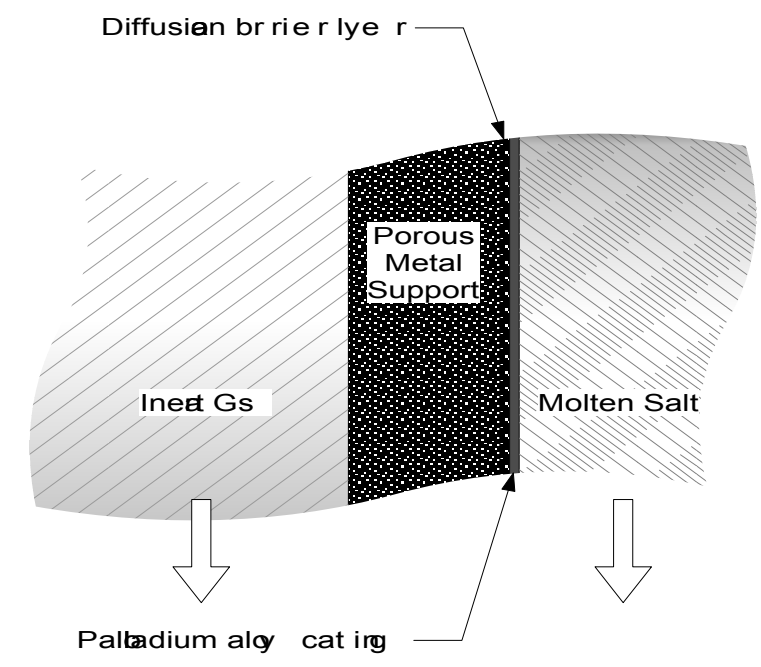

Fig. 4.1. Layer structure of tritium stripping system.

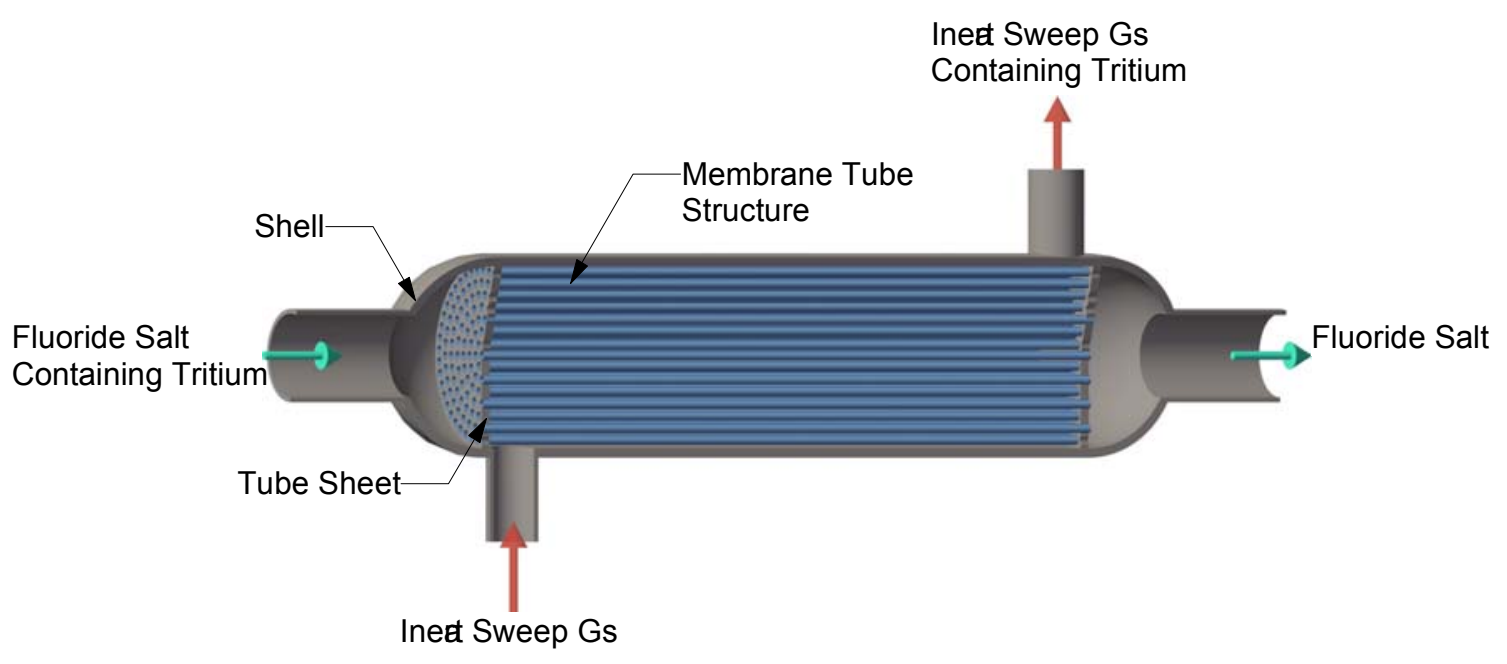

Fig. 4.2. Tube and shell tritium stripper.

In FHR designs where substantial carbon content (graphite and fuel pebbles) are removed from the primary coolant during operation, tritium capture on the pebbles (and subsequent flushing while out of the coolant) will provide an additional tritium stripping mechanism. Higher temperature reactor operation with consequent higher temperature carbon materials in the core will reduce carbon's tritium retention properties. FHR fuel, however, may have a higher amount of surface-connected porosity due to the lower heat treatment temperature feasible in TRISO-fueled structures, increasing the tritium retention.

\subsubsection{Capture}

A sodium fluoroborate eutectic was planned as the intermediate coolant salt for the MSBR to trap the tritium as a borohydrate. ${ }^{38}$ This recommendation was based on experiments conducted in an engineeringscale facility that demonstrated the chemical trapping capability of the sodium fluoroborate salt. Boron trifluoride $\left(\mathrm{BF}_{3}\right)$-based tritium trapping is not intended in current FHR design concepts due to several deleterious properties such as high toxicity and a tendency to hydrolyze to form hydrogen fluoride and 
hydroxyfluoroborate upon contact with moist air (or in the lung). Any leakage of moisture into the coolant system would rapidly generate highly corrosive $\mathrm{HF}$ and hydroxyfluoroborate. $\mathrm{BF}_{3}$ has a relatively high vapor pressure, and even operations such as bubbling an inert gas through the salt can cause plugging problems due to the local depletion of $\mathrm{BF}_{3}$ from the salt and the resultant local increase in the melting point. ${ }^{39}$

Chemically trapping the tritium into a hydride, however, remains a useful element of FHR tritium release prevention. Trapping the tritium within the nuclear island is preferable, as this configuration preserves the separation of the nonnuclear power cycle from radionuclides. An optimal configuration for tritium containment has not yet been determined. However, over the past few decades, double-walled heat exchangers, which are expressly designed to prevent contact between the primary and secondary fluids, have become more common. Providing a chemical trap (i.e., a getter) within the central section of a double-walled heat exchanger appears to be an effective tritium containment mechanism. Several rare earth elements (notably yttrium) form high-temperature stable hydrides upon contacting tritium. Several alternate yttrium gettering configurations are possible within the central section of a double-walled heat exchanger.

\subsubsection{Particles}

Contamination particles within the primary coolant (especially carbon dust) may float to the surface of the pool, eventually forming an opaque scum layer. A coolant overflow line will be incorporated in the reactor vessel to skim off surface materials. Particles can also be entrained into the salt flow. In particular, oxygen present in the salt will tend to become $\mathrm{BeO}$, which has low solubility in FLiBe. ${ }^{40}$ Converting surface structural oxides into fluorides will result in initially high surface corrosion, dissolved structural elements, and circulating $\mathrm{BeO}$ (some of which is dissolved). Solid oxide particles that are not themselves highly deleterious can lead to the accumulation of scale and decrease in heat transfer performance. HF and $\mathrm{H}_{2}$ sparging will be performed by the salt cleanup system in batches in a dedicated tank to avoid corroding the primary piping. $\mathrm{HF}$ and $\mathrm{H}_{2}$ sparging will be performed prior to initial criticality to remove the oxygen. The circulating structural alloy corrosion products (either as fluorides or dissolved ions) will be removed by the primary salt cleanup system (chapter 4.5 ).

\subsubsection{Noble Gases}

Failed or contaminated fuel will result in noble fission gases that are dissolved or entrained as small bubbles in the primary coolant. Most of the gases will eventually emerge into the gas plenum above the salt pool. Under normal operations, the upper plenum is cooled with an inert sweep gas. The cooling gas will be chilled using a cryogenic system with the heat rejected to external air. FHRs will likely employ a significant cryogenic cooling system to avoid the use of substantial component cooling water inside of containment. Employing cryogenic (chilled argon) coolant that is normally in vapor phase and requires operation of an active system to liquefy reduces the potential to inadvertently pressurize containment under accident conditions. The cryogenic system will incorporate cold traps for the fission gases as well as carbon filters for any suspended particulates. Passive, normally closed valves will be located at the entrance and exit from the reactor vessel to preserve the integrity of containment under accident conditions. The exit gas flow will impinge on flow baffles to condense salt vapor within the gas stream. This will allowing it to flow back into the pool and will minimize the potential for plugging the flow lines.

Noble gases are precursors of both salt-seeking and noble metal elements. The high mobility of noble gas fission products will thus result in widely distributed contamination by daughter products.

Examination of the concentration profiles of nuclides within MSRE graphite indicated that nuclides with noble-gas precursors were deposited within the graphite by decay of the noble gases that had diffused into the porous graphite structures. Indications were also noted of further diffusion of the relatively volatile cesium isotopes. ${ }^{26}$ 


\subsubsection{Noble and Seminoble Metals}

Some fission products are metals that do not form stable fluorides and are not wetted by the primary coolant under the conditions present at FHRs. These elements are referred to as noble and seminoble metals. Details of noble metal fission product migration at MSRE were evaluated in a focused report. ${ }^{41}$ Multiple containment layers and source term reduction mechanisms prevent significant quantities of noble metal fission products from entering the environment. The combined effect of the barriers and source term reduction mechanisms is such that the safety impact of any misinterpretation of the relatively complex and not yet fully understood noble metal migration in molten salt systems is small. The dominant potential pathway for noble metal radionuclide to bypass the primary coolant containment boundary would be through the cover gas cleanup system. The concentration of noble metal fission products in the form of a gaseous particulate suspension in the cover gas would be higher than the negligible amount indicated by their thermal vapor pressure due to the lack of wetting by the salt and consequent lack of surface tension inhibition to evaporation. ${ }^{42,43}$ Noble metal particles suspended in the cover gas cooling system piping can be readily precipitated from the stream using an electrostatic precipitator.

The MSRE salt was not processed online apart from spraying through helium in the pump bowl and periodically contacting the salt with metallic beryllium to compensate for the oxidizing fission process. Prior to the fuel salt becoming excessively oxidizing, at the beginning of MSRE's operation with ${ }^{233} \mathrm{U}$, over $90 \%$ of the noble metal fission products deposited on metal surfaces in the primary loop. Only $1 \%$ was found deposited on graphite structures in the core. ${ }^{41}$ The MSR program predicted a clearance time of 2.4 hours for noble metal fission products due to attachment to metal surfaces. ${ }^{44}$ Some noble metal fission products adhered tightly to the metal surfaces and could not be removed with flush salt ${ }^{41}$, while others resuspended as finely divided metal particles ${ }^{26}$ for reasons that are not well understood.

Leaking noble metal fission products at FHRs will (1) be removed through contacting the salt with Bi-Li alloy (see following text), (2) be trapped on filters in the cover gas sweep system, (3) be trapped on mechanical filters in the overflow skimmer system, or (4) be deposited onto the metal surfaces within the loop. The noble metals are generally soluble in bismuth and largely insoluble in fluoride salt. Thus, they would transfer efficiently to the metal phase. Once dissolved in the liquid bismuth, the noble metals can be transferred to lithium chloride salt (see following text) and from there electroplated into a concentrated form for disposal. This is similar to planned pyroprocessing of metallic reactor fuel.

\subsubsection{Salt-Seeking Elements}

Uranium, the alkali metals, alkaline earths, and rare earth elements are all form stable fluorides. As such, salt-seeking elements from leaking fuel would contaminate the primary coolant but would not contribute significantly to potential releases into the environment. The MSBR program intended to remove the salt-seeking elements by reductive extraction into a liquid bismuth-lithium alloy. Conceptually, reductive extraction into bismuth-lithium relies upon the combination of the high solubility of nearly all of the dissolved and entrained contaminants in bismuth, the strong tendency of lithium to form lithium fluoride, and the near complete insolubility of beryllium in bismuth.

Reduced-scale demonstrations of the reductive extraction process were performed during the $1970 \mathrm{~s} .{ }^{45}$ Mass transfer coefficients for the process were also measured for the MSBR program. ${ }^{44}$ Process thermodynamics were studied experimentally and theoretically. ${ }^{47,48}$ The kinetics of reductive extraction from fluoride salts continued to be studied in Japan until the $1990 \mathrm{~s} .{ }^{49}$ Nearly all of the uranium in the fuel salt of dissolved fuel MSRs was planned to be removed prior to bismuth-lithium reductive extraction through fluorination. Residual uranium would also have been removed in the reductive extraction process.

Over time, the liquid bismuth will contain progressively more contamination. In order to minimize the volume of radioactive waste generated, the radionuclides will be transferred from the bismuth to lithium chloride, where they can be concentrated for disposal. Lithium chloride has a high solubility for nearly all of the fission products and the structural material corrosion products. Lithium chloride salt has 
advantageous characteristics to serve as a carrier salt for nuclear fuel pyroprocessing. Therefore, the technologies for pyroprocessing can be applied once the radionuclides are transferred into the lithium chloride. Both electrodeposition and float zone refining are candidate technologies to concentrate radionuclides dissolved in lithium chloride.

\subsubsection{Iodine}

Iodine is a halogen fission product element that may be introduced into the primary coolant as a result of leaking fuel. Iodine will exist in the primary coolant almost entirely as a low concentration of dissolved I ions. The MSBR program sought to remove iodine- 135 from the fuel salt as a precursor to the neutron poison xenon-135. ${ }^{50}$ All of the proposed MSBR stripping methods included shifting the salt's redox condition to a more oxidizing state by sparing with hydrogen fluoride. However, all of the calculations and experimental work showed that removing iodine would require substantial effort (large HF flow rates through large mixing systems), providing confidence that significant quantities of iodine will not be released during accidents.

Adding an additional source of hydrogen to the salt would dilute dissolved tritium, making it more difficult to isolate. The current design intent is to allow the short-lived iodine radionuclides to decay in the primary coolant loop and to eventually remove any long-lived iodine-129 via HF sparging either during a longer-duration maintenance outage or at the end of plant life. Both iodine-131 and iodine-129 are beta emitters, and while they are in the primary coolant salt, they would not contribute significantly to worker dose.

\subsubsection{Intermediate or DRACS Coolant}

Over time, the primary-to-intermediate heat exchanger will likely develop small leaks due to the thin tubing walls, long time, and large flow rates. As the intermediate loop is at a slightly higher pressure than the primary loop, the leaks will be inward, contaminating the primary coolant. Both $\mathrm{KF}$ and $\mathrm{ZrF}_{4}$ activate and have higher neutron absorption cross sections than the elements in the primary coolant. Both potassium and zirconium will remain as dissolved fluorides in the primary coolant. Zirconium removal from fluoride salts via reductive extraction into bismuth-lithium was studied for the MSBR. ${ }^{51}$ Similarly, potassium extraction properties were measured as part of the effort to determine the extractabilities of the alkali metals. ${ }^{52}$ The relative extractabilities of the alkali metals from fluoride salt into bismuth lithium alloy were measured to be $\mathrm{Cs}: \mathrm{Na}: \mathrm{Rb}: \mathrm{K}:: 1: 0.80: 0.57: 0.53 .^{53}$

\subsubsection{Corrosion Products}

Alloy N corrosion products (principally nickel, iron, and chromium) will all exist as dissolved fluorides in the primary coolant salt. They also are all soluble in liquid bismuth and will also be removed from the primary coolant salt via liquid-liquid contacting. Operating the cleanup system prior to reactor startup will be particularly useful to minimize the dissolved corrosion product concentration prior to activating the materials as they flow through the core. It is important to (1) maintain a slightly reducing chemical environment to minimize overall corrosion and (2) maintain corrosion product concentration below solubility limits at the lowest temperature in the system to avoid depositing activated corrosion products in the primary loop piping.

\subsubsection{Bismuth Carryover}

FHRs would not use identical separation components as were proposed for the MSBR due to the volumetric differences between separation systems and the much smaller concentration of contaminants in FHRs. A principal issue for a bismuth-salt liquid-liquid contacting system is the potential to carry over small bismuth droplets that have been entrained in the salt phase. Bismuth has high solubility for nickel 
and is therefore not compatible with nickel-based alloys. Consequently, the MSR program planned on using nondispersing contactors for the liquid-liquid extraction process. However, nondispersing contactors do not allow for a close mixing of the two phases, so they require larger components and more time to achieve the same separation efficiency as centrifugal contactors. With the larger salt flow in an FHR, high flow rate annular centrifugal contactors would be preferable, followed by a liquid-liquid separator drum to minimize bismuth carryover. A nickel-based filter may also be incorporated into the exit of the separator drum to provide additional assurance that only insignificant amounts of bismuth will be returned to the primary coolant loop.

Electrochemically driving the reductive extraction of contaminants from the primary coolant into liquid bismuth-lithium alloy is an alternate method to increase the extraction rate that avoids the bismuth mixing issue of mechanical contacting. In this case, the liquid bismuth would act as an anode, with a portion of the dissolved lithium exchanging with dissolved impurities. Lithium has the highest electrochemical reduction potential of any element. While electrochemical processes can have high efficiency, systems that operate with substantial material flow rates have not yet been developed.

\subsection{SALT CLEANUP SYSTEM INTEGRATION}

Salt cleanup will be performed on a side stream of the primary coolant. The current design intent is for a $\sim 0.03 \%$ bypass. Figure 4.3 shows a general component layout of the cleanup system. The primary salt cleanup system will extract its flow downstream of the primary coolant pump, with the cleaned salt being returned downstream from the primary-to-intermediate heat exchanger. A throttle valve will regulate salt flow through the cleanup system. Throttle valves were developed for the MSBR program ${ }^{54}$. The primary salt to bismuth-lithium centrifugal contactor will be located within the beryllium and tritium containment layer. The bismuth-lithium to lithium-chloride contactor will also be located within the beryllium and tritium containment layer. Contaminated lithium chloride will be pumped to the waste handling section of the flood containment to concentrate the contaminants for disposal. Two batches of lithium chloride are planned. The batches will be exchanged (requiring opening of valves between the tritium and beryllium containment and the flood containment) as the lithium chloride becomes loaded with contaminants.

Structural and functional materials for the reductive extraction components were investigated for the MSR program. Graphite, molybdenum, Ta-10\%W, and T-111 exhibited little corrosion with either salt or bismuth ${ }^{54}$ Carbon-carbon continuous fiber ceramic composites would be a candidate for interior components today, with refractory alloys serving as the container materials. Tantalum and ferrous alloys have also been shown to have acceptable compatibility with chloride salts under reducing conditions. ${ }^{55}$ The technology for fabricating refractory alloy structures has advanced substantially since the 1970s. A trade study is recommended to determine an initial fabrication method for the hydraulic components.

The salt cleanup system is essentially a liquid transfer system. The basic hydraulic components to couple to the primary salt loop are flanges, piping, pumps, and valves, in addition to the components of the cleanup system itself.

\subsubsection{Flanges}

Flanged junctions between the different material systems are desirable to facilitate inspection and replacement. Both freeze type and mechanical flanges are potential alternatives. Mechanical flanges would be preferable to avoid the potential to generate large stresses in the flange joints due to salt expansion during melting. Developing acceptable gasket materials is a key issue to enable mechanical flange joints. Gold-plated soft metal gaskets using an indented mechanical seal were successfully employed at the MSRE. ${ }^{56,57}$ Sealing technology has advanced over the past few decades, and more modern gaskets may be preferable due to their improved characteristics. Metallic hollow O-rings (inert gas-filled thin-walled tubing hoops) with a chemically compatible coating and spiral-wound nickel 
reinforced graphoil gaskets are currently the leading candidate sealing structures. However, further testing is recommended prior to selecting a specific design.

\subsubsection{Piping}

Refractory metal piping is commercially available.

\subsubsection{Pumps}

The bismuth-lithium alloy will be pumped using a cantilever style mechanical pump with a rotating gas seal and bearings located above of the bismuth. Mechanical transfer pumps from salt- and bismuth-compatible refractory materials are not currently available commercially. However, manufacturing processes for the necessary refractory alloy pump structures (impeller, shaft, and volute) are reasonably well known.

\subsubsection{Valves}

Only freeze-type shutoff valves have been demonstrated for use in fluoride salts. Mechanical valves are preferable due to their lower complexity and improved response time. The contact sections of the mechanical shutoff valves developed under the MSR program experienced galling and sticking in fluoride salts due to the removal of the oxide layer on the valve surfaces. Oxide layers prevent the bare metal surfaces from adhering to each other. Because valves could be exposed to either salt or bismuth, refractory alloy or carbide-coated valve components are leading candidate materials for shut-off valves. Valves that would only be exposed to salt would more likely be fabricated from nickel-based alloy. Mechanically compliant valve seats would be necessary to produce a seal. Hollow-tube O-rings coated with precious metal are a candidate sealing structure. While high-temperature sealing technology has advanced markedly over the past few decades, specific designs for fluoride salt mechanical valves have not yet been demonstrated.

\subsection{SYSTEM LAYOUT}

While the distribution coefficients for selective extraction of contaminants from FLiBe into Bi-Li alloy are reasonably well known, the process kinetics have not been as thoroughly investigated. The MSBR program intended to employ mechanically agitated, nondispersing, two-phase contactors to minimize the bismuth carryover. However, the mass transfer coefficients measured using these systems were much lower than would be required for reasonably sized systems (Ref 45, p. 51). Results from Moriyama et $\mathrm{al}^{49}$ indicate that the rate-limiting process step for the transfer of elements between the salt and metal phases is the formation of limited solubility solid bismuthides at the salt-to-metal interface.

Increased intermixing of the phases (perhaps accompanied by sieving of the solid bismuthides) would be required to substantially increase the mass transfer coefficients. Overall, the kinetics of the extraction processes are not sufficiently known to permit more than an early phase conceptual design of the system and components at present. 


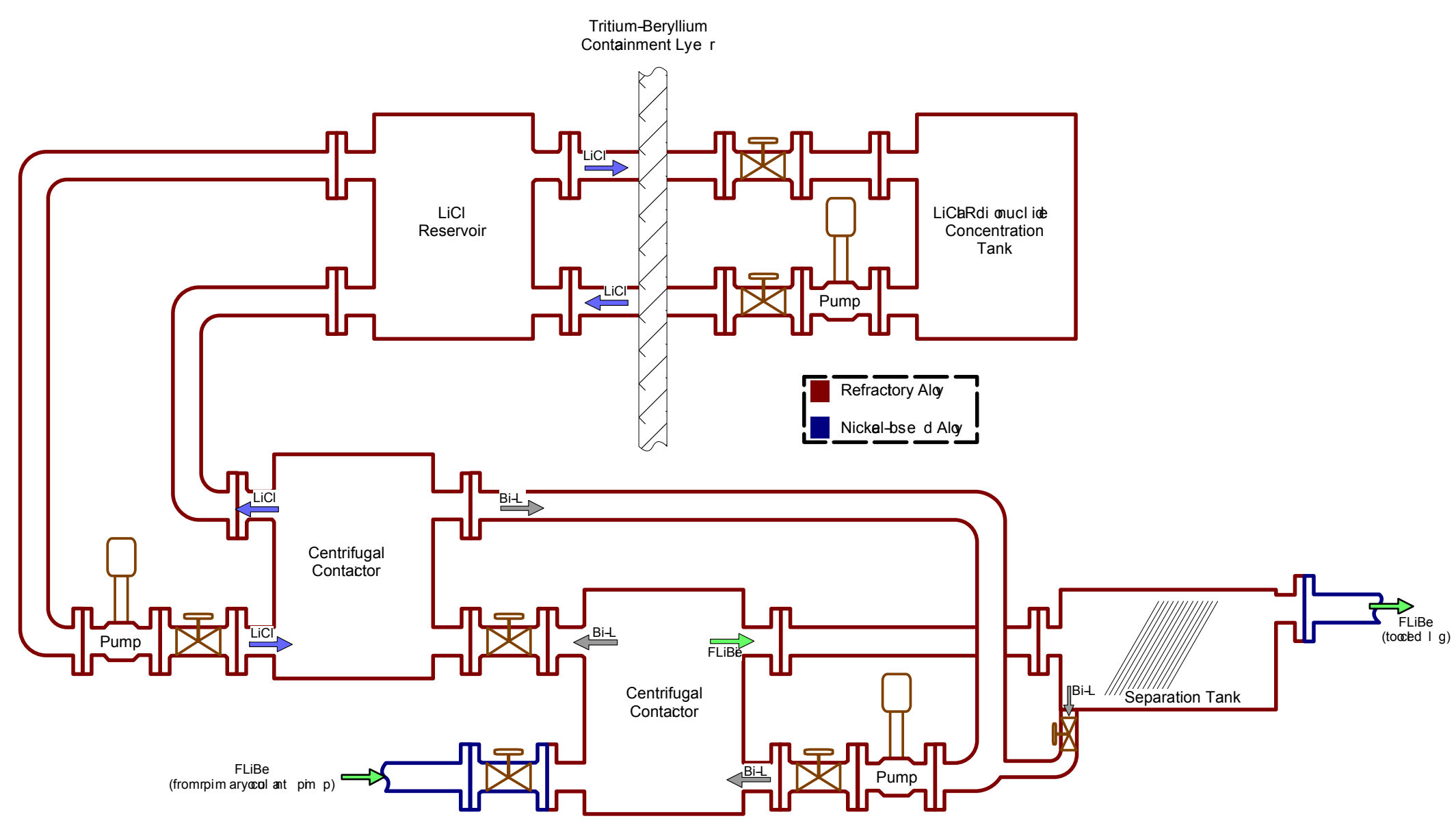

Fig. 4.3 Cleanup system layout. 


\subsection{SUMMARY}

The FHR primary coolant salt will unavoidably become contaminated over the course of the reactor's lifetime. Developing the technology necessary to remove contamination from the salt is an element of maturing FHR technology and is especially important in enabling FHR fuel performance requirements to rely on acceptable fuel leakage precedents from LWRs.

The amount of radioactive waste produced by the salt cleanup system depends on the quality of the fuel, the corrosion of the salt-wetted materials, and material ingress from other systems. The potential contaminants, their origin, and the primary removal method are summarized in Table 4.1.

Table 4.1. Methods for removing contaminants from primary coolant salt ${ }^{58}$

\begin{tabular}{|c|c|c|c|}
\hline Contaminant Group & Components & Origin & Primary removal method \\
\hline Tritium & $\mathrm{T}$ & Neutron capture in salt & $\begin{array}{l}\text { Tritium stripper - primary } \\
\text { salt. Cover gas and } \\
\text { containment atmosphere } \\
\text { traps }\end{array}$ \\
\hline Entrained particles & $\mathrm{C}, \mathrm{BN}, \mathrm{BeO}$ & $\begin{array}{l}\text { Fuel and structural } \\
\text { material surfaces }(\mathrm{C}) \text {, } \\
\text { thermowell failures } \\
(\mathrm{BN}) \text {, and surface } \\
\text { oxides }(\mathrm{BeO})\end{array}$ & $\begin{array}{l}\text { Overflow tubing - } \\
\text { mechanical filtering }\end{array}$ \\
\hline Noble gases & $\mathrm{Kr}, \mathrm{Xe}$ & Fuel failure & $\begin{array}{l}\text { Cryogenic separation from } \\
\text { cover gas }\end{array}$ \\
\hline $\begin{array}{l}\text { Noble \& Semi-noble } \\
\text { metals }\end{array}$ & $\begin{array}{l}\mathrm{Nb}, \mathrm{Mo}, \mathrm{Tc}, \mathrm{Ru}, \mathrm{Rh}, \mathrm{Ag} \\
\mathrm{Cd}, \mathrm{In}, \mathrm{Sn}, \mathrm{Sb}, \mathrm{Te}, \mathrm{Zn}, \\
\text { Ga, Ge, As, Se }\end{array}$ & Fuel failure & $\begin{array}{l}\text { Transfer to bismuth and } \\
\text { subsequently to } \mathrm{LiCl} \text {. } \\
\text { Concentration by zone } \\
\text { refining. }\end{array}$ \\
\hline Salt-seeking elements & $\begin{array}{l}\text { Y, La, Ce, Pr, Nd, Pm, } \\
\text { Gd, Tb, Dy, Ho, Er, Zr, } \\
\text { Sm, Eu, Sr, Ba, Rb, Cs }\end{array}$ & $\begin{array}{l}\text { Fuel failure or reserve } \\
\text { shutdown system } \\
\text { activation }\end{array}$ & $\begin{array}{l}\text { Reductive extraction into Bi- } \\
\mathrm{Li} \text { alloy followed by transfer } \\
\text { into } \mathrm{LiCl} \text { and concentration } \\
\text { via zone refining }\end{array}$ \\
\hline Halogens & $\mathrm{Br}, \mathrm{I}$ & Fuel failure & $\begin{array}{l}\text { Accumulate in primary } \\
\text { coolant salt strip via HF } \\
\text { sparging during maintenance } \\
\text { outages }\end{array}$ \\
\hline $\begin{array}{l}\text { Intermediate or DRACS } \\
\text { coolant }\end{array}$ & $\mathrm{K}, \mathrm{Zr}$ & $\begin{array}{l}\text { Heat exchanger tube } \\
\text { failure }\end{array}$ & $\begin{array}{l}\text { Reductive extraction into Bi- } \\
\mathrm{Li} \text { alloy followed by transfer } \\
\text { into } \mathrm{LiCl} \text { and concentration } \\
\text { via zone refining }\end{array}$ \\
\hline Corrosion products & $\mathrm{Ni}, \mathrm{Fe}, \mathrm{Cr}, \mathrm{Si}$ & Structural materials & $\begin{array}{l}\text { Reductive extraction into Bi- } \\
\mathrm{Li} \text { alloy followed by transfer } \\
\text { into LiCl and concentration } \\
\text { via zone refining }\end{array}$ \\
\hline Bismuth carryover & $\mathrm{Bi}$ & $\begin{array}{l}\text { Entrainment during } \\
\text { cleaning system } \\
\text { operation }\end{array}$ & Nickel wool absorption \\
\hline
\end{tabular}




\subsubsection{Development Tasks}

As part of an overall FHR development activity, an improved understanding of some aspects of salt chemistry must be developed, as well as significant engineering development of the hydraulic components.

1. Kinetic studies of salt-to-metal contaminant transfer process. The kinetics of the phase transfer process between the primary salt and the liquid bismuth are not sufficiently well known to enable detailed system design. This task would measure the kinetics of the contaminant transfer process between the salt and metal phases to enable component sizing as well as required mixing parameters. The impact of the low-solubility bismuth intermetallic phase would be a particular emphasis. Electrochemical acceleration of the reductive extraction processes would also be considered as an alternative (or adjunct) to increased physical contact.

2. Materials and fabrication methods trade study. Several refractory alloys appear to be reasonable choices for the salt cleanup system. Evaluating the available fabrication technologies in terms of cost and availability would form the bulk of this task.

3. Bismuth separator design study. While two-phase liquid separator technology is relatively well known, design parameters for removing finely dispersed bismuth droplets from the primary coolant salt remain to be determined. Addressing the relatively difficulty of fabricating components from refractory alloys will also be a significant element of the design process.

4. Hydraulic component development and testing. Fabricating and demonstrating the necessary hydraulic components is the central element of this task. While cantilever style pumps are generally a known technology, they are not commercially available with their wetted elements fabricated from refractory alloys. Moreover, flanges and seals that are suitable for the cleanup system need to be designed and demonstrated. The cleanup system includes several valves. Developing and demonstrating acceptable valve sealing technology is anticipated to be a significant element of the hydraulic component development activity.

5. Noble metal fission product transport and adherence. The underlying science of noble metal fission product transport in a fluoride salt is not yet well understood. This task would focus on modeling and measuring noble element transport (especially adhesion to metal surfaces) within the primary coolant.

6. Develop conceptual design. Once models for all of the process steps have been developed, a conceptual design for the primary salt cleanup system will be created. The conceptual design will include the materials and instrumentation, as well as process flow. 


\section{CONCLUSIONS}

This report initiates the thermal hydraulic analysis that will be needed to design the AHTR. CFD analysis on $1 / 3$ of a fuel assembly was used to examine the core thermal and fluid behavior, and recommendations were made to inform the next cycle of fuel design. This analysis extended beyond the fuel plate region to highlight the jet behavior above the assembly. A TRACE system model was also developed, which included the entire primary system including the core, downcomer, DRACS, PHX, etc. This model was used to better refine the DRACS components and also to evaluate the reactor performance under a LOFF accident. Based on the results of these simulations, recommendations were made to improve the design and identify the next analysis steps.

The report also discusses issues related to the primary salt cleanup system that will be needed in reactors of this type. It overviews cleanup system requirements by discussing contamination mechanisms, and it identifies potential technologies that could be used to maintain salt purity. A cleanup system layout is also proposed.

A major design effort still remains before the AHTR moves beyond the conceptual stage. However, the analysis and the cleanup system concept presented in this report can serve as a basis for future reactor development and design efforts in AHTR thermal hydraulic and salt purification technologies.

\section{REFERENCES}

1. V. K. Varma, D. E. Holcomb, F. J. Peretz, E. C. Bradley, D. Ilas, A. L. Qualls, and N. M Zaharia, AHTR Mechanical, Structural, and Neutronic Preconceptual Design, ORNL/TM-2012/320, Oak Ridge, TN, September 2012.

2. D. E. Holcomb, F. S. Peretz and A. L. Qualls, "Advanced High Temperature Reactor Systems and Economic analysis," ORNL/TM-2011/364, Oak Ridge, TN, September 2011.

3. STAR-CCM+, v. 9.04.009-R8, CD-adapco, 2014.

4. TRACE VSiO Users Guide, U.S. Nuclear Regulatory Commission, 2012.

5. D. E. Holcomb, G. F. Flanagan, G. T. Mays, W. D. Pointer, K. R. Robb, and G. L. Yoder, Jr., Fluoride SaltCooled High-Temperature Reactor Technology Development and Demonstration Roadmap, ORNL/TM2013/401, Oak Ridge, TN, September 2013.

6. D. Holcomb and S. Cetiner, An Overview of Liquid-Fluoride-Salt Heat Transport Systems, ORNL/TM2010/156, Oak Ridge, TN, September 2010.

7. C. Folsom, "Effective Thermal Conductivity of Tri-Isotropic (TRISO) Fuel Compacts" (2012). All Graduate Theses and Dissertations. Paper 1448. http://digitalcommons.usu.edu/etd/1448.

8. Y. Katoh, et al., "Continuous $\mathrm{SiC}$ fiber, CVI SiC matrix composites for nuclear applications: Properties and irradiation effects," Journal of Nuclear Materials, Vol 448, Issues 1-3, May 2014, Pages 448-476.

9. Y. H. Tung, "Effects of graphite surface roughness on bypass flow computations for an HTGR" Tung, Yu-Hsin, Nuclear Engineering and Design, Vol 252, pp. 78-87, 2012.

10. C. Wang, P. Gao, S. Tan, Z. Wang, "Forced Convection Heat Transfer and Flow Characteristics in Laminar to Turbulent Transition Region in Rectangular Channel," Experimental Thermal and fluid Science, 44, pp. 490497, 2013.

11. D. Q. Kern, Process Heat Transfer, McGraw-Hill, New York, 1950.

12. G. Towler, R.K. Sinnott, Chemical Engineering Design: Principles, Practice and Economics of Plant and Process Design, Butterworth-Heinemann, Nov 26, 2007.

13. Haynes International, www.haynesintl.com/pdf/h2052.pdf.

14. National Institute of Standards and Technology (NIST), http://www.ceramics.nist.gov/srd/summary/dcdscs.htm.

15. L. L. Snead, T. Nozawa, Y. Katoh, T. S. Byun, S. Kondo, D. A. Petti, "Handbook of SiC Properties for Fuel Performance Modeling," Journal of Nuclear Materials, 371, pp. 329-377, 2007.

16. F. P. Incropera, et al., Fundamentals of Heat and Mass Transfer, Wiley, 2007. 
17. E.S. Gaddis, V. Gnielinski, "Pressure drop in cross flow across tube bundles," Vol. 25, No. 1 International Chemical Engineering, 1985.

18. S. Kakac, R. K. Shah, W. Aung, Handbook of Single-Phase Convective Heat Transfer, WileyInterscience, 1987.

17. D. A. Petti, G. R. Smolik, M. F. Simpson, J. P. Sharpe, R. A. Anderl, S. Fukada, Y. Hatano, M. Hara, Y. ya, T. Terai, D.-K. Sze, and S. Tanaka, "JUPITER-II Molten Salt FLiBe Research: An Update on Tritium, Mobilization and Redox Chemistry Experiments," Fusion Engineering and Design, 81, pp. 1439-1449 (2006).

18. M. F. Simpson, G. R. Smolik, J. P. Sharpe, R. A. Anderl, D. A. Petti, Y. Hatano, M. Hara, Y. Oya, S. Fukada, S. Tanaka, T. Terai, and D.-K. Sze, "Quantitative Measurement of Beryllium-Controlled Redox Of Hydrogen Fluoride in Molten FliBe,” Fusion Engineering and Design, 81, pp. 451-547 (2006).

19. Satoshi Fukada, Flibe-Tritium Research for Fission or Fusion Reactors at Kyushu University, J. Plasma Fusion Res., 10 (2013).

20 R. B. Briggs and R. B. Korsmeyer, "Distribution of Tritium in an MSBR," pp. 54-57 in Molten Salt Reactor Semiannual Progress Report for Period Ending February 28, 1970, ORNL-4548, Oak Ridge, TN, Aug. 1970

21. Glen R. Longhurst, Robert A. Anderl, R. Scott Willms, "Tritium Loss in Molten FLiBe Systems," Fusion Technology, 38, November 2000, 376-383.

22. G. T. Mays, A. N. Smith, and J. R. Engel, Distribution and Behavior of Tritium in the Coolant-Salt Technology Facility, ORNL/TM-5759, Oak Ridge, TN, April 1977.

23. M. W. Rosenthal, et al, Molten-Salt Reactor Program Semiannual Progress Report for Period Ending February 28, 1970, ORNL-4548, Oak Ridge, TN, August 1970, p.10.

24. E. L. Compere, S. S. Kirslis, E. G. Bohemian, F. F. Blankenship, and W. R. Grimes, Fission Product Behavior in the Molten Salt Reactor Experiment, ORNL-4865, Oak Ridge, TN, October 1975.

25. E. S. Bettis and Roy C. Robertson, The Design and Performance Features of a Single-Fluid MoltenSalt Breeder Reactor, Nuclear Applications \& Technology, 8, February 1970, 190-207.

26. US Atomic Energy Commission Division of Reactor Technology, An Evaluation of the Molten Salt Breeder Reactor, WASH-1222, Sep. 1972.

27. M. D. Shapiro and C. M. Reed, Removal of Tritium from the Molten Salt Breeder Reactor Fuel, ORNL-MIT-117, Oak Ridge, TN, Nov. 1970.

28. G. I. Eskin, "Cavitation Mechanism of Ultrasonic Melt Degassing," Ultrasonics Sonochemistry, 2(2), pp. S137-S141 (1995).

29. Jan. B. Talbot, A Study of Tritium Removal from Fusion Reactor Blankets of Molten Salt and LithiumAluminum, ORNL/TM-5104, March 1976.

30. W. F. Calaway, "Electrochemical Extraction of Hydrogen from Molten LiF-LiCl-LiBr and its Application to Liquid-Lithium Fusion Reactor Blanket Processing," Nuclear Technology, 39, pp. 6374 (June 1978).

31. D. E. Holcomb and D. F. Wilson, Apparatus and Method for Stripping Tritium from Molten Salt, US Patent Application 14333627, filed July 17, 2014.

32. E. L. Compere, S. S. Kirslis, E. G. Bohlmann, F. F. Blankenship, and W. R. Grimes, Fission Product Behavior in the Molten Salt Reactor Experiment, ORNL-4865, Oak Ridge National Laboratory, Oak Ridge, TN, October 1975.

33. Y. S. Cheng, K. L. Yeung, "Palladium-Silver Composite Membranes by Electroless Plating Technique," Journal of Membrane Science, 158 (1999) 127-141.

34 P. P. Mardilovich, Y. She, Y. H. Ma, and M.-H. Rei, "Defect-Free Palladium Membranes on Porous Stainless Steel Support," AIChE Journal, 44(2), Feb. 1998, 310-322.

35. K. Zhang, H. Gao, Z. Rui, P. Liu, Y. Li, and Y. S. Lin, High-Temperature Stability of Palladium Membranes on Porous Metal Supports with Different Intermediate Layers, Industrial \& Engineering Chemistry Research, 48 (2009) 1880-1886. 
36. G. T. Mays, A. N. Smith, and J. R. Engel, Distribution and Behavior of Tritium in the Coolant-Salt Technology Facility, ORNL-TM-5759, ORNL, Oak Ridge, TN, April 1977.

37. D. F. Williams, Assessment of Candidate Molten Salt Coolants for the NGNP/NHI Heat-Transfer Loop, ORNL-TM-2006/69, ORNL, Oak Ridge, TN.

38. W. R. Grimes, Chemical Research and Development for Molten-Salt Breeder Reactors, ORNL-TM1853, Oak Ridge TN, June 1967, p. 21.

39. R. J. Kedl, The Migration of a Class of Fission Products (Noble Metals) in the Molten-Salt Reactor Experiment, ORNL-TM-3884, Oak Ridge, TN, December 1972.

40. M. W. Rosenthal, R. B. Briggs, and P. R. Kasten, "Hot-Cell Tests on Fission Product Volatilization from Molten MSRE Fuel," Molten-Salt Reactor Program Semiannual Progress Report for Period Ending February 29 1968, ORNL-4254, Oak Ridge, TN, August 1968, pp. 100-108.

41. F. F. Blankenship, "A Possible Origin of Smokes and Mists Emitted by MSRE Fuel,” in M. W. Rosenthal, R. B. Briggs, P. N. Haubenreich, Molten-Salt Reactor Program Semiannual Progress Report for Period Ending August 31, 1970, ORNL-4622, Oak Ridge, TN, pp. 70-71.

42. M. W. Rosenthal, R. B. Briggs, P. N. Haubenreich, Molten-Salt Reactor Program Semiannual Progress Report for Period Ending August 31, 1971, ORNL-4728, Oak Ridge, TN, February 1972, p. 181.

43. H. C. Savage and J. R. Hightower, Jr. Engineering Tests of the Metal Transfer Process for Extraction of Rare-Earth Fission Products from a Molten-Salt Breeder Reactor Fuel Salt, ORNL-5176, Oak Ridge, TN, February 1977

44. C. H. Brown, Jr., J. R. Hightower, Jr., and J. A. Klein, Measurement of Mass Transfer Coefficients in a Mechanically Agitated, Nondispersing Contactor Operating with a Molten Mixture of LiF-BeF $\mathrm{ThF}_{4}$ and Molten Bismuth, ORNL-5143, November 1976.

45. L. M. Ferris, Some Aspects of the Thermodynamics of the Extraction of Uranium, Thorium, and Rare Earths form Molten LiF-BeF ${ }_{2}$ into Liquid Li-Bi Solutions, ORNL-TM-2486, Oak Ridge, TN, March 1969.

46. C. F. Baes, Jr., "The Chemistry and Thermodynamics of Molten Salt Reactor Fuels," Journal of Nuclear Materials, 51, 1974, 149-162

47. H. Moriyama, M. Miyazaki, Y. Asaoka, K. Moritani, and J. Oishi, "Kinetics of Reductive Extraction of Actinide and Lanthanide Elements from Molten Fluoride into Liquid Bismuth, Journal of Nuclear Materials, 182, 1991, 113-117

48. R. P. Wichner, Sidestream Processing for Continuous Iodine and Xenon Removal from MSBR Fuel, ORNL-CF-6-12, Oak Ridge, TN, June 1972.

49. L. M. Ferris, J. C. Mailen, J. J. Lawrence, F. J. Smith, and E. D. Nogueira, "Equilibrium Distribution of Actinide and Lanthanide Elements between Molten Fluoride Salts and Liquid Bismuth Solutions," Journal of Inorganic and Nuclear Chemistry, 32, 1970, pp. 2019-2035.

50. D. M. Richardson and J. H. Shaffer, "Distribution of Sodium and Potassium in the Metal Transfer Process at $650^{\circ} \mathrm{C}$, Molten-Salt Reactor Program Semiannual Progress Report for Period Ending August 31, 1970, ORNL-4622, p. 107.

51. D. M. Richardson and J. H. Shaffer, "Extraction of Rubidium and Cesium from MSBR Fuel Solvent into Bismuth by Reduction with Lithium at $650^{\circ} \mathrm{C}$," Molten-Salt Reactor Program Semiannual Progress Report for Period Ending February 28, 1971, ORNL-4676 p. 129.

52. J. R. DiStefano and O. B. Cavin, Temperature Gradient Compatibility Tests of Some Refractory Metals and Alloys in Bismuth and Bismuth-Lithium Solutions, ORNL/TM-5503, Oak Ridge, TN, November 1976.

53. J. E. Indacochea, J. L. Smith, K. R. Litko, and E. J. Karell, "Corrosion Performance of Ferrous and Refractory Metals in Molten Salts under Reducing Conditions," Journal of Materials Research, 14(5), May 1999, 1990-1995.

54. R. H. Guymon, MSRE Systems and Components Performance, ORNL-TM-3039, Oak Ridge, TN, June 1973, p. 127. 
55. W. B. McDonald, E. Storto, and A. S. Olson, Screening Test of Mechanical Pipe Joints for a Fused Salt Reactor System, ORNL-CF-8-33, Oak Ridge, TN, August 13, 1958.

56. Adapted from J. R. Engel, W. R. Grimes, W. A. Rhoades, and J. F. Dearing, Molten-Salt Reactors for Efficient Nuclear Fuel Utilization Without Plutonium Separation, ORNL/TM-6413, Oak Ridge, TN, August 1978, p. 10. 